VATT Working Papers 130

\title{
Physician Prices and Competition: Evidence from Acquisitions in the Private Health Care Sector
}

Mikko Nurminen

Tanja Saxell 


\title{
VATT WORKING PAPERS
}

Physician Prices and Competition:

Evidence from Acquisitions in the Private Health Care Sector

\author{
Mikko Nurminen
}

Tanja Saxell 
Mikko Nurminen, Turku School of Economics.Email: mmnurm@utu.fi

Tanja Saxell, VATT Instute for Economic Research and Helsinki GSE. Email: tanja.saxell@vatt.fi

We thank Riina Hiltunen, Jiekai Zhang, Hennamari Mikkola, Lauri Virta, Petri Böckerman, Markku Siikanen, and Teemu Lyytikäinen, in addition to the participants of the VATT seminar and Helsinki GSE Industrial Organization PhD Student Workshop for their comments and suggestions. We also thank Tuomas Markkula for excellent research assistance. The authors gratefully acknowledge the Social Insurance Institution of Finland for funding this research and providing data.

ISBN 978-952-274-252-0 (PDF)

ISSN 1798-0291 (PDF)

URN:ISBN:978-952-274-252-0

Valtion taloudellinen tutkimuskeskus

VATT Institute for Economic Research

Arkadiankatu 7, 00100 Helsinki, Finland

Helsinki, April 2020 


\title{
Physician Prices and Competition: Evidence from Acquisitions in the Private Health Care Sector*
}

\author{
Mikko Nurminen $^{\dagger} \quad$ Tanja Saxell ${ }^{\ddagger}$
}

April 28, 2020

\begin{abstract}
We consider the effects of mergers and acquisitions for private physicians, who compete for patients on price. To estimate the effects, we use nationwide administrative data on private physicians and the organization of their practice over 10 years in Finland. We show that acquisitions can reduce competition among physicians, leading to higher prices. We estimate the strongest price increase to be in gynecology, in which switching costs and inertia in physician choice may decrease physician competition, at least locally (within a health care unit). The reduction in the number of physicians in a target unit is the key mechanism behind the estimated effect.
\end{abstract}

Keywords: Physicians, Mergers and Acquisitions, Market Power, Private Health Care, Independent Contractors

JEL Codes: L11, I11, J21, K21

${ }^{*}$ We thank Riina Hiltunen, Jiekai Zhang, Hennamari Mikkola, Lauri Virta, Petri Böckerman, Markku Siikanen, and Teemu Lyytikäinen, in addition to the participants of the VATT seminar and Helsinki GSE Industrial Organization PhD Student Workshop for their comments and suggestions. We also thank Tuomas Markkula for his excellent research assistance. The authors gratefully acknowledge the Social Insurance Institution of Finland for funding this research and providing data.

†Turku School of Economics. Email: mmnurm@utu.fi.

‡VATT Instute for Economic Research and Helsinki GSE. Email: tanja.saxell@vatt.fi. 


\section{Introduction}

The markets for both health care firms and physicians have become more concentrated in recent years. In many countries, such as the U.S., the Netherlands, and Finland, physicians are progressively moving away from small practices toward larger, consolidated firms or medical systems (Welch et al. 2013; Hiltunen et al. 2017; Roos 2018). Previous research has shown that M\&As can affect hospital market structure and competition (Gowrisankaran et al. 2015; Gaynor et al. 2015; Lewis and Pflum 2017; Dafny et al. 2019). In this study, we argue that acquisitions can also result in notable reductions in competition among physicians, increasing their service prices. We show that the product market outcomes of M\&As are linked to the outcomes in the physician labor market.

We study empirically whether and how organizational changes through M\&As affect physician prices and utilization of their services in the private health care sector in Finland. The crucial feature of this sector is that physicians typically work for firms as independent contractors on a revenue sharing basis, allowing physicians to compete for patients on price even within a health care unit (FMA 2017; Hiltunen et al. 2017). ${ }^{1}$ To interpret the potential changes in prices and utilization, we also look at physician employment; competition among physicians may decrease if the number of jobs is reduced in the target unit after an acquisition.

We use a difference-in-differences (DiD) approach to study a wave of acquisitions by large health care firms (chains) and administrative claims data on over 6 million private physician visits during 2008-2017. Historically, empirical analysis of physician service markets has been challenging, because comprehensive data from physician practices has rarely been available (Gaynor et al. 2015). In contrast, our nationwide claims data from private physicians identify their patient visits and exact prices, and also allow us to comprehensively measure physician employment in the private sector. The key advantage of our data is that we can separately analyze different types of physicians and provide suggestive evidence of

\footnotetext{
${ }^{1}$ Physician prices can vary substantially within a health care unit (Tuominen et al. 2016).
} 
the mechanisms behind their differential price responses to acquisitions, such as changes in physician employment and competition. ${ }^{2}$

M\&As have ambiguous effects on physician prices and employment ex ante. The firm's product or labor market power can increase, leading to higher prices and falling employment (Berger et al. 2019; Arnold 2020). In our setting, the increased market power over independent contractors could mean that the firm increases its revenue share (physician office rents), which may be passed through to physician service prices. However, the production process may also improve, for example because of synergy gains, economies of scale, and higher quality of care (Farrell and Shapiro 1990; Gaynor and Vogt 2000; Dafny and Lee 2015). Improved quality of care may increase physician employment - even with higher prices. Conversely, realizing the productivity gains may require restructuring or downsizing labor. ${ }^{3}$

The standard analysis of horizontal mergers can be extended to capture additional institutional features that characterize markets for physician services, especially in the Finnish private health care sector. Two features may generally facilitate competition among physicians: (i) a physician's revenue is determined by patient choice and prices in a fee-for-service system, and (ii) physicians set or bargain about their own prices (Hiltunen et al. 2017). When M\&As entail job losses, local price competition could also reduce, leading to higher prices and market shares for the remaining physicians in target units.

We find that an acquisition increases incumbent physician prices approximately by 1-2 percent on average in the target unit. However, the extent of the price increase depends critically on the clinical setting. The increase is small for primary care physicians, who are a relatively low-educated and competitive group of physicians. Also, for some specialists such as orthopedists, the price effects are statistically insignificant. In contrast, for the largest group of specialists, gynecologists, we find a robust price increase of 5 percent after one year. The price increase is not met with an increase in the overall health care utilization

\footnotetext{
${ }^{2}$ Additionally, this analysis mitigates the possibility that price changes are merely driven by changes in the composition of labor within the target unit. For example, low-price primary care physicians can be replaced with high-price specialists.

${ }^{3}$ See Datta et al. (2010) for a review of the empirical literature on employment reductions of M\&As.
} 
or market share in the target unit. In the light of these results and prior work (Gugler and Siebert 2007; Lewis and Pflum 2017), there is little evidence that a significant improvement in quality or attractiveness to patients is the main source of the price increase.

We then look at the effects on physician employment in target units. In primary care, we do not find any large changes in the overall number of physicians. In gynecology, we find evidence of job losses as departing physicians are not replaced with new physicians. This results in an increased share of patient visits for the remaining incumbent physicians within the target unit, but not in the whole market area. Physician competition thus seems to be limited by the decreasing stock of physicians in the unit, which may partly explain the observed price increase. Gynecology is exactly a field of specialization in which repeat checkups and the inherent reluctance of patients to switch physicians may allow incumbents to gain market power over new physicians.

Finally, we look at how private physicians in nearby rival units respond to acquisitions. We find no evidence of changes in prices for these physicians nor any evidence of changes in rival units' market shares. These findings provide suggestive evidence that acquisitions do not cause substantial, market-wide changes in price competition. Instead, price competition seems to change very locally, within a target unit.

Our results are of direct relevance for antitrust policy. Our study highlights the importance of assessing competition not only in the product market but also in the labor market. This is especially relevant in many service sectors where independent contractors or freelancers provide services under the same platform or firm and compete with each other. Mergers may not only increase the market concentration of firms, but they may also promote consolidation at the local (within-firm) level through reductions in the workforce. As much as this can also be seen as a cost effective measure from the firm's point of view, it may also have a crucial impact on workers' and consumers' welfare.

Our paper contributes to the recent literature on hospital mergers and competition studying the price effects of within-market and cross-market mergers (Lewis and Pflum 2017; 
Cooper et al. 2019; Dafny et al. 2019), merger-induced multimarket contact (Schmitt 2018), and mergers on hospital cost savings (Schmitt 2017). A related strand of literature has studied mergers between smaller physician practices and larger provider systems (Baker et al. 2016; Carlin et al. 2017). The general conclusion has been that mergers increase prices. We additionally provide evidence of heterogeneous price responses across physician specialties.

On the labor market side, perhaps the closest works to our paper are DePasquale (2015) and Prager and Schmitt (2019). DePasquale (2015) studies hospital mergers in the U.S. and their effect on nurse wages and employment levels. She finds no effect on wages and a decreasing effect on employment following a merger. Prager and Schmitt (2019) also directly study the effects of merger-driven employer concentration on the wages of low- and high-skilled hospital workers (non-physicians) in the U.S. They find that merger-induced concentration lowers wages for skilled workers. In contrast to prior work, we study inde-

pendent contractors (physicians) and their service prices, rather than employees and their wages. We also contribute to this and the aforementioned merger literature by studying the links between the labor and product market outcomes of mergers. More precisely, we study how merger-induced labor turnover affects competition at the local level and how it translates into changes in physician service prices.

\section{Institutional Setting}

\subsection{Private Health Care Sector, Physician Prices and Payment Contracts}

Private provision has a crucial role in health care markets worldwide, but the scale of this provision varies across countries. The U.S. health care sector has a strong element of private provision. Although many European countries such as the U.K. and Finland (our setting) rely more on public provision, the role of private provision has significantly increased over time in response to long waiting times and lack of access in public health care. In Finland, 
private health care accounted for 1.1 billion of costs in the National Health Insurance (NHI) scheme in 2017, an increase of 18 percent from 2010 (THL 2019).

In the Finnish health care system, private sector services complement public services and employer-sponsored occupational health care. Private health care covered by the NHI accounts for approximately 10 percent of health care costs in primary and specialized (hospital) health care (THL 2019). Moreover, the private health care costs are approximately 1.3 times of the costs in occupational health care (THL 2019). Employers may acquire occupational health care services for their employees from private health care units, but we do not study these services in this paper.

Usually in the case of government-provided health insurance or large private insurers, individual physicians have limited power to set their prices. This is especially true in publicly provided health care, where prices are set administratively. In contrast, in the Finnish private health care sector that we analyze, physician price setting is relatively free and marketdetermined. In this case, physicians can compete for patients on price (or non-price means such as quality).

In Finland, private physicians typically work for firms or health care units as independent contractors (FMA 2017), which is one form of vertical integration. A physician signs a contract with the firm's unit, which provides the physician with an office space in the unit, as well as use of its brand, technologies and in-house production of diagnostic services. A physician decides its own prices (visiting fees) and pays a certain share of its revenue to the firm as office rent, which is determined by negotiation between the firm and the physician (FMA 2017; (Lehtonen 2017)). The firm's revenue share is 20 percent on average and is fairly similar in many specialties, for example 21 percent in general medicine and 20 percent in obstetrics and gynecology (hereafter, gynecology) (FMA 2017).

In the Finnish private health care sector, a patient can directly book an appointment with a primary care physician or specialist and then pays for these services out-of-pocket (fee-for-service). There is no gatekeeping by primary care physicians to specialized health 
care. A small fraction of the private physician fees, approximately 15 percent in 2018, is reimbursed to the patient by the NHI scheme (Kela 2020). The out-of-pocket costs of private physician visits can thus be much higher than in public and occupational health care. ${ }^{4}$ Some patients may, however, also have private insurance that covers the costs of private physician visits, at least partly. ${ }^{5}$ Relatively low cost sharing and free choice of physicians may both facilitate price competition among physicians in the private sector.

Prices for specialists are generally higher than for primary care physicians (Section 3.4). Physician prices vary substantially, also within a health care unit (Tuominen et al. 2016). Prices may vary for various reasons, depending, for example, on the extent of competition that physicians face within their unit.

\subsection{Mergers and Acquisitions of Private Physician Practices}

Many developed countries such as Finland and the U.S. have experienced consolidation of (private) physician practices. Moreover, many of the mergers and acquisitions involve small practices that never come under the scrutiny of antitrust authorities despite the potential for anti-competitive effects (Capps et al. 2017). In the standard model of horizontal mergers, there is a trade-off between the productivity gains of mergers and the deadweight loss of reduced competition.

On the product market side, if horizontal mergers reduce competition, a common prediction is that prices will increase. If mergers also improve the production process, the effects on prices are, however, ambiguous; with a substantial reduction in marginal costs and increase in output, prices can even decrease (Farrell and Shapiro 1990). In health care, the productivity gains can result, for example, from cost savings in administrative expenses, or improvements in management practices or quality of care through consolidation of care for

\footnotetext{
${ }^{4}$ For example, in 2020-2021 the maximum out-of-pocket cost for a physician visit in public primary care is 20.60 euros (STM 2020). In 2019, the out-of pocket cost per visit to a private physician specialized in general medicine (primary care) was 63 euros (Kela 2020).

${ }^{5}$ In Finland, approximately 20 percent of households had one or more medical expense insurance from a private insurance company in 2016. (Kajantie 2019).
} 
specific subgroups of patients or better capacity to invest in diagnostic technologies (Gaynor and Vogt 2000; Dafny and Lee 2015). ${ }^{6}$

On the labor market side, when labor supply is inelastic and concentration of labor markets increases, mergers may additionally increase firm market power over workers (Shapiro 2019). In the absence of productivity improvements, employment and wages can decline. Recent empirical literature supports the idea of negative effects of increased concentration and mergers on wages (Azar et al. 2017; Benmelech et al. 2018; Bassanini et al. 2019; Qiu and Sojourner 2019; Prager and Schmitt 2019). Even in the case of productivity improvements, the acquiring firm may have to reduce some jobs in duplicated or low-productive services to achieve these productivity gains (Datta et al. 2010).

Our setting differs crucially from the standard model: physicians work for firms or health care units as independent contractors, not as employees. Thus, rather than decreasing wages, the increased labor market power could increase firm revenue share (physician office rents). This increased cost to a physician may be passed through to physician service prices, depending on how tight the competition is between physicians.

Physicians also compete for patients within a health care unit, not just between units or firms. The extent of physician competition is generally limited by the stock of physicians who supply certain services (Gaynor and Town 2011). M\&As can thus have additional implications for competition and prices through the effects on employment. For example, if the number of workers (physicians) substantially decreases in the target unit, the remaining physicians face less competition from other physicians within that unit. As a result, prices and market shares may increase for these physicians.

Finally, if M\&As after all lead to productivity improvements and increased employment, competition among physicians may increase. Overall, the price and labor market effects of private health care acquisitions are ambiguous and ultimately an empirical problem.

\footnotetext{
${ }^{6}$ See Bloom et al. (2015) for the impacts of competition on hospital management quality.
} 


\section{$3 \quad$ Data and Descriptive Evidence}

\subsection{Data}

We use administrative claims data on visits to private health care physicians for the period 2008-2017 from the Social Insurance Institution of Finland. These data include the universe of physician visits in the NHI scheme. As all residents of Finland are entitled to the NHI scheme, the data are highly representative of visits to the Finnish private health care sector. However, the limitation of our data is that they do not include physician visits in other health care sectors (public and occupational health care).

The data contain decoded identifiers for patients and physicians, reimbursed physician visits, the date of the visit, the length of the visit $(10,20,30,45$, or 60 minutes), whether there is a specialization fee included (an additional 50 percent on top of the NHI "base" reimbursement rate if the visit is made to a specialist), and the exact price of the visit. The patient characteristics include the zip code of residence, gender, age, and income (salary and assets) at the end of the year. ${ }^{7}$ The physician characteristics include gender, age of the physician, the specialty, and time of specialization.

We restrict our data to four physician specialties: primary care, gynecology, orthopedics, and ear, nose and throat diseases (ENT). We define primary care physicians as those who have not specialized or have a specialization in general medicine. ${ }^{8}$ One advantage of focusing on these specialties is that they are the most common specialties in the Finnish private health care sector (58 percentage of overall visits). ${ }^{9}$ While there may be some demand substitutability between these four specialties, they also have unique features. Primary care physicians have the least amount of education and their service provision is least concentrated. In gynecology, patients have repeat visits to the same physician more often than in other specialties,

\footnotetext{
${ }^{7}$ We do not observe whether the patient has an additional private insurance to cover medical expenses.

${ }^{8}$ Some unspecialized physicians may, however, later specialize in fields other than primary care (general medicine).

${ }^{9}$ Two other notable fields are pediatrics and ophthalmologists, with 8 percent and 6 percent shares, respectively. The remaining fields generally have shares of less than three percent.
} 
possibly because of regular health checkups, as shown in Figure 1. Switching costs (repeat visits) and inertia in physician choice allow incumbent physicians to gain market power over new physicians. Online Appendix Figure A1 provides additional evidence supporting these switching costs, showing a gradual increase in a gynecologist's share of patient visits in a health care unit after starting to work in that unit.

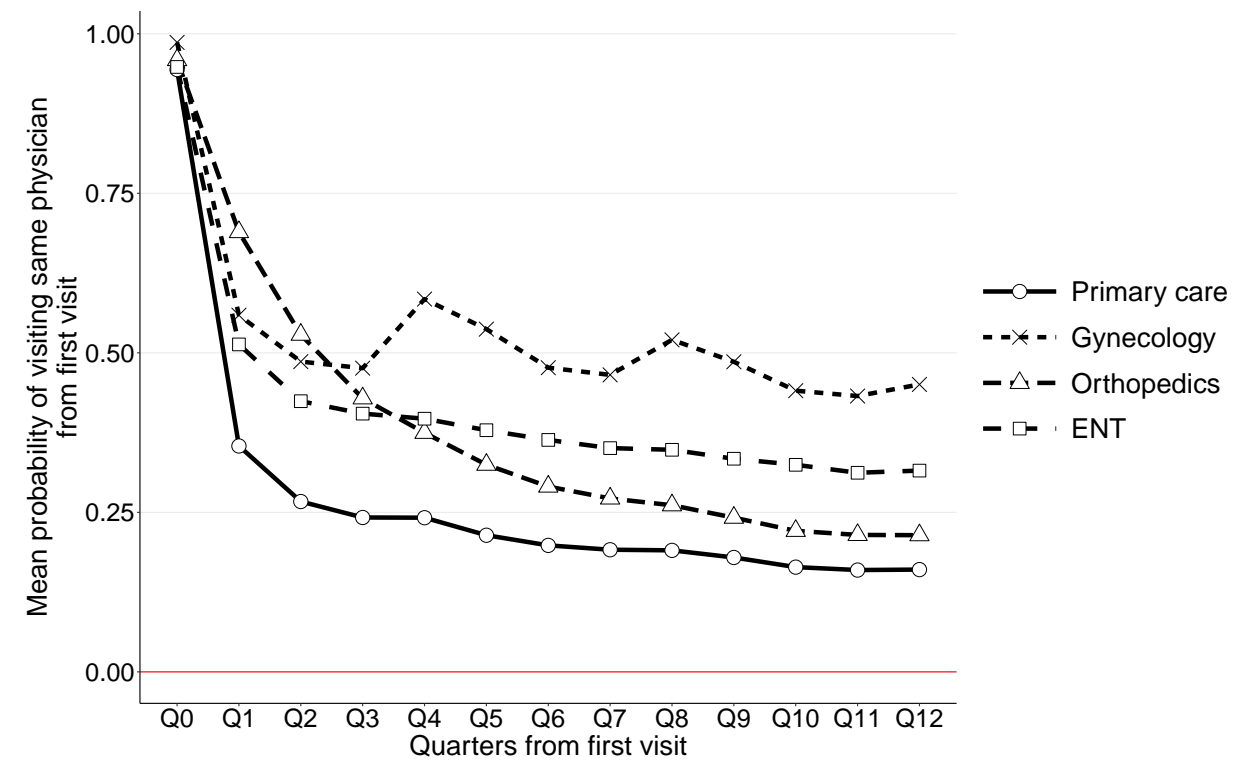

Figure 1: Probability of visiting same physician as in the first visit, by specialty

Notes: First visits in data before 2009 are dropped because of left censoring. Y-axis is the probability of visiting the same physician as in the first visit in the data, aggregated over patients. $\mathrm{X}$-axis is the quarter relative to the first visit, $Q 0$ being the first quarter when the first visit takes place.

The key feature of our data is that they link physicians to health care units and firms throughout the years. We identify different units and firms by their name and location zip code. However, for a fraction of units that do not use the NHI direct reimbursement system, we do not observe the location and name. ${ }^{10}$ Units that do not have this technology installed are typically smaller or solo practices. In Table A1 we show the fraction of visits across time to different specialties where we do not observe these variables. The fractions decrease over time depending on specialty. In 2008, the fraction is highest in primary care (0.27) and

\footnotetext{
${ }^{10}$ When a unit is part of the reimbursement system, a patient gets reimbursed for medical expenses directly at the unit. The direct reimbursement method is used by health care firms that have a voluntary agreement with the Social Insurance Institution. If a firm does not have such an agreement, a patient has to contact the Social Insurance Institution to get the reimbursements.
} 
lowest in ENT (0.12). In 2017, the fractions are between 0.07 and 0.03 for all specialties.

We use the private health care firms' annual reports from the Finnish Patent and Registration Office to identify acquisition dates for each geographical unit throughout the years 2008-2017. We link this information to the claims data, using the names of the geographic units and the date. In the analysis, we use quarterly-level precision for the time of acquisitions.

\subsection{Outcomes}

We construct several outcomes related to physician visiting prices, market shares, and employment. The outcomes are particularly beneficial for measuring and understanding potential changes in physician price competition.

Our main outcome for prices is the log physician price per visit measured at the patientvisit level (no aggregation). We also construct an outcome for log price per visit minute at the physician-quarter level. This outcome is simply the total revenue from a physician's visits divided by the sum of the overall minutes this physician was visited in a given quarter. In addition to these, we calculate the average price per minute of health care units at the unit-quarter level.

For physician market shares, we use three distinct outcomes. The first outcome is the physician's overall market share, defined as the number of visits to the physician in a given unit divided by the overall number of visits in all specialties (primary care, gynecology, orthopedics and ENT) in the market area. The second outcome is the physician within-unit share, defined as the number of visits to the physician in the unit divided by the overall number of visits in all specialties in the unit. For these two outcomes, we use the physician quarter-level aggregation. The third outcome is the physician within-unit and specialty

Herfindahl-Hirschman Index (HHI), defined as the sum of the squared market shares of each physician within that unit and specialty. The index is measured at the unit-quarterly level and is closely related to the second outcome as it captures the extent of (local) competition 
among physicians within their respective specialty and unit.

We also measure the health care unit's overall market share, defined as the number of physician visits to the unit divided by the overall number of visits in the market. For this outcome, we use unit-quarter level aggregation. In Section 3.4, we additionally measure the HHI of firms in the market.

For physician employment outcomes, we also use data aggregated to the unit-quarter level. These outcomes are based on the number of physicians working in the unit. We decompose this outcome into the number of continuing physicians and the number of new physicians. The former consists of physicians that had observations in the unit in the previous quarter. The latter consists of physicians that did not have observations in the unit in the previous quarter. In addition, to get an idea of where the new physicians migrate from, we further decompose the new physicians into those that come from the same market, outside the market, and outside the private sector (i.e. had no observations in our data prior to starting working in the unit). For all these outcomes, we take the log-transformation. ${ }^{11}$

\subsection{Market Definition, Treatment, and Control Groups}

We define local markets in the following way. We draw radii of 30 kilometers around each zip code centroid. Units that are located in zip codes whose centroid falls within this radius are part of the local market. ${ }^{12}$ A similar approach has been taken in the recent literature (Gaynor et al. 2012; Bloom et al. 2015; Lewis and Pflum 2017; Schmitt 2018; Beaulieu et al. 2020). The upside of this approach compared to a market definition based on fixed municipality borders or geographical areas is that the units located in nearby zip codes but in different municipalities are still in the same market area.

As the choice of the radius is to some extent arbitrary, we validate our approach by looking at distances where patients travel to health care units. Figure A2 shows that almost

\footnotetext{
${ }^{11}$ To account for the zeros in the outcome, we use $\log ($ outcome +1$)$.

${ }^{12} \mathrm{We}$ do not have information on the exact address of the unit, so we use coordinates for the zip code centroids.
} 
90 percent of patients travel less than 30 kilometers. The fraction is only slightly lower for visits to orthopedists. In online Appendix D, we show that our results are robust to using 20 and 50 kilometer radii.

An alternative empirical approach for defining a local market would be to look at the size of physician labor market such as distances between a physician's workplaces. We, however, opt to look at patients' travel distances because we focus on various mechanisms through which acquisitions affect physician prices and health care utilization. Moreover, local markets based on longer distances (30 and 50 kilometer radii) are arguably fairly large, although physicians may move across local markets because of acquisitions, as shown in Section 5.3.

In our main analysis, units (or their physicians) that are the target of an acquisition are treated units. We drop all other units that are not targets and are in the market area of the target unit (within 30 kilometers from the target unit). We also perform additional analyses where we look at the effects of an acquisition on nearby competitors (Section 5.5). Our control units are located in markets that do not undergo an acquisition.

We perform a number of restrictions on target and control units. First, we only consider acquisitions that were made by large firms or chains and drop four units that were acquired but not by these large firms. ${ }^{13}$ Second, we restrict the sample to target units that have observations at least four quarters before and after the acquisition. Similarly, we restrict the control units to those that have at least four quarters of observations. Third, we drop units that were acquired more than once ( 5 units). Also, a few units were merged with a unit that was already acquired earlier. We drop rows after the merger happens for these units. Finally, we drop a few units owned by not-for-profit foundations as these units may be outliers. Our results are robust to relaxation of these restrictions. Figure 2 plots the number of acquired units in our sample over time. The acquisitions occur during 2010-2017 and there were no acquisitions during the first two years of our data, 2008-2009.

\footnotetext{
${ }^{13}$ For data confidentiality, we do not publish the identity of these firms.
} 
Table 1 shows that in our sample the total number of target (i.e. acquired) units is 60 and the total number of control units is 88. Similarly to Lewis and Pflum (2017), we define in-market acquisitions as acquisitions where the acquiring firm already had a unit in the same market. Approximately 70 percent of the acquisitions fall into this category. Despite the fact that there are fewer target than control units, the target units have much larger shares of physicians, patients, and visits in total. The sample is large: the target units themselves have approximately 5 million visits to 3,366 physicians in total, which is 16 percent of the number of all working-age physicians in Finland in 2016 (FMA 2016). In the target units, the total number of patients is 1.4 million, which equals to 25 percent of the size of the Finnish population in 2017.

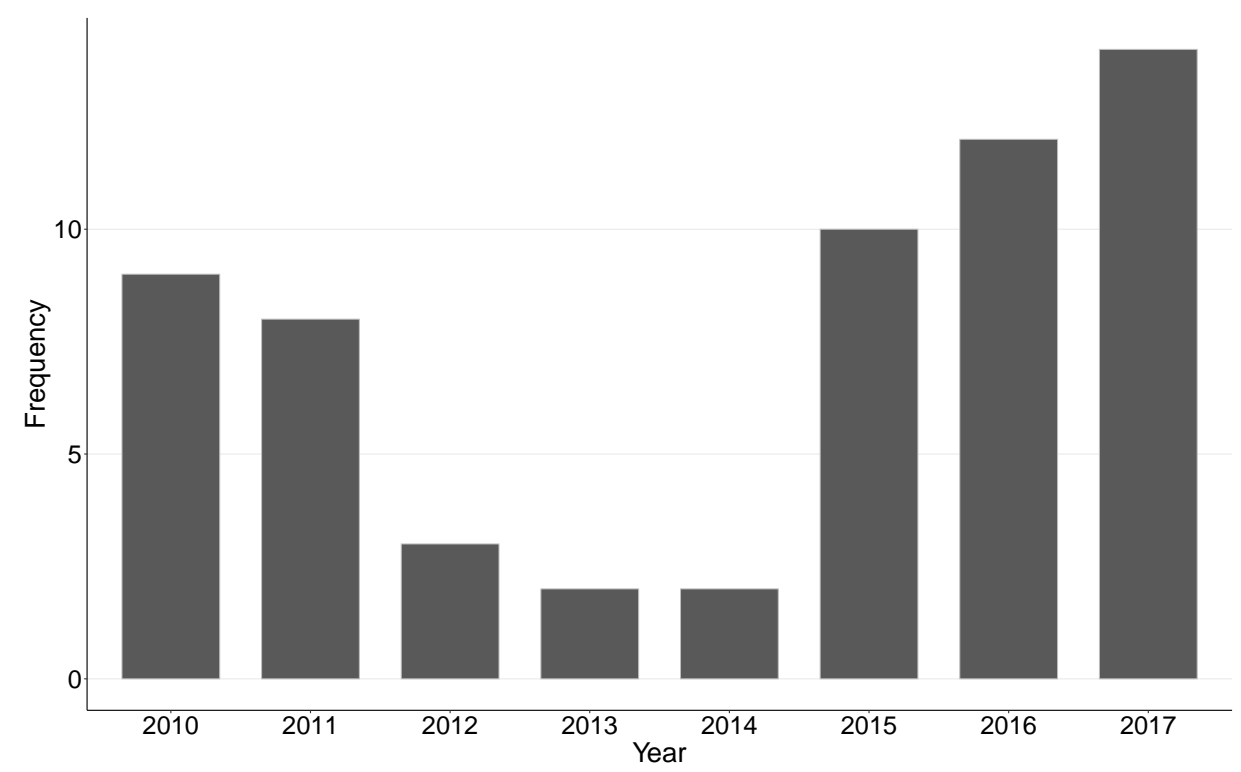

FiguRE 2: Number of units acquired by large firms (chains), by year 
TABLE 1: Overall frequencies

\begin{tabular}{lrr}
\hline & Target units & Control units \\
\hline Number of units & 60 & 88 \\
In-market acquisitions & 41 & 0 \\
Out-of-market acquisitions & 19 & 0 \\
Number of physicians & 3,366 & 1,059 \\
Primary care & 2,425 & 742 \\
Gynecology & 455 & 145 \\
Orthopedics & 329 & 101 \\
ENT & 246 & 84 \\
Number of patients & $1,365,166$ & 342,064 \\
Number of visits & $5,002,979$ & $1,175,368$ \\
\hline
\end{tabular}

Notes: Values are calculated over the entire sample of visits. Target units are those units that were acquired. Control units are units that are not the subject of acquisitions and are at least 30 kilometers away from the closest zip code of an acquired unit. Sum of physicians in different specialties do not equal the overall number of physicians because a few physicians specialize in one of the four specializations in the sample and thus are calculated twice.

\subsection{Descriptive Evidence}

Market shares and prices.-Figure 3 plots the cumulative distribution function of the market share of large firms across markets by specialty and for the years 2009, 2013, and 2017. The number of markets where large firms have a significant market share increases dramatically over the years for all specialties. ${ }^{14}$ Especially in gynecology, the increase is large: in 2009 in 50 percent of the markets the large firms' market share is less than 40 percent, while in 2017 the percentage drops to a little over 10 percent. Online Appendix Figure A3 shows similar increases in physician employment shares across the markets.

Online Appendix Figure A4 additionally plots the total visit and labor shares of all large firms over time, showing a strong increase in these two outcomes at the national level. To illustrate this further, based on a rough measure of HHI from visits to our four specialties in the year prior to acquisition, the median in-market acquisition results in a hypothetical HHI increase of 88 points in the local market. This is below the threshold of an increase in

\footnotetext{
${ }^{14}$ The market share need not increase solely through acquisitions of smaller units. It can also increase because of the market entry of large firms and exit of smaller units.
} 
the HHI of less than 100 points, which is unlikely to have adverse competitive consequences as outlined in the U.S. FTC's Horizontal Merger Guidelines. However, some 35 percent of the in-market acquisitions result in an increase of over 200 points.

Figure 4 shows that the average yearly prices of 20 -minute physician visits increase steadily from 2008 to 2017 . The increase is the largest for gynecologists and ENT physicians, approximately 20 euros or a 28 percent increase. The figure also shows the level difference between specialties: for primary care physicians the price is approximately 30 euros lower than for orthopedists. Moreover, Figure A5 shows that the number of primary care physicians has increased over this time period, while the number of physicians in the other three specialties has been stable.
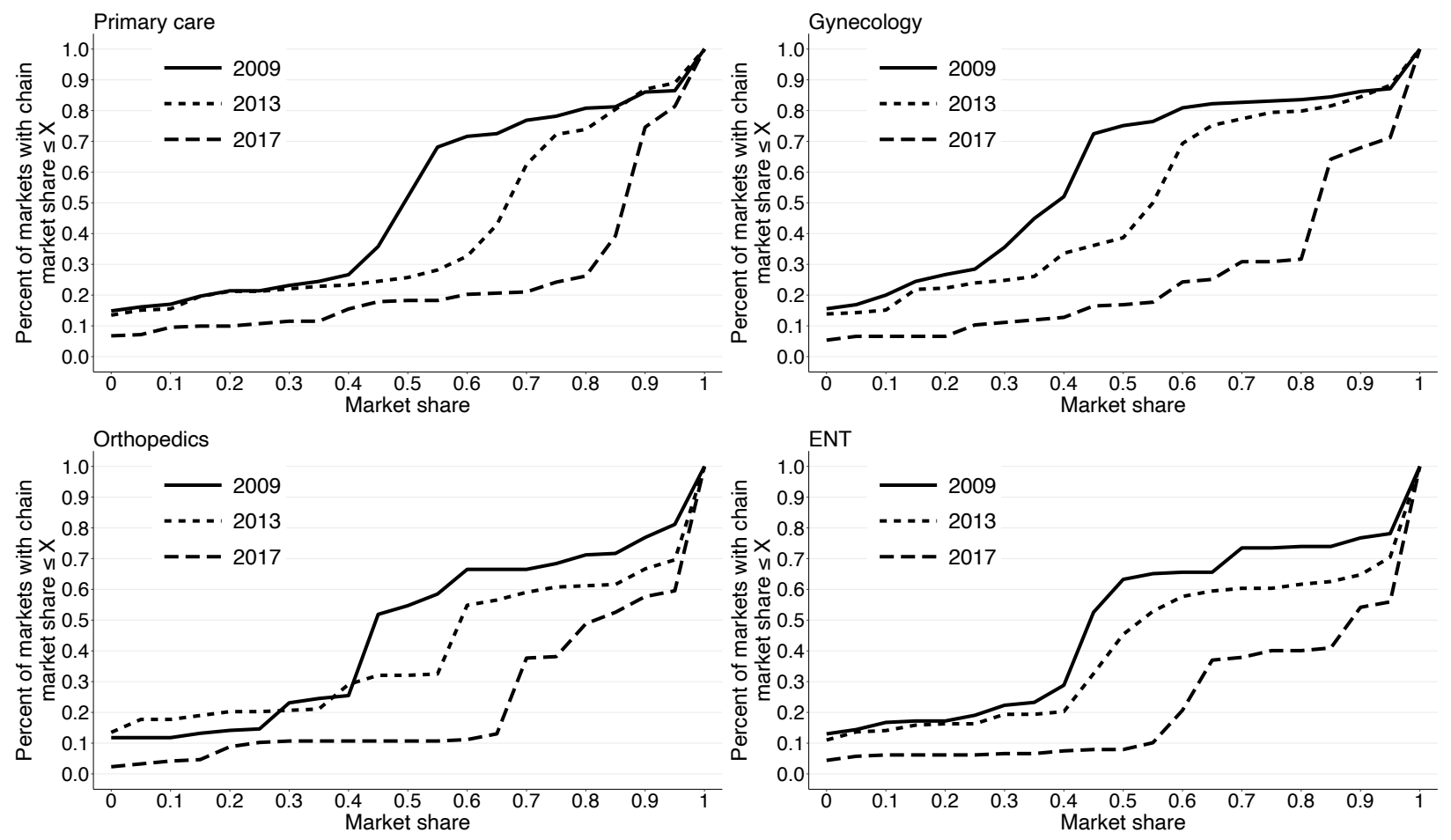

FiguRE 3: CDF of large firms' (chains') market shares, by year and specialty

Notes: Each zip code has its own market area of a 30 kilometer radius. Y-axis is the cumulative fraction of markets that have a market share under or equal to the number depicted on the $\mathrm{x}$-axis. Large firms' market shares are calculated from visits to private health care physicians.

Physicians in target and control units.-Table 2 shows the summary statistics for control 


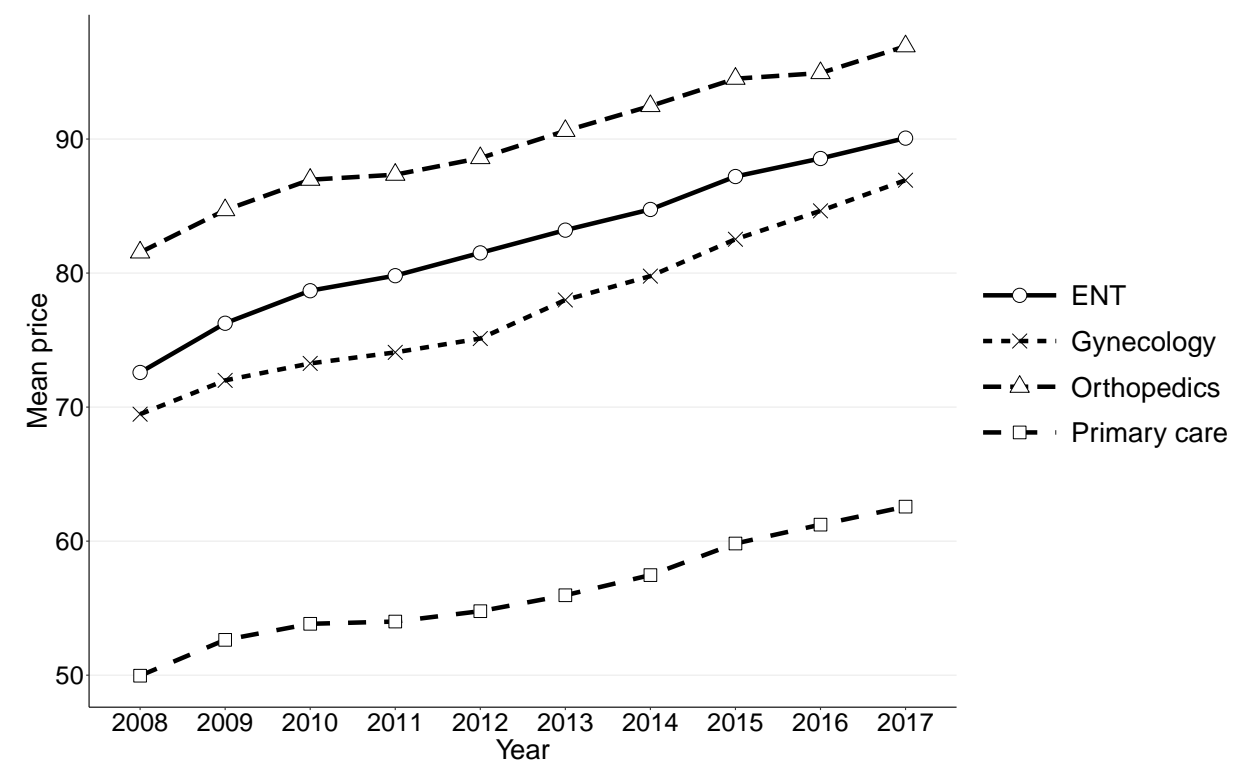

Figure 4: Prices of 20 min physician visits, by speciality

Notes: Price deflated with CPI with 2017 as the base year.

units and units targeted for an acquisition by physician specialty in 2009, one year before any acquisition took place in our data. Prices per visit vary substantially between and within fields of specialization in both target and control units. Primary care physicians have the lowest price per visit on average, slightly under 50 euros, both in target and control units. Compared to control units, the mean prices for specialists are fairly similar in target units. The biggest difference is for orthopedists, 76 versus 82 euros on average in target versus control units.

Table 2 also shows that target units tend to be larger in terms of the number of physicians. Primary care is the most common specialty in units, with 16 physicians in target units and 5 physicians in control units on average. In specialized services, gynecology has the highest number of physicians per unit, 7 in target units and 3 in control units on average. The differences are also reflected in smaller physician within-unit shares and physician overall market shares in target compared to control units, which tend to be located outside the densest regions. Physician overall market shares are generally much smaller than withinunit shares. These findings together suggest that the share of a physician's patient visits 
TABLE 2: Summary statistics in 2009, by specialty

\begin{tabular}{|c|c|c|c|c|c|c|c|c|}
\hline & \multicolumn{4}{|c|}{ Target units } & \multicolumn{4}{|c|}{ Control units } \\
\hline & Mean & $\mathrm{SD}$ & $\mathrm{P} 10$ & P90 & Mean & SD & P10 & P90 \\
\hline Price per visit & 60.321 & 17.678 & 40.000 & 81.000 & 56.610 & 15.608 & 40.000 & 80.000 \\
\hline Primary care & 49.733 & 14.085 & 38.000 & 69.000 & 47.119 & 10.072 & 39.300 & 60.000 \\
\hline Gynecology & 67.906 & 15.164 & 50.000 & 87.000 & 66.316 & 11.398 & 50.000 & 80.000 \\
\hline Orthopedics & 75.738 & 14.590 & 60.000 & 90.000 & 82.083 & 10.626 & 72.000 & 95.000 \\
\hline ENT & 69.189 & 12.754 & 59.000 & 84.000 & 69.122 & 9.631 & 60.000 & 85.000 \\
\hline Number of physicians per unit & 28.463 & 23.827 & 4.900 & 56.000 & 8.425 & 10.746 & 1.000 & 22.500 \\
\hline Primary care & 15.769 & 13.645 & 2.100 & 29.900 & 4.541 & 5.173 & 1.000 & 13.400 \\
\hline Gynecology & 6.729 & 4.770 & 2.000 & 14.000 & 3.240 & 2.962 & 1.000 & 7.000 \\
\hline Orthopedics & 5.109 & 4.653 & 1.000 & 10.000 & 2.500 & 2.229 & 1.000 & 5.600 \\
\hline ENT & 3.786 & 2.798 & 1.000 & 8.900 & 2.263 & 1.661 & 1.000 & 5.000 \\
\hline Physician within-unit share & 0.035 & 0.073 & 0.001 & 0.089 & 0.119 & 0.226 & 0.003 & 0.278 \\
\hline Primary care & 0.033 & 0.074 & 0.001 & 0.090 & 0.155 & 0.276 & 0.002 & 0.532 \\
\hline Gynecology & 0.045 & 0.066 & 0.004 & 0.102 & 0.127 & 0.209 & 0.010 & 0.382 \\
\hline Orthopedics & 0.033 & 0.090 & 0.001 & 0.055 & 0.033 & 0.044 & 0.005 & 0.068 \\
\hline ENT & 0.030 & 0.047 & 0.001 & 0.064 & 0.049 & 0.046 & 0.004 & 0.101 \\
\hline Physician market share & 0.009 & 0.025 & 0.000 & 0.022 & 0.063 & 0.143 & 0.001 & 0.136 \\
\hline Primary care & 0.008 & 0.028 & 0.000 & 0.017 & 0.077 & 0.173 & 0.001 & 0.187 \\
\hline Gynecology & 0.012 & 0.023 & 0.000 & 0.028 & 0.072 & 0.143 & 0.005 & 0.141 \\
\hline Orthopedics & 0.005 & 0.010 & 0.000 & 0.016 & 0.024 & 0.040 & 0.003 & 0.042 \\
\hline ENT & 0.011 & 0.027 & 0.000 & 0.032 & 0.029 & 0.024 & 0.003 & 0.065 \\
\hline
\end{tabular}

Notes: The values are calculated in 2009 before any acquisitions took place in our sample. Target (treated) units are those units that are acquired during the observation period. Control units are units that are not the subject of acquisitions and are at least 30 kilometers away from the closest zip code of an acquired unit.

is small in the market, but is much larger within units and varies across different fields of specialization.

Table 3 shows the summary statistics of various measures of physician mobility in the acquired units one year after an acquisition. We present the summary statistics for acquired, rather than non-acquired or control, units, because we are particularly interested in the mobility of incumbent physicians who worked in the unit before its acquisition. Primary care physicians are mobile: only 22 percent of incumbent primary care physicians continue in the health care unit on average. Also, acquired units have the largest number of new physicians in this specialty, 27 on average. In contrast, gynecologists appear to be the least mobile: almost 50 percent of incumbents continue to work in the unit one year after its acquisition. An acquisition may make the unit particularly attractive to the incumbents, 
TABLE 3: Physician job mobility in acquired units in the post-acquisition year, by specialty

\begin{tabular}{lrrrr}
\hline & Mean & SD & P10 & P90 \\
\hline Share of incumbent physicians who continue & 0.32 & 0.18 & 0.12 & 0.56 \\
Primary care & 0.22 & 0.17 & 0.00 & 0.47 \\
Gynecology & 0.49 & 0.24 & 0.18 & 0.77 \\
Orthopedics & 0.33 & 0.28 & 0.00 & 0.68 \\
ENT & 0.44 & 0.30 & 0.00 & 0.87 \\
Number of new physicians & 41.58 & 64.11 & 2.00 & 83.00 \\
Primary care & 26.83 & 43.22 & 1.00 & 62.00 \\
Gynecology & 7.19 & 12.15 & 1.00 & 13.00 \\
Orthopedics & 3.56 & 4.68 & 0.00 & 8.00 \\
ENT & 4.00 & 6.64 & 0.00 & 7.00 \\
Ratio of new physicians to continuing physicians & 1.45 & 3.71 & 0.00 & 2.84 \\
Primary care & 2.03 & 4.29 & 0.09 & 4.24 \\
Gynecology & 0.52 & 1.81 & 0.00 & 1.00 \\
Orthopedics & 0.47 & 0.89 & 0.00 & 1.58 \\
ENT & 0.29 & 0.50 & 0.00 & 1.00 \\
\hline
\end{tabular}

Notes: The values are calculated for the year following the units' acquisition. Incumbent physicians who continue working in the unit are defined as those physicians that have observations in all four quarters in the post-acquisition year. New physicians are defined as those physicians that do not have observations in the acquired unit in the pre-acquisition period.

which may induce them to stay in that unit. Also, physician market power and a large pool of patients in a unit may reduce willingness to switch units.

\section{Econometric Approach}

\subsection{Regression Model Specification}

We examine acquisitions in the Finnish private health care market using data from the period 2008-2017. We identify the effects using variation in the acquisition time and units in markets that undergo no acquisitions. We use a difference-in-differences (DiD) approach, starting with the following specification:

$$
y_{\text {iut }}=\alpha_{i}+\gamma_{t}+\delta A C Q\{t \geq \tau(u), u \in A\}+X_{i t} \beta+\epsilon_{\text {iut }},
$$


where $y_{\text {iut }}$ is the outcome of interest for physician $i$ in unit $u$ in quarter $t$. The terms $\alpha_{i}$ and $\gamma_{t}$ represent physician fixed effects and year fixed effects, respectively. The term $A C Q\{t \geq \tau(u), u \in A\}$ is a dummy that turns on for all physicians after the post-acquisition quarter $\tau(u)$ working in a unit that is part of the set of target units $A$. The model includes controls for physician and visit characteristics that include physician and patient age, squared ages, patient gender, patient yearly income (bins of $0-10000,10001-20000, \ldots, \geq 100000$ euros), fixed effects for the length of the visit (10, 20, 30, 45, and 60 min), and whether there is a specialization fee included in the visit. We cluster the standard errors at the unit level to take into account correlation in $\epsilon_{i u t}$ across physicians in the same unit.

Physicians may have a contract for office space in more than one unit at the same time. To better control for time invariant differences between different physicians and units (e.g. patient mix or popularity), we replace the physician fixed effects with an interaction term between physicians and units, $\theta_{u} \times \alpha_{i}$. Furthermore, any effects of acquisitions may not instantaneously take effect in the first quarters. Rather, the effects may slowly evolve over time. To take these dynamic effects into account, we additionally split the post-acquisition dummy into a short-run dummy (first four post-acquisition quarters), ShortRun $\{t \in[\tau(u), \tau(u)+3], u \in A\}$, and a long-run dummy (all subsequent quarters), LongRun $\{t \geq \tau(u)+4, u \in A\}$. The estimated baseline specification is now of the form:

$$
\begin{aligned}
y_{\text {iut }} & =\theta_{u} \times \alpha_{i}+\gamma_{t}+\delta_{1} \text { ShortRun }\{t \in[\tau(u), \tau(u)+3], u \in A\} \\
& +\delta_{2} \text { LongRun }\{t \geq \tau(u)+4, u \in A\}+X_{i t} \beta+\epsilon_{\text {iut }} .
\end{aligned}
$$

The key assumption behind estimating the unbiased DiD coefficients $\delta_{1}$ and $\delta_{2}$ is that the pre-acquisition trends in the outcomes are similar between acquired versus control units and early acquired versus late acquired units. Also, to credit any effects properly as a result of acquisitions, the target units need to be free of any shocks specific to these units that would affect their outcomes in the post-acquisition period. To explicitly test the pre-trend 
assumption, we estimate the event study specification of equation 2 :

$$
y_{i u t}=\theta_{u} \times \alpha_{i}+\gamma_{t}+\sum_{k=-9}^{9} \delta_{k} A C Q\{t=\tau(u)+k, u \in A\}+X_{i t} \beta+\epsilon_{i u t}
$$

which includes leads and lags up to nine quarters before and after the acquisition. The end points, $k \in\{-9,9\}$, are binned so that they also include all quarters prior to and after these points (when plotting the results we drop these event dummies). As the model includes

fixed effects for units and physicians, we omit the first pre-acquisition period $t=\tau(u)-1$, meaning that the results are normalized relative to this period.

We estimate our models in three different aggregation levels: physician-visit level, physicianquarter level, and unit-quarter level, depending on the outcome of interest. In the physicianquarter level estimations we estimate models similar to equations 2 and 3 but drop all variables in $X_{i t}$ except physician age and squared age. In the unit-quarter level estimations we additionally drop all $X_{i t}$ and replace the interaction term $\theta_{u} \times \alpha_{i}$ with the unit fixed effect $\theta_{u}$

\subsection{Identification}

As explained in the previous section, the identification of the causal effect of acquisitions relies on the exogeneity of the acquisitions, conditional on the observables and fixed effects. A firm's decision to acquire units is, however, endogenous and may depend on, for example, the future profitability of the unit, the labour structure of the unit, and the local market structure. For example, firms acquire units in markets that are expanding.

For the outcome of an individual physician, the concern regarding the endogeneity of acquisitions is arguably less relevant than for the outcome of a health care unit. The shock from an acquisition experienced by the physician originates largely from a higher-level decision by the firm and not from the trajectory of the individual physician. This is likely, especially in larger units. 
The fixed effects for physicians and units absorb any observed and unobserved timeinvariant differences between target (treated) and control units. Nevertheless, there may remain the concern that the trends between these units differ. To mitigate this concern, we follow Lewis and Pflum (2017) and also estimate specifications that have a separate set of time fixed effects for target units. These specifications additionally absorb any differences in the trends between target and control units. The remaining identifying assumption is that the timing of the acquisition is uncorrelated with unobservable factors that affect our outcomes. The downside to this specification is that it kills part of the variation in the identification of the treatment effect.

Another concern is the unobserved quality (or popularity) of physicians. Both market share and prices may be higher for higher quality physicians. Thus, analyzing only associations between prices and concentration measures could result in mistakenly interpreting that higher concentration leads to higher prices. In our regressions, physician fixed effects control for any time-invariant quality differences between physicians. Also, in our setting this is less of a concern as we identify the changes directly from acquisitions. We follow the same physicians that worked in the unit already in the pre-acquisition and continued in the post-acquisition period. This ensures that any estimated changes in outcomes result from changes in the physicians' environment.

It is important to form the control group so that it is not contaminated by the effects of acquisitions. If a control unit is located near a target unit, the prices of its physicians could be affected by the acquisition and the possible relaxation of physician or firm competition. To mitigate this issue, we do not use units in the market areas of acquired units as controls. In the robustness checks we explore market areas of 50 kilometer instead of 30 kilometer radii (see Section 6). In theory, it is possible that the control units owned by large firms are somehow also affected by acquisitions by these firms in other markets. This may occur, for example, if the acquisitions lead to productivity gains at the firm level (and across markets). Our results are robust to dropping the units of large firms from our control group. 


\section{Results}

\subsection{Physician Prices}

Price per visit: incumbent physicians.-We begin by estimating the average effect of an acquisition on physician price per visit. We define the treated physicians as those who also worked in the target units in the pre-acquisition period (referred as incumbents throughout the paper). We define the treatment group this way because incumbent physicians have observations in the target unit before and after its acquisition, providing us with the key identifying variation to estimate the effects using visit-level data. Estimating the effects for incumbents is also of particular interest because they may posses market power over new physicians in some fields of specialization such as gynecology (Section 3.1). ${ }^{15}$ Nevertheless, we additionally analyze the average price of health care units below. The results from these additional analyses are fairly similar to our baseline results for incumbent physicians.

Figure 5 plots the baseline event study coefficients $\delta_{k}$ and their confidence intervals from estimating Equation (3). Online Appendix Table A2 shows the DiD coefficients and their standard errors from estimating variants of the specification in equation (2). The specification in column 1 includes physician fixed effects. The baseline specification in column 2 replaces physician fixed effects with unit-specific physician fixed effects. Columns 3 and 4 additionally include treatment group-specific time fixed effects in these two specifications.

Figure 5 shows that the price increases 1-2 percent after an acquisition. There is no evidence of a pre-trend, supporting the credibility of our research design. Columns 1 and 2 of Table A2 confirm that prices increase only 1 percent in the long run, one year after the acquisition. The effect is, however, imprecisely estimated in both specifications. Adding treatment group-specific time fixed effects into these specifications in columns 3-4 makes the magnitudes of the point estimates even closer to zero. The additional specifications only use within-treatment group variation in the timing of acquisitions to identify the treatment

\footnotetext{
${ }^{15}$ Also, a substantial share (32 percent) of all physicians continue to work in the unit after the acquisition (Section 3.4).
} 
effects, in contrast to the specifications in columns 1 and 2 that also use variation from the never-acquired units.

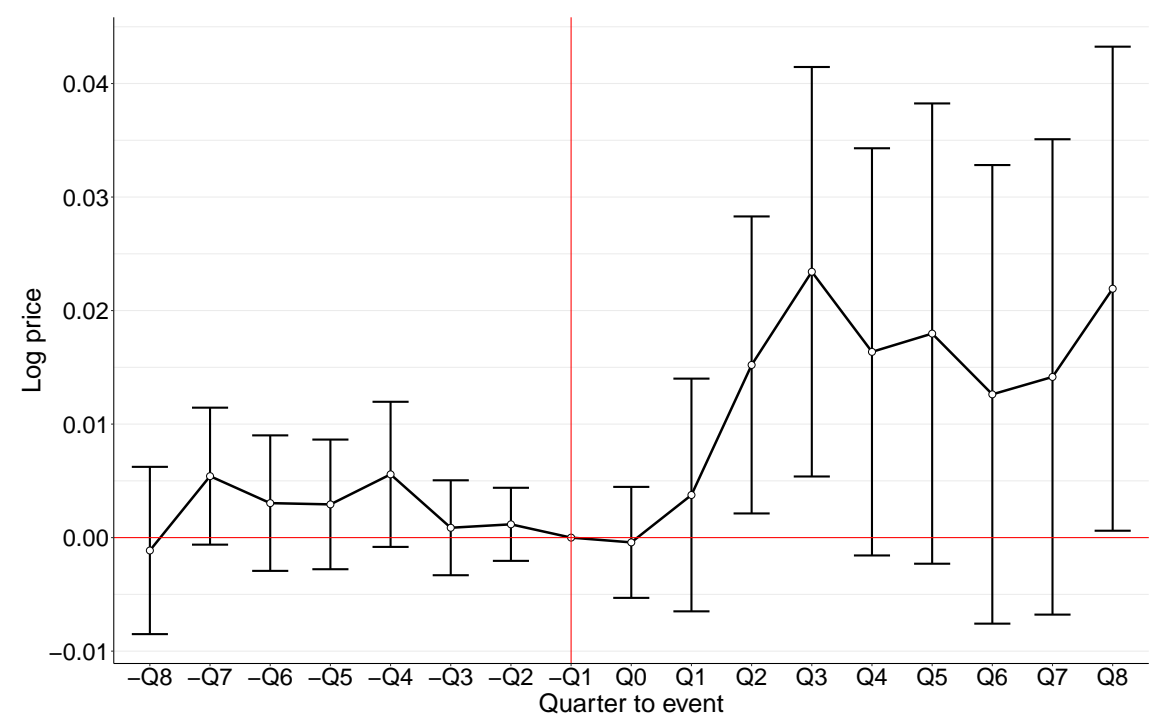

Figure 5: Price per visit for incumbent physicians

Notes: Unit of observation is physician $\times$ unit $\times$ visit. Treated physicians are those that worked in the target unit in the pre-acquisition period. Data include primary care physicians (unspecialized and general medicine), gynecologists, orthopedists, and ENT physicians. Controls include fixed effects for physician $\times$ unit, time period, length of the visit fixed effects, whether there is a specialization fee included in the visit, patient gender, patient income, as well as controls for physician and patient age and square of age.

Heterogeneity by physician specialty.-Figure 6 plots the event study estimates of the price effects for incumbent physicians by specialty. Online Appendix Table A3 shows the corresponding DiD estimates. We find substantial heterogeneity in the effects across different specialties. In primary care, we find little effect: the long-run point estimate in column 1 of Table A3 shows a price decrease, which is less than 1 percent and statistically insignificant. The corresponding confidence interval allows us to rule out a decrease larger than 4 percent and an increase of more than 2 percent in the long run. In contrast, we find that prices increase gradually in gynecology. The increase is approximately 5 percent in the long run and statistically significant, as shown in column 3 of Table A3. We find little price response in other fields of specialization, although the short-run point estimate for ENT physicians shows a statistically significant one percent price increase. The alternative DiD specifications 
with with treatment group specific time fixed effects show similar results.
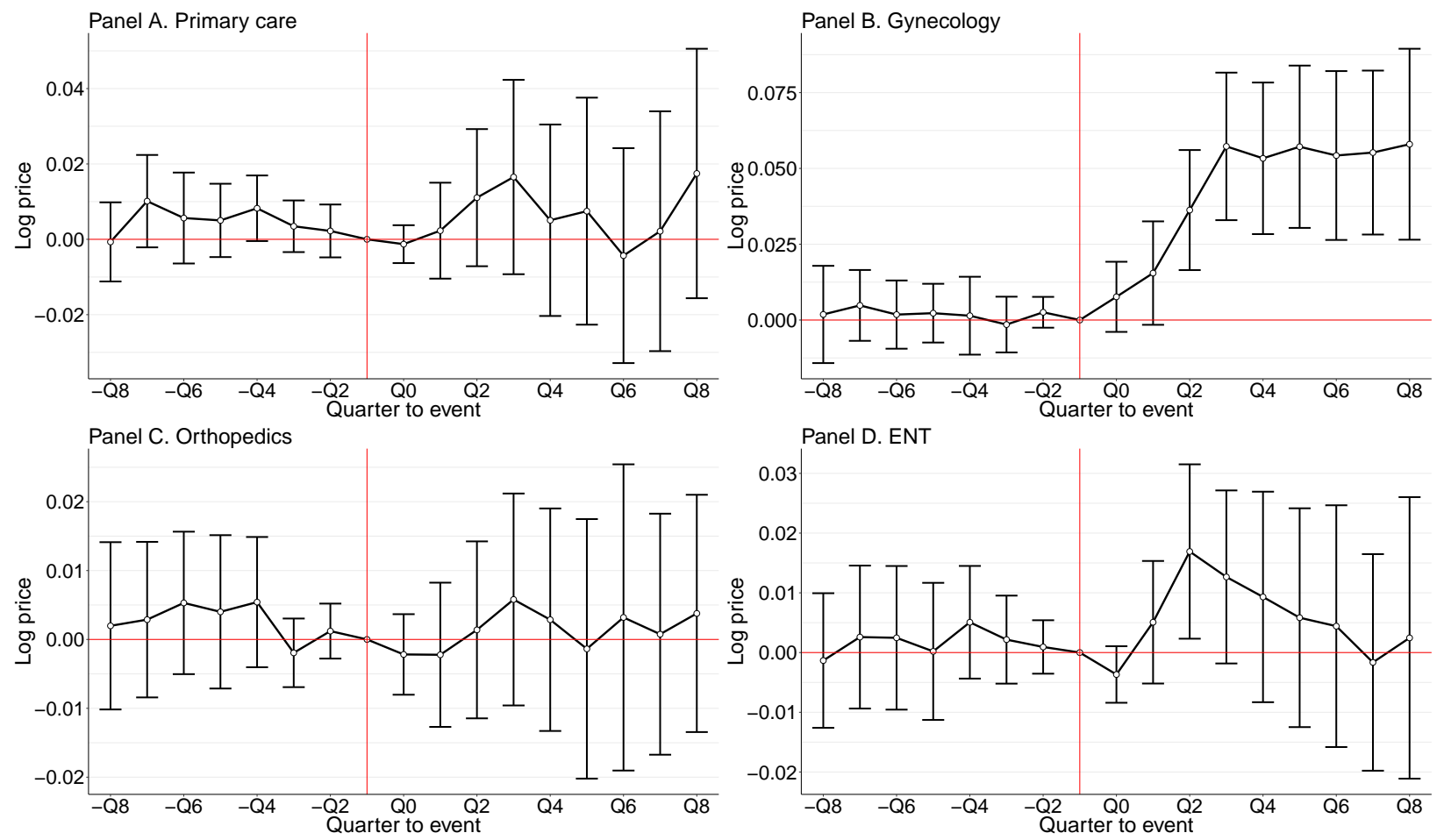

FiguRe 6: Price per visit for incumbent physicians, by specialty

Notes: Unit of observation is physician $\times$ unit $\times$ visit. Treated physicians are those that worked in the target unit in the pre-acquisition period. Primary care physicians include both unspecialized physicians and general medicine physicians. Controls include fixed effects for physician $\times$ unit, time period, length of the visit, whether there was a specialization fee included in the visit, patient gender, patient income, as well as controls for physician and patient age and square of age.

Price per minute: incumbent physicians and health care units.-Online Appendix Figure A6 and Table A4 show the event study and DiD results, respectively, when we use aggregated physician-quarter-level data and price per minute as an outcome. The results are similar to our baseline results, and for incumbent gynaecologists, we even find a larger increase in the target unit post-acquisition (6 percent in the long run). Moreover, Online Appendix Table A5 shows the complementary results for the average quarterly price per minute of health care units. The outcome is conceptually similar to price per minute, but created at different levels of aggregation. It is also noteworthy that we calculate the average unit-level prices over both incumbent and new physicians. The results for health care units are similar to those obtained for incumbent physicians. 


\subsection{Market Shares}

Overall market shares.-Acquisitions may be followed by significant investments in quality that may give rise to price increases for gynecologists (rather than increased market power on the firm or physician side). Unfortunately, it is difficult to measure quality directly with our data. Nevertheless, if a target unit exhibits an increase in health care utilization or overall market share despite the fact that prices have increased post-acquisition, this is commonly viewed as a fairly good indication that the unit improved its quality or became more attractive to patients. See Lewis and Pflum (2017) for a similar argument. ${ }^{16}$

Based on this background, we examine the effects of an acquisition on the utilization of physician services in the target unit. We begin by plotting the event study estimates of the incumbent physician's overall market share in Figure 7, using our aggregated physicianquarterly-level data. We find no statistically significant change in the physician's overall market share for any physician group in the target unit. Not even gynecologists experience a significant change in their market shares post-acquisition, despite the significant increase in prices. The overall market share of a physician is, however, very small in our data (mean share of less than 1 percent) and may primarily reflect the fairly large number of physicians working in the market area, as opposed to the quality or attractiveness of their services.

Acquisition-induced improvements in quality or attractiveness may show up only at the health care unit-level. In fact, health care units, rather than individual physicians, make investments in facilities, diagnostic services, and advertising of the brand name. In Online Appendix Table A6, we show the effects on the health care unit's overall market share. The point estimates are statistically insignificant and fairly close to zero, which suggests that the target units do not exhibit a substantial increase in the utilization of services that would indicate improved quality of services.

\footnotetext{
${ }^{16}$ One common feature of most of the horizontal merger models is that increased market share post-merger is a sign of productivity gains (such as quality improvements) by merging firms or, alternatively, that the productivity gains of the merger outweighed any market power effects (Gugler and Siebert 2007).
} 

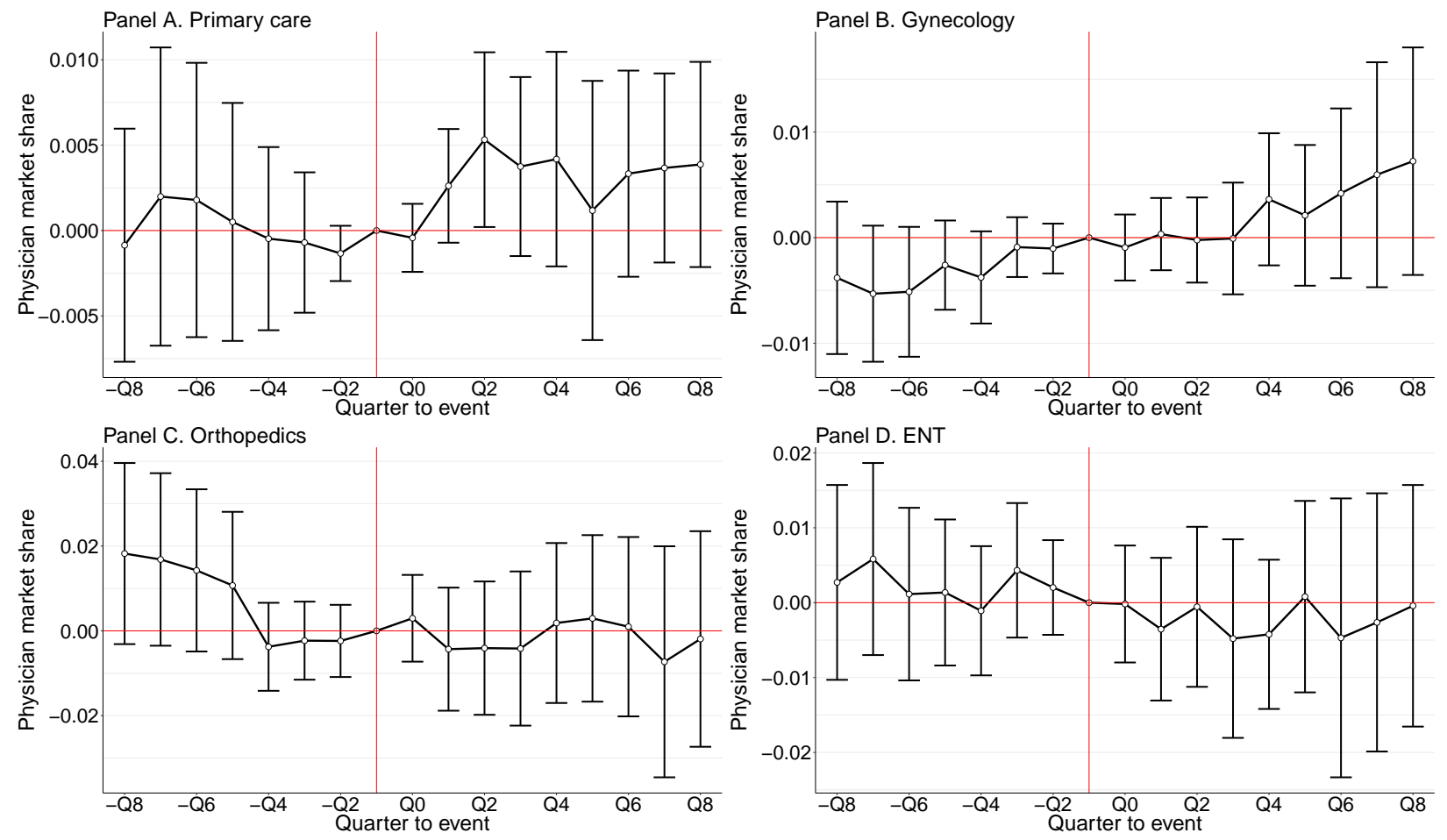

Figure 7: Physician overall market shares for incumbent physicians, by specialty

Notes: Unit of observation is physician $\times$ unit $\times$ quarter. The outcome is the number of visits a physician has within a unit per quarter divided by the overall number of visits in the market. Market areas are defined by radii of 30 kilometers, calculated from the centroid of the zip codes. Treated physicians are those that worked in the target unit in the pre-acquisition period. Primary care physicians include both unspecialized physicians and general medicine physicians. Controls include fixed effects for physician $\times$ unit, time period, as well as controls for physician age and square of age. 
Physician within-unit shares and hours worked.-Physician prices could also increase with local (within-unit) market power, especially if there are less physicians working in the target unit after its acquisition. We first estimate the effects on the incumbent physician's quarterly share of visits within a health care unit, as shown in Figure 8. Incumbent gynecologists experience an increase in the share of patient visits within the unit in the long run (although not statistically significantly, as shown in Online Appendix Table A7). In contrast, there is no evidence of an increasing effect for incumbents in other specialties. Thus, the local increase in utilization occurs only for those incumbents (gynecologists) who experienced an increase in prices post-acquisition.

We then estimate the effects on the concentration of physicians' shares of the total visits within a health care unit, as measured by the within-unit HHI and shown in Online Appendix Figure A7 and Table A8. The local concentration of physician visits increases substantially in gynecology, but not in other specialties. The increase is 8 percentage points (16 percent) in the long run and statistically significant at the 10 percent level. The increase may reflect a relaxation of physician competition within a health care unit, which would also explain the higher prices for gynecologists post-acquisition.

We also consider the possibility that acquisitions affect the quarterly hours worked by physicians in the private sector, as shown in Online Appendix Table A9. Despite the higher prices and increased concentration of patient visits for (incumbent) gynecologists, the hours worked change little. Similarly, we find no statistically significant effects for primary care physicians, but some effects for other specialists. 

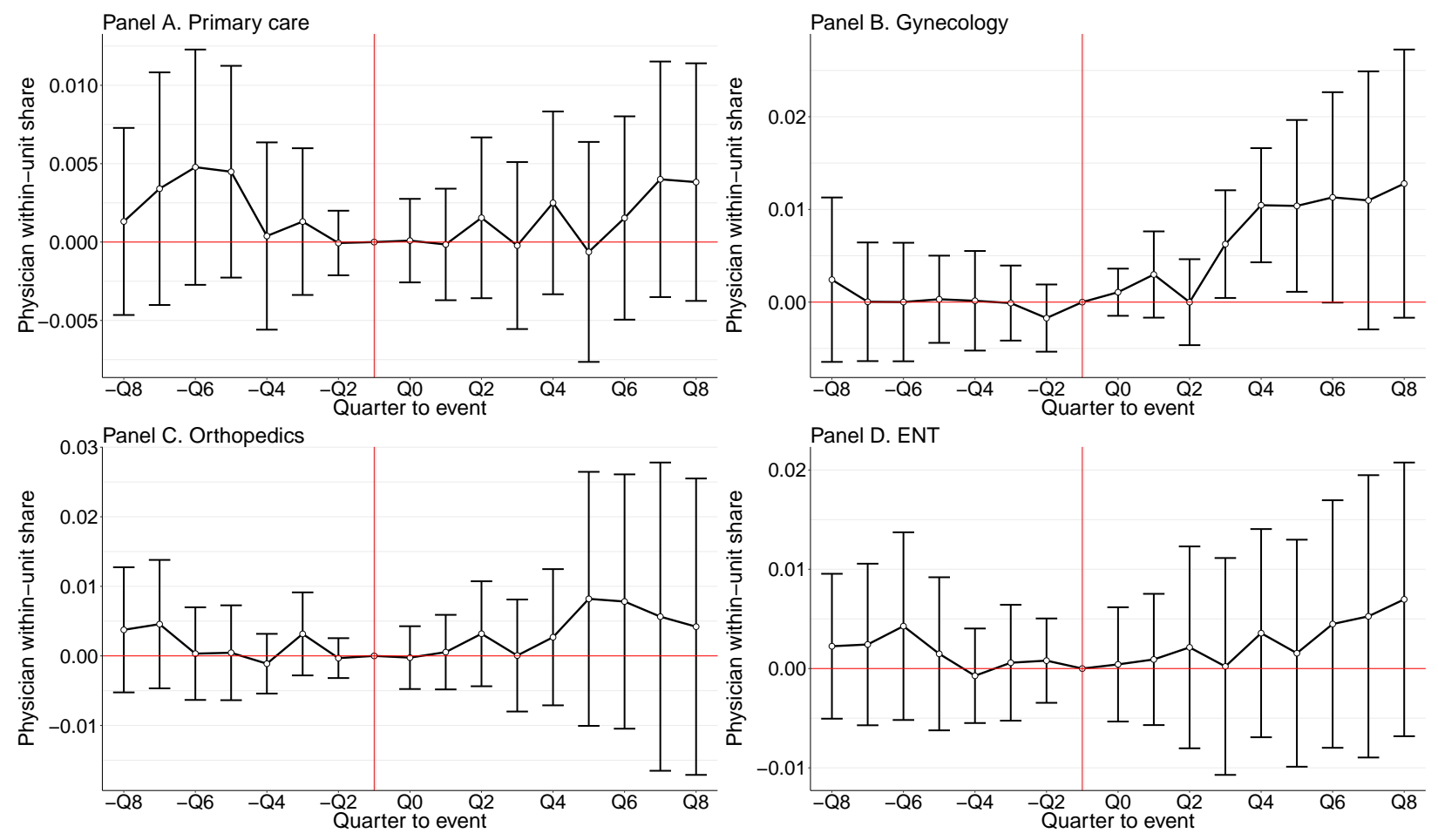

FiguRE 8: Physician within-unit share for incumbent physicians, by specialty

Notes: Unit of observation is physician $\times$ unit $\times$ quarter. The outcome is the number of visits a physician has within a unit per quarter divided by the overall number of visits in the unit. Treated physicians are those that worked in the target unit in the pre-acquisition period. Primary care physicians include both unspecialized physicians and general medicine physicians. Controls include fixed effects for physician $\times$ unit, time period, as well as controls for physician age and square of age. 


\subsection{Physician Employment}

Next we study the effect of an acquisition on physician employment. The acquisition may increase the firm's market power, leading to higher prices and falling employment in the target unit; job destruction (a smaller number of competing physicians) may also explain higher prices and an increased concentration of physician visits within target units in gynecology. Additionally, the acquisition may lead to productivity gains, entailing a restructuring or downsizing of labor. ${ }^{17}$

Total number of physicians.-Panel A of Table 4 reports the effects of an acquisition on the total number of physicians in a health care unit by specialty, using aggregated unit quarterly-level data. In all specialties, the long-run estimates are relatively imprecise, possibly because of the small sample size $(N=3,758)$. Nevertheless, the short- and long-run point estimates suggest that the number of primary care physicians increases slightly (approximately 6-4 percent) in the target unit. In contrast, we find much less evidence of such job creation in specialized services. In gynecology, we instead find most evidence that the target unit reduces the number of physicians, by approximately 10 percent in the long run, but the effect is also fairly imprecisely estimated. Next we look further into the drivers of these effects.

Continuing physicians.-Panel B of Table 4 reports the effects on the number of physicians who continue working in the unit from the previous quarter. Again, we find relatively imprecisely estimated effects. In primary care, the point estimates show little change in the number of continuing physicians in the target unit. The negative coefficient in gynecology suggests a 9 percent decrease in the long run. This finding provides additional evidence that acquisitions can lead to job losses by worsening the job stability of workers.

\footnotetext{
${ }^{17}$ See Lehto and Böckerman (2008) for results on domestic M\&As and downsizing of labor in other service sectors in Finland.
} 
New physicians and mechanisms.- Next we estimate the effect on the number of new physicians, as shown in Panel C of Table 4. The number of new primary care physicians increases by 19 percent in the short run and 24 percent in the long run, and the effects are statistically significant. However, as we observed only little change in the total number of primary care physicians, acquisitions seem to facilitate job turnover (rather than job creation) in primary care. In all other fields of specialization, the point estimates of the number of new physicians are, however, relatively small in the short run and even smaller in the long run. In gynecology, the long-run coefficient is statistically insignificant and close to zero. Overall, the evidence in gynecology suggests that acquisitions lead to job losses because departing physicians are not replaced with new physicians. This result explains the earlier finding of increased within-unit concentration among remaining gynecologists.

These results support the idea that it is easier for the firm to adjust labor among relatively low-educated (primary care) physicians. It is arguably more difficult for the acquiring firm to hire new specialists from fields where the labor supply is less elastic and the physicians are less mobile (Section 3.4). Also, some specialists may be discouraged from applying new jobs in units in which they expect incumbents to have significant competitive advantage over them, for example because of a large pool of (repeat) customers.

Online Appendix Table A10 further decomposes the number of new physicians into those who come from other units in the same market (Panel A), those who come from units outside of the market (Panel B), and those who come from outside of the private sector (Panel C), possibly from the public sector. The attractiveness of jobs to applicants may sharply decay with distance (Manning and Petrongolo 2017), and thus it may be easier for the acquiring firm unit to hire workers for the unit within the same market.

Panel A shows that in the short run a larger fraction of the increase in the number of new primary care physicians results from those who come from other units in the same market. Panel B shows that the long-run increase in the number of new primary care physicians 
results primarily from those who come from units outside the market. A comparison of the short- and long-run effects suggests that it takes more time for physicians to move to the target unit across markets, rather than within the market. Moreover, there is a notable (8 percent) and statistically significant increase in the number of new primary care physicians who come from outside the private sector, possibly from the public sector. 
TABLE 4: Number of physicians in the unit

\begin{tabular}{|c|c|c|c|c|c|}
\hline & All physicians & Primary care & Gynecology & Orthopedics & ENT \\
\hline & (1) & $(2)$ & (3) & (4) & (5) \\
\hline Panel A. Log $n$ & umber of physici & ans & & & \\
\hline Short-run & 0.076 & 0.056 & 0.038 & $0.112^{*}$ & $0.083^{*}$ \\
\hline & $(0.049)$ & $(0.058)$ & $(0.046)$ & $(0.057)$ & $(0.049)$ \\
\hline Long-run & -0.038 & 0.038 & -0.101 & -0.031 & 0.006 \\
\hline & $(0.071)$ & $(0.072)$ & $(0.073)$ & $(0.069)$ & $(0.058)$ \\
\hline Mean outcome & 19.279 & 10.111 & 4.370 & 2.696 & 2.101 \\
\hline Observations & 3,758 & 3,758 & 3,758 & 3,758 & 3,758 \\
\hline Adjusted $R^{2}$ & 0.931 & 0.915 & 0.878 & 0.86 & 0.879 \\
\hline Panel B. Log n & umber of continu & ing physicians & & & \\
\hline Short-run & 0.034 & -0.017 & 0.021 & $0.096^{*}$ & 0.058 \\
\hline & $(0.047)$ & $(0.051)$ & $(0.044)$ & $(0.054)$ & $(0.040)$ \\
\hline Long-run & -0.071 & -0.019 & -0.092 & -0.055 & 0.025 \\
\hline & $(0.074)$ & $(0.071)$ & $(0.078)$ & $(0.068)$ & $(0.058)$ \\
\hline Mean outcome & 16.602 & 8.257 & 3.993 & 2.462 & 1.890 \\
\hline Observations & 3,758 & 3,758 & 3,758 & 3,758 & 3,758 \\
\hline Adjusted $R^{2}$ & 0.923 & 0.909 & 0.888 & 0.872 & 0.902 \\
\hline Panel C. Log n & umber of new ph & ysicians & & & \\
\hline Short-run & $0.210^{* * *}$ & $0.188^{* * *}$ & $0.086^{*}$ & $0.078^{* *}$ & $0.073^{*}$ \\
\hline & $(0.070)$ & $(0.069)$ & $(0.049)$ & $(0.036)$ & $(0.039)$ \\
\hline Long-run & $0.220^{* * *}$ & $0.238^{* * *}$ & 0.005 & $0.071^{*}$ & -0.001 \\
\hline & $(0.081)$ & $(0.077)$ & $(0.048)$ & $(0.038)$ & $(0.034)$ \\
\hline Mean outcome & 2.677 & 1.855 & 0.376 & 0.234 & 0.212 \\
\hline Observations & 3,758 & 3,758 & 3,758 & 3,758 & 3,758 \\
\hline Adjusted $R^{2}$ & 0.589 & 0.579 & 0.254 & 0.217 & 0.222 \\
\hline Time FE & Yes & Yes & Yes & Yes & Yes \\
\hline Unit FE & Yes & Yes & Yes & Yes & Yes \\
\hline
\end{tabular}

Notes: Unit of observation is unit×quarter. To account for zeros in the data, a value of one is added to each observation before log-transformation of the outcome. Continuing physicians are those that had an observation in the unit in the previous quarter. New physicians are defined as those physicians that had no observations in the unit in the previous quarter. Each unit's first period and solo practices are dropped from the data. The mean outcomes are values before performing the log transformation. 


\subsection{Prices and Within-Unit Shares of New Physicians}

Next, we turn to analyzing how prices and within-unit shares evolve for new physicians after starting to work in the acquired unit. ${ }^{18}$ We perform these analyses for two reasons. First, they provide information on the potential reasons for new physicians to move to the acquired unit, rather than about the effects of the acquisition itself. Second, they provide additional evidence about the changes in a physician's market power in the target unit over time after the acquisition.

In our analyses, the treatment turns on when the physician starts to work in the new unit and the event time is computed relative to that. The change in the outcome is the difference in the outcome between the pre-treatment unit(s) (physician may work in more than one unit) and the new unit. ${ }^{19}$ We only analyze a subset of physicians who started working in the acquired unit within a year from the acquisition. Also, we opt to use physician fixed effects $\alpha_{i}$ instead of unit-specific physician fixed effects $\theta_{u} \times \alpha_{i}$ as it would kill the necessary variation at the change in the event time from the old unit(s) to the new unit. Thus, the estimated changes may reflect unobserved (time-invariant) differences between physicians and units, for example, in patient mix.

Figure 9 shows the changes in price per visit after the physician starts to work in the acquired unit. For primary care physicians there is a large increase in prices immediately after staring to work in the acquired unit. The effect seems to persist over time. For specialists, we observe heterogeneous changes in prices. Especially for gynecologists, the change is rather subtle and inconclusive as there seems to be some pre-trend in the outcome. Nevertheless, the possible market power of incumbent gynecologists through patient switching costs and inertia may limit the ability of new gynecologists to increase prices.

Figure 10 shows the changes in the physician's share of visits within a unit. Primary

\footnotetext{
${ }^{18}$ As we are interested in changes around the migration to the new unit, we refrain from including physicians that do not have any observations in any other unit prior to appearing in the acquired unit.

${ }^{19}$ In the case of many pre-treatment units, the outcome for a physician would be a weighted average between these units.
} 

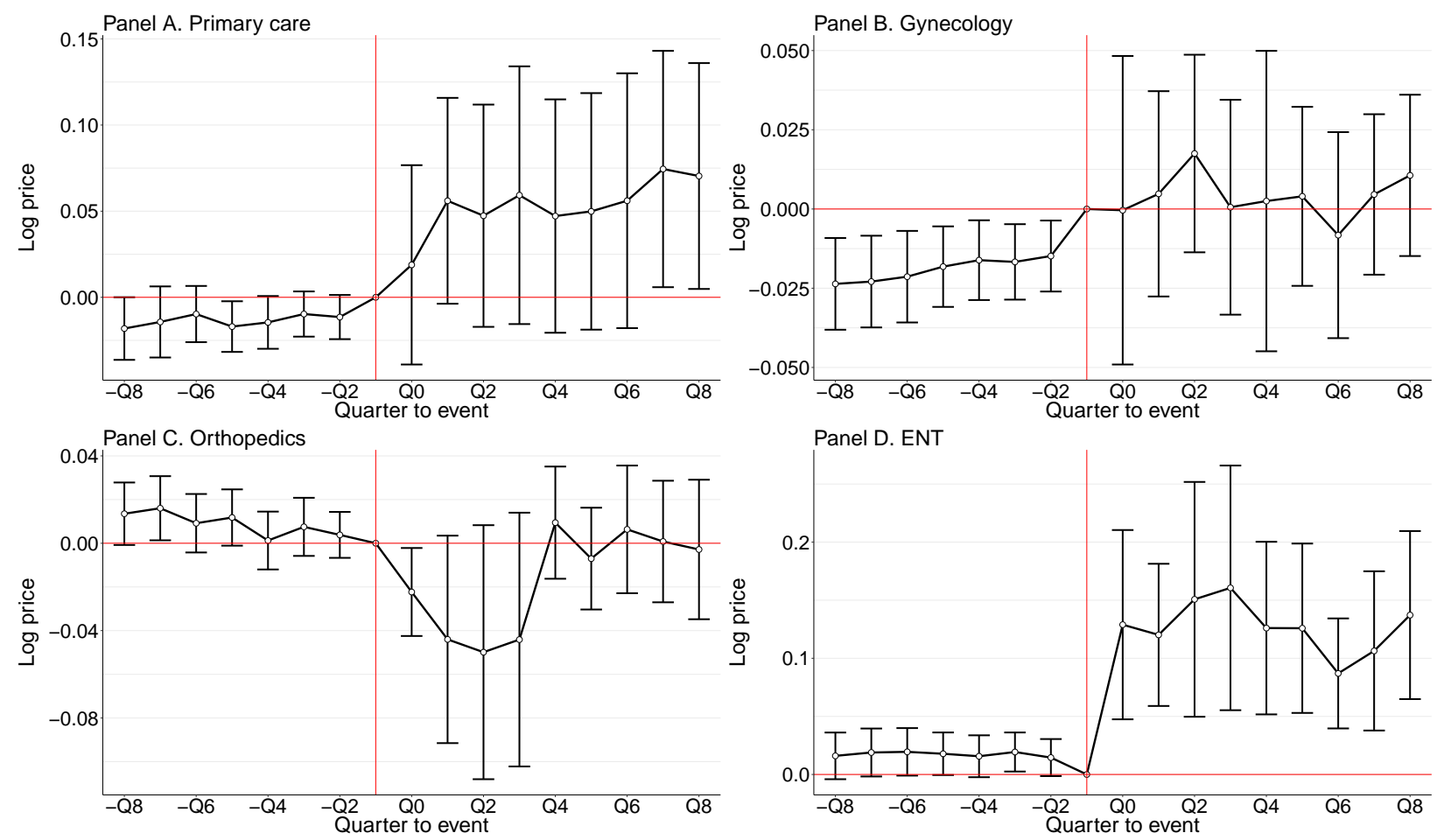

Figure 9: Price per visit for new physicians, by specialty

Notes: Unit of observation is physician $\times$ unit $\times$ visit. Treated physicians are those that started working in the unit after the acquisition. Event time is calculated relative to the physician's arrival in the newly acquired unit. Primary care physicians include both unspecialized physicians and general medicine physicians. Controls include fixed effects for physician, unit, time period, length of visit, whether there was a specialization fee included in the visit, patient gender, patient income, as well as controls for physician and patient age and square of age. 
care physicians have a relatively similar share of patient visits in the acquired unit as in the previous unit(s) in the long run. This suggests that the local competition environment does not change much. Higher prices or better revenue, together with a fairly similar competition environment, might be potential reasons why more new physicians move to the target unit after its acquisition in primary care, as shown in the previous section.

In contrast to primary care physicians, new specialists have a smaller share of patient visits within the acquired unit than in the previous unit(s). This is true, especially in relatively small fields of specialization, including orthopedics and ENT. For gynecologists, however, the decrease seems to be smaller than for other specialists and wanes in the long run, possibly because physicians are able to attract more repeat customers over time.
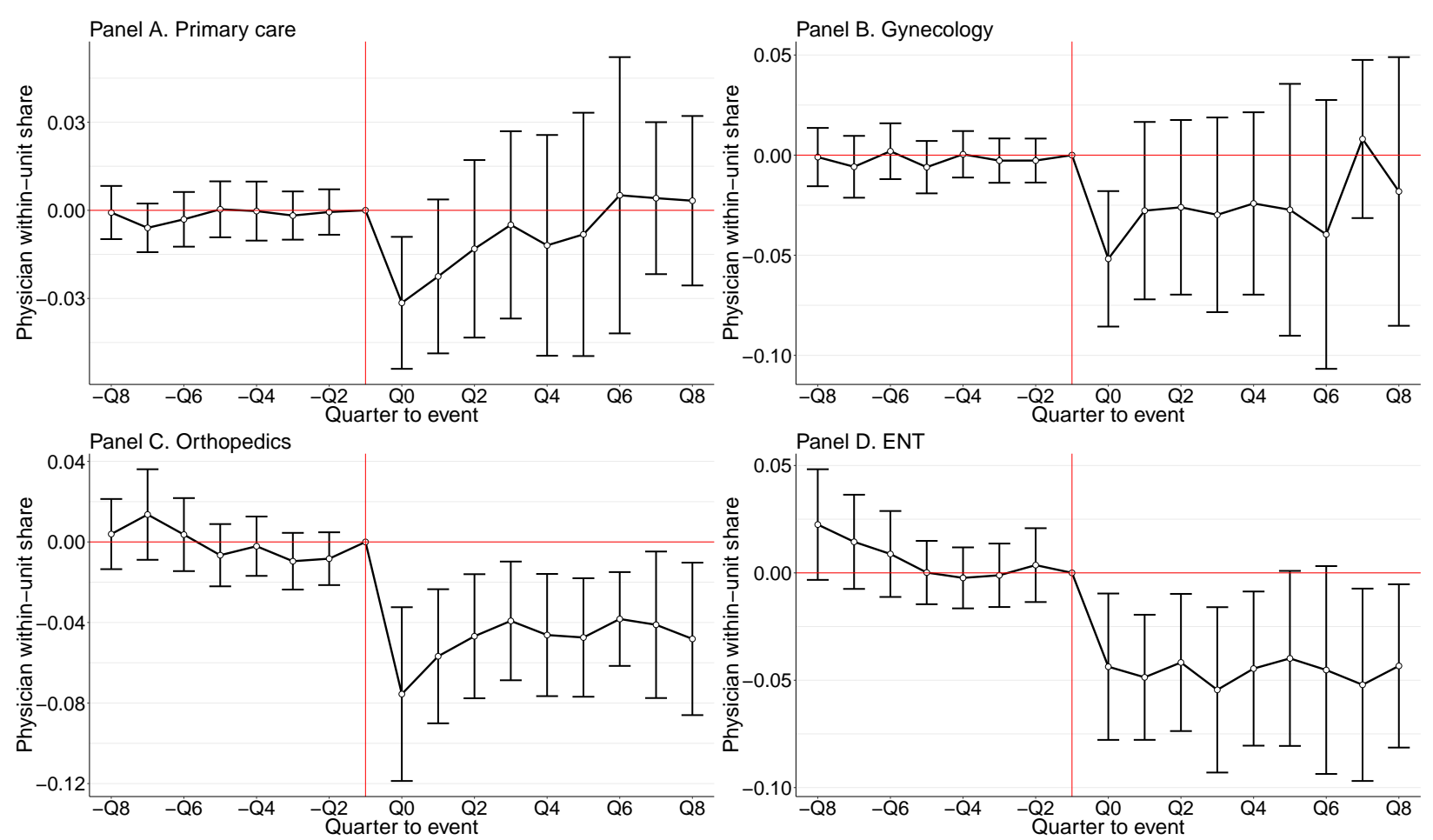

Figure 10: Physician within-unit share for new physicians, by specialty

Notes: Unit of observation is physician $\times$ unit $\times$ quarter. Treated physicians are those that started working in the unit after the acquisition. Event time is calculated relative to the physician's arrival in the newly acquired unit. The outcome is the number of visits a physician has within a unit per quarter divided by the overall number of visits in all specialties (primary care, gynecology, orthopedics and ENT) in the unit. Treated physicians are those that worked in the acquired unit in the pre-acquisition period. Primary care physicians include both unspecialized physicians and general medicine physicians. Controls include fixed effects for physician, unit, time period, as well as controls for physician age and square of age. 


\subsection{Prices and Market Shares of Nearby Competitors}

Figure 11 and Online Appendix Table A11 show the effect of an acquisition on the prices of incumbent physicians in nearby rival units. We define these physicians as those that work in units located within a 10 kilometer radius of a target unit before the acquisition of this unit takes place. The nearby competing physicians do not experience any statistically significant change in their prices in any specialty. We also find little evidence that prices rise for incumbent gynecologists at nearby rival units in response to price increases in target units. The results are robust to relaxation of the 10 kilometer neighbor definition, and to analyzing only the first neighbor acquisition while dropping all observations starting from the second acquisition (see Online Appendix B).

Table 5 shows the effects on the market share of nearby competing units (incumbents). Nearby units or their physicians could have increased their market shares in response to the price increase in gynecology at the target unit. The effects on the market share of the competing units are, however, near to zero in all specialties, including gynecology.

The lack of change in prices or health care utilization among nearby competitors suggest that acquisitions do not cause substantial, market-wide changes in price competition. $\mathrm{Pa}$ tients may choose their physicians from units that they find most attractive (e.g. in terms of location, brand, or diagnostic services) and may not switch units easily, even if prices increased. This may explain why physicians in nearby rival units react very little to acquisitions and increasing prices in target units. The lack of change among nearby competitors additionally suggests that the estimated price increase in target units does not result from market-wide unobserved shocks or changes in costs or patient mix during acquisitions. 

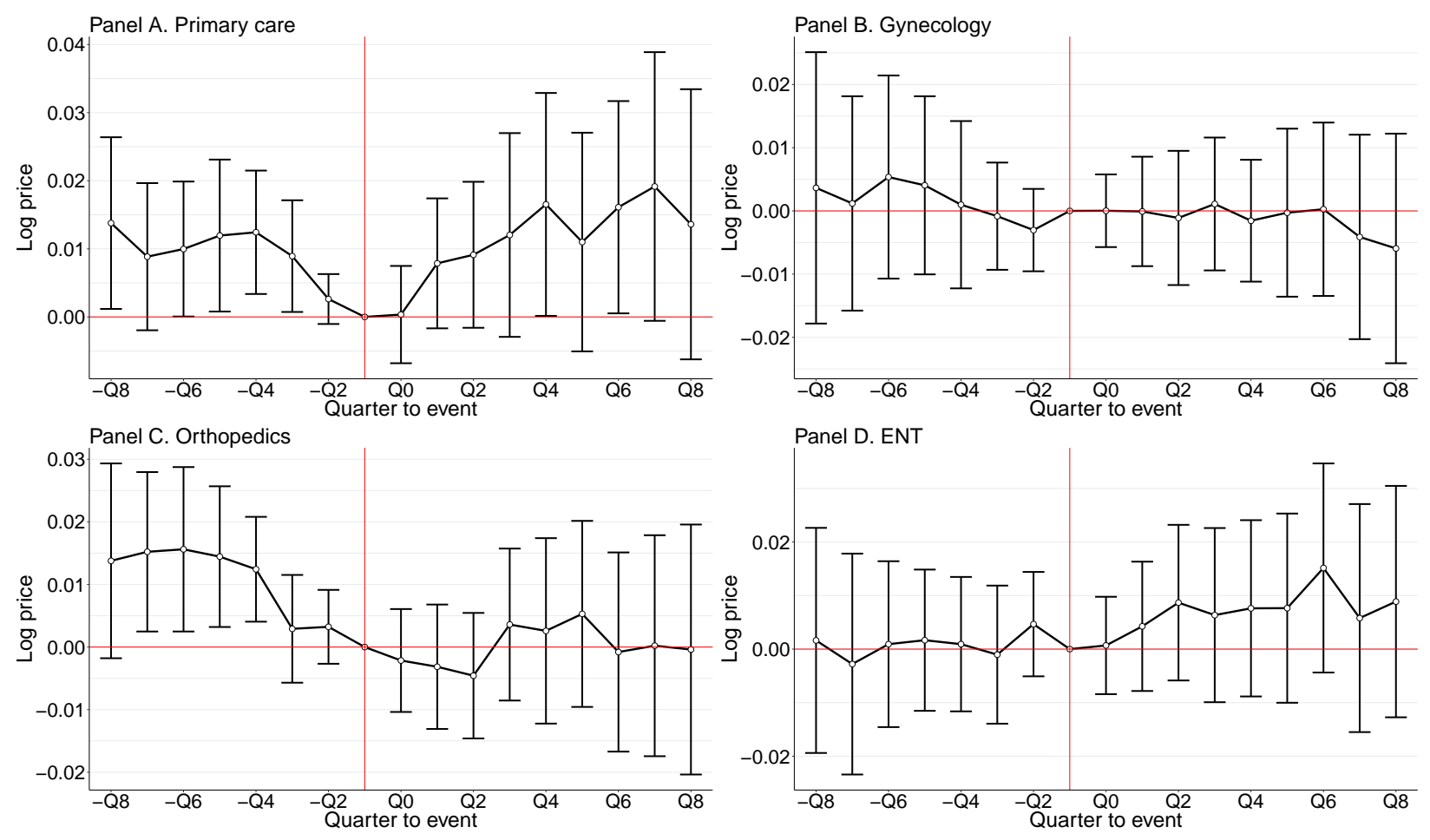

FiguRE 11: Price per visit for incumbent competing physicians within 10 kilometers

Notes: Unit of observation is physician $\times$ unit $\times$ visit. Treated physicians are those that work in units within a 10 kilometer radius of a target unit before the acquisition. The event time is relative to the acquisition in a neighboring unit. Primary care physicians include both unspecialized physicians and general medicine physicians. Controls include fixed effects for physician $\times$ unit, time period, length of visit, whether there was a specialization fee included in the visit, patient gender, patient income, as well as controls for physician and patient age and square of age. 
TABLE 5: Unit market shares for rival units within 10 kilometers

\begin{tabular}{|c|c|c|c|c|c|}
\hline & All physicians & Primary care & Gynecology & Orthopedics & ENT \\
\hline & (1) & $(2)$ & $(3)$ & $(4)$ & $(5)$ \\
\hline Short-run & $\begin{array}{l}0.020^{*} \\
(0.012)\end{array}$ & $\begin{array}{c}0.011 \\
(0.015)\end{array}$ & $\begin{array}{c}0.002 \\
(0.011)\end{array}$ & $\begin{array}{c}0.000 \\
(0.017)\end{array}$ & $\begin{array}{c}-0.000 \\
(0.010)\end{array}$ \\
\hline Long-run & $\begin{array}{c}0.037 \\
(0.025)\end{array}$ & $\begin{array}{c}0.030 \\
(0.026)\end{array}$ & $\begin{array}{c}0.012 \\
(0.025)\end{array}$ & $\begin{array}{c}0.008 \\
(0.024)\end{array}$ & $\begin{array}{c}0.002 \\
(0.024)\end{array}$ \\
\hline Mean outcome & 0.178 & 0.174 & 0.154 & 0.125 & 0.136 \\
\hline Observations & 5,985 & 5,943 & 5,721 & 5,336 & 5,432 \\
\hline Adjusted $R^{2}$ & 0.922 & 0.911 & 0.946 & 0.901 & 0.953 \\
\hline Time FE & Yes & Yes & Yes & Yes & Yes \\
\hline Unit FE & Yes & Yes & Yes & Yes & Yes \\
\hline
\end{tabular}

Notes: Unit of observation is unit $\times$ quarter. The outcome is the number of physician visits to the unit divided by the overall number of visits in the market. Treated units are those that are located within a 10 kilometer radius of an acquired unit. The time of the treatment is generated from the acquisition in the neighboring unit. Primary care physicians include both unspecialized physicians and general medicine physicians. Solo practices are dropped from the data. 


\section{Robustness and Alternative Mechanisms}

In-market and out-of-market acquisitions. - The baseline specifications look at the effects of an acquisition; as shown in Section 3.1, approximately 70 percent of acquisitions are inmarket, as opposed to out-of-market acquisitions. These two types of acquisitions may both increase prices, but the underlying sources are likely to differ (Lewis and Pflum 2017). The price increase after an in-market acquisition may originate from reductions in the number of competing firms within that local market. ${ }^{20}$ In contrast, price increases after an out-ofmarket acquisition may come through different mechanisms such as superior productivity over other firms, increased labor market power, and a well-established brand name.

We find that the effects of in-market acquisitions on physician prices and employment are similar to our main results from estimating the baseline specifications, as shown in Online Appendix Section C (Tables A14 and A16). This finding is expected, as most of the acquisitions are in-market acquisitions in our data. Most notably, in gynecology, we find that an in-market acquisition increases physician prices and decreases the number of physicians in the target unit, although the latter effect is imprecisely estimated.

Interestingly, out-of-market acquisitions seem to lead to fairly similar increases in physician prices for gynecologists compared to in-market acquisitions, as shown in Table A15. The point estimates for out-of-market acquisitions are imprecise, however, possibly because the number of these acquisitions is very small in our data $(N=19)$. We also find imprecisely estimated evidence that the number of physicians increases in every specialty, including gynecology, as shown in Table A17. This finding is consistent with productivity gains as the source of price increases, in contrast to our main results and the effects of in-market acquisitions. Although the estimates are imprecise, they suggest that the underlying sources of price increases generated by these two types of acquisitions are likely to differ. More detailed analyses of these different sources is the focus of previous research (Lewis and Pflum 2017;

\footnotetext{
${ }^{20} \mathrm{An}$ in-market acquisition reduces the number of firms because, by definition, the acquiring firm already has a unit in the same market.
} 
Dafny et al. 2019), but are beyond the scope of this paper.

Alternative market definitions. - In our baseline specifications, we defined a health care unit's market as those zip codes that fall within a 30 kilometer radius of the unit's zip code. As the choice of the radius is to some extent arbitrary, we show the robustness of the baseline estimates to using alternative 50 and 20 kilometer market definitions in Online Appendix Section D. The results are similar to our baseline estimates.

Discussion of other mechanisms.-Firms often justify mergers on the basis of claimed cost savings. In our setting, cost savings could be passed through to physicians through lower office rents. With a sufficiently large decrease in office rents, physician prices should decrease. Unfortunately, a lack of data on the cost of care and office rents prevents us from studying cost savings and the pass-through mechanism directly. Our result that physician prices increase provides little support for this mechanism, however.

\section{Discussion and Conclusions}

We consider the effects of mergers and acquisitions on private physician prices and competition, using comprehensive administrative data over 10 years in Finland. We emphasize mechanisms through which acquisitions may increase physician prices that go beyond the traditional firm's market power explanation. When the firm's market power increases, prices will increase and the number of jobs will fall. As private physicians have substantial control over their own prices and revenue, the exit of competing physicians may increase the remaining physician's market power and prices. We also discuss and analyze alternative explanations such as quality improvements for how prices can increase even in the absence of such effects.

We find that an acquisition leads to a small increase in the prices of incumbent physicians 
in the target unit. The strongest price increase occurs for gynecologists, while for a relatively lower educated and competitive group of physicians, primary care physicians, we find little evidence of price increases. In gynecology, we also find most evidence that acquisitions lead to job losses in the target unit, which may explain the observed increase in the incumbent physician's share of patient visits in that unit. In fact, gynecology is precisely a field of specialization where physician market power is likely to be present: switching costs create inertia in physician choice, increasing the incumbent's market power over new physicians in pricing decisions.

Overall, we cautiously interpret these results as being consistent with a decrease in the number of physicians (and the resulting relaxation of physician competition) increasing incumbent physician prices and market shares in the target unit. However, lack of data on physician office rents prevents us from analyzing the division of revenue between physicians and firms, or the pass-through of physician office rents to their prices. We also find that an acquisition has very little impact on the target unit's market share, which suggests that changes in the unit's operations or overall popularity are not the main driver of the estimated price effects. Finally, we find little price response for physicians in nearby rival units. This suggests that acquisitions do not cause substantial, market-wide changes in price competition. Relaxation of price competition among physicians may occur very locally, within a target unit.

\section{References}

Arnold, D. (2020). Mergers and acquisitions, local labor market concentration, and worker outcomes. Mimeo.

Azar, J., I. Marinescu, and M. I. Steinbaum (2017, December). Labor market concentration. Working Paper 24147, National Bureau of Economic Research. 
Baker, L. C., M. K. Bundorf, and D. P. Kessler (2016, December). The effect of hospital/physician integration on hospital choice. Journal of Health Economics 50, 1-8.

Bassanini, A., C. Batut, and E. Caroli (2019). Labor market concentration and stayers' wages: Evidence from France. LEDa-LEGOS Working Paper 6.

Beaulieu, N. D., L. S. Dafny, B. E. Landon, J. B. Dalton, I. Kuye, and J. M. McWilliams (2020). Changes in quality of care after hospital mergers and acquisitions. New England Journal of Medicine 382(1), 51-59.

Benmelech, E., N. Bergman, and H. Kim (2018, February). Strong employers and weak employees: How does employer concentration affect wages? Working Paper 24307, National Bureau of Economic Research.

Berger, D., K. Herkenhoff, and S. Mongey (2019). Labor market power. Working Paper 25719, National Bureau of Economic Research.

Bloom, N., C. Propper, S. Seiler, and J. Van Reenen (2015, April). The impact of competition on management quality: Evidence from public hospitals. The Review of Economic Studies 82(2), 457-489.

Capps, C., D. Dranove, and C. Ody (2017). Physician practice consolidation driven by small acquisitions, so antitrust agencies have few tools to intervene. Health Affairs 36(9), 1556-1563.

Carlin, C. S., R. Feldman, and B. Dowd (2017). The impact of provider consolidation on physician prices. Health Economics 26(12), 1789-1806.

Cooper, Z., S. V. Craig, M. Gaynor, and J. V. Reenen (2019, February). The price ain't right? Hospital prices and health spending on the privately insured. The Quarterly Journal of Economics 134(1), 51-107. 
Dafny, L., K. Ho, and R. S. Lee (2019). The price effects of cross-market mergers: theory and evidence from the hospital industry. The RAND Journal of Economics 50(2), 286-325.

Dafny, L. S. and T. H. Lee (2015). The good merger. New England Journal of Medicine 372(22), 2077-2079.

Datta, D. K., J. P. Guthrie, D. Basuil, and A. Pandey (2010). Causes and effects of employee downsizing: A review and synthesis. Journal of Management 36(1), 281-348.

DePasquale, C. (2015). Hospital consolidation and the nurse labor market. Working paper.

Farrell, J. and C. Shapiro (1990). Horizontal mergers: An equilibrium analysis. The American Economic Review 80(1), 107-126.

Finnish Institute for Health and Welfare (THL) (2019). Health expenditure and financing in 2017 (in Finnish). Technical Report 15.

Finnish Medical Association (FMA) (2016, 12). Physicians in Finland: Statistics on physicians and the health care system 2016. Helsinki: The Finnish Medical Association. https://www.laakariliitto.fi/site/assets/files/5223/1116_tilasto2016_ net1_170114.pdf.

Finnish Medical Association (FMA) (2017). Työmarkkinatutkimus 2017. https: //www.laakariliitto.fi/site/assets/files/5221/tyomarkkinatutkimus_2017_ tuloksia_korj_160419.pdf.

Gaynor, M., K. Ho, and R. J. Town (2015). The industrial organization of health care markets. Journal of Economic Literature 53(2), 235-284.

Gaynor, M., M. Laudicella, and C. Propper (2012, May). Can governments do it better? Merger mania and hospital outcomes in the English NHS. Journal of Health Economics 31(3), 528-543. 
Gaynor, M. and R. J. Town (2011). Chapter nine - competition in health care markets. In M. V. Pauly, T. G. Mcguire, and P. P. Barros (Eds.), Handbook of Health Economics, Volume 2 of Handbook of Health Economics, pp. 499 - 637. Elsevier.

Gaynor, M. and W. B. Vogt (2000). Chapter 27 Antitrust and competition in health care markets. In Handbook of Health Economics, Volume 1, pp. 1405-1487. Elsevier.

Gowrisankaran, G., A. Nevo, and R. Town (2015). Mergers when prices are negotiated: Evidence from the hospital industry. American Economic Review 105(1), 172-203.

Gugler, K. and R. Siebert (2007). Market power versus efficiency effects of mergers and research joint ventures: Evidence from the semiconductor industry. The Review of Economics and Statistics 89(4), 645-659.

Hiltunen, R., H. Mikkola, and L. Virta (2017). Do private gps compete with prices? (in Finnish). Yhteiskuntapolitiikka 82, 377-391.

Kajantie, M. (2019). Yksityisiä sairauskuluvakuutuksia hankitaan yhä enemmän - selvä enemmistö jää tappiolle. Statistics Finland Articles.

Lehto, E. and P. Böckerman (2008). Analysing the employment effects of mergers and acquisitions. Journal of Economic Behavior \& Organization 68(1), 112 - 124.

Lehtonen, K. (2017). Miten neuvottelen sopimukseni yksityisellä sektorilla? Finnish Medical Journal 72, 2914-2916.

Lewis, M. S. and K. E. Pflum (2017). Hospital systems and bargaining power: evidence from out-of-market acquisitions. The RAND Journal of Economics 48(3), 579-610.

Manning, A. and B. Petrongolo (2017, October). How local are labor markets? evidence from a spatial job search model. American Economic Review 107(10), 2877-2907.

Ministry of Social Affairs and Health (STM) (2020). Terveydenhuollon maksut. https: //stm.fi/terveydenhuollon-maksut. 
Prager, E. and M. Schmitt (2019). Employer consolidation and wages: Evidence from hospitals. Washington Center for Equitable Growth Working Paper. https://www.ssrn.com/abstract=3391889.

Qiu, Y. and A. J. Sojourner (2019). Labor-market concentration and labor compensation. Technical report. https://ssrn.com/abstract $=3312197$.

Roos, A.-F. (2018). Mergers and competition in the Dutch healthcare sector. Doctoral thesis, Erasmus University Rotterdam.

Schmitt, M. (2017, March). Do hospital mergers reduce costs? Journal of Health Economics 52, 74-94.

Schmitt, M. (2018, August). Multimarket contact in the hospital industry. American Economic Journal: Economic Policy 10(3), 361-87.

Shapiro, C. (2019, August). Protecting competition in the American economy: Merger control, tech titans, labor markets. Journal of Economic Perspectives 33(3), 69-93.

The Social Insurance Institution (Kela) (2020). Reimbursements of medical expenses: Number of recipients and reimbursements paid out.

Tuominen, U., H. Ruuska, J. Tervola, and T. Maljanen (2016). Yksityissektorin erikoislääkärien vastaanottopalkkioiden hintavertailu. Suomen Lääkärilehti 71(7), 499506.

Welch, W. P., A. E. Cuellar, S. C. Stearns, and A. B. Bindman (2013). Proportion of physicians in large group practices continued to grow in 2009-11. Health Affairs 32(9), $1659-1666$. 
A Online Appendix 
TABLE A1: Fraction of missing unit names and locations in the data, by specialty

\begin{tabular}{ccccc}
\hline Year & Primary care & Gynecology & Orthopedics & ENT \\
\hline 2008 & 0.27 & 0.18 & 0.24 & 0.12 \\
2009 & 0.24 & 0.15 & 0.20 & 0.11 \\
2010 & 0.21 & 0.13 & 0.16 & 0.09 \\
2011 & 0.18 & 0.11 & 0.15 & 0.08 \\
2012 & 0.17 & 0.09 & 0.12 & 0.06 \\
2013 & 0.15 & 0.09 & 0.10 & 0.05 \\
2014 & 0.12 & 0.07 & 0.08 & 0.05 \\
2015 & 0.11 & 0.06 & 0.06 & 0.05 \\
2016 & 0.09 & 0.07 & 0.06 & 0.04 \\
2017 & 0.07 & 0.05 & 0.04 & 0.03 \\
\hline
\end{tabular}

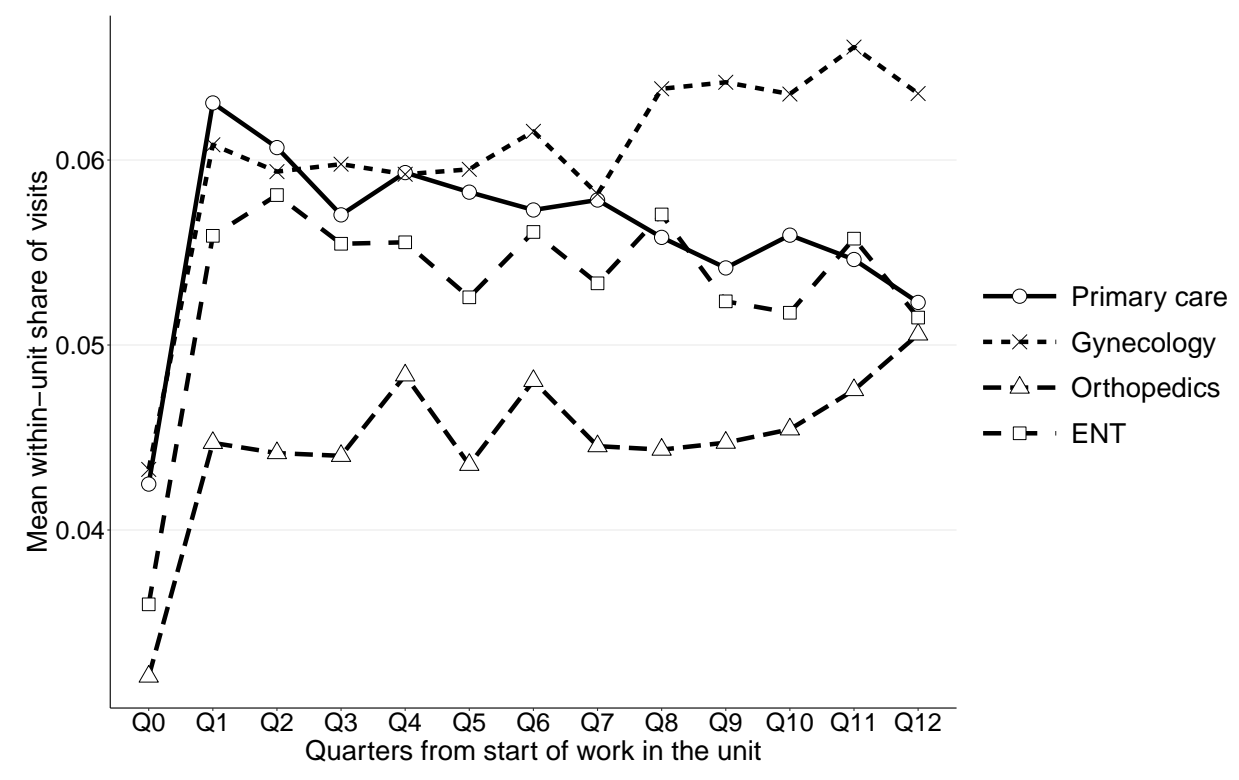

Figure A1: Evolution of physician within-unit share of visits, by specialty

Notes: First observations in data before 2009 are dropped because of left censoring. Y-axis is the mean physician's share of visits in a health care unit, aggregated over all physicians. X-axis is the quarter relative to starting working in the health care unit, $Q 0$ being the first quarter when the physician is observed in the unit. 

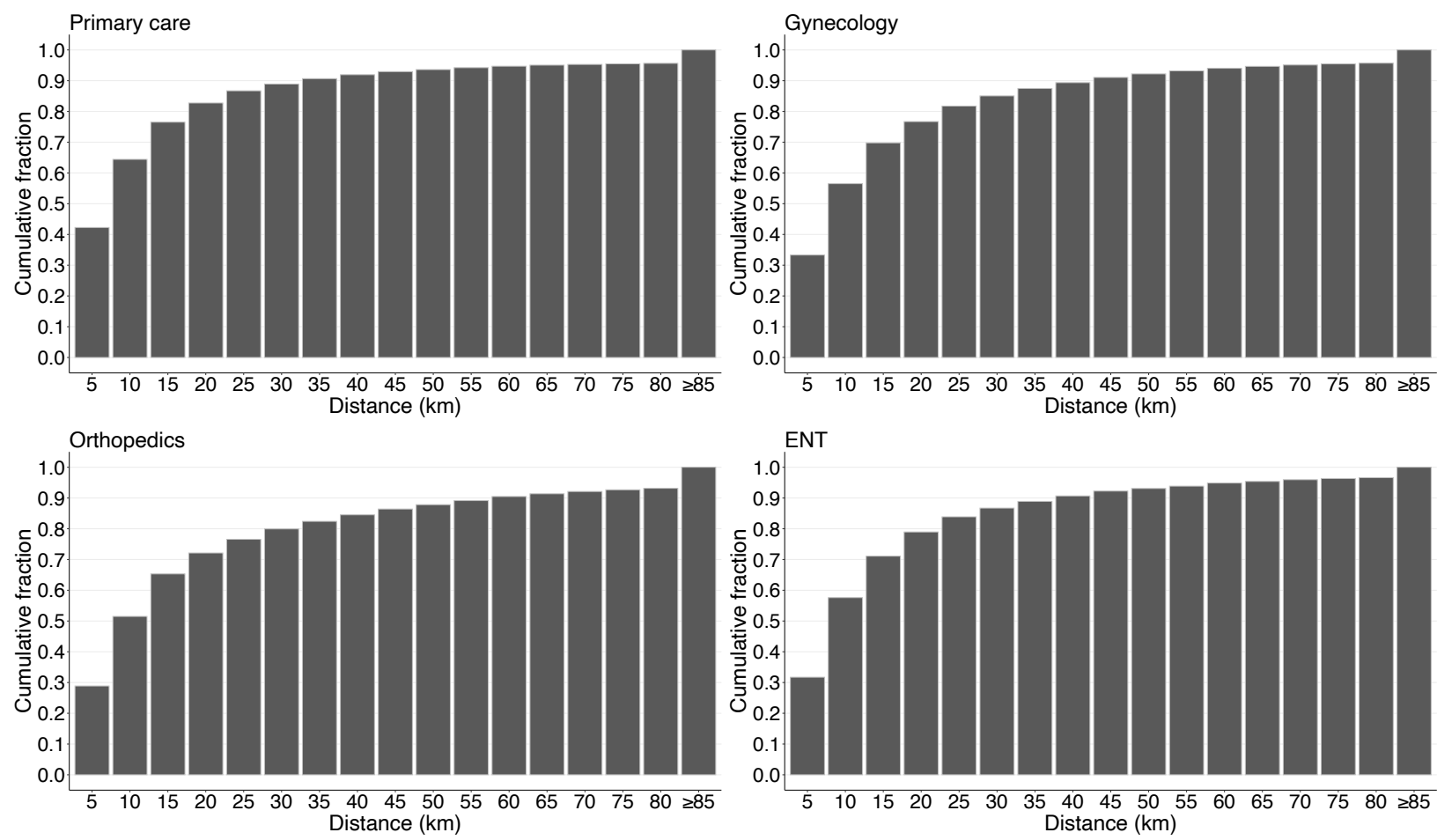

Figure A2: Cumulative fractions of patients' visiting distances to physicians

Notes: This figure shows the cumulative fraction of patients whose travelling distance to physicians is within the value depicted on the x-axis. The distance between a physician and a patient is calculated from their respective zip codes. 

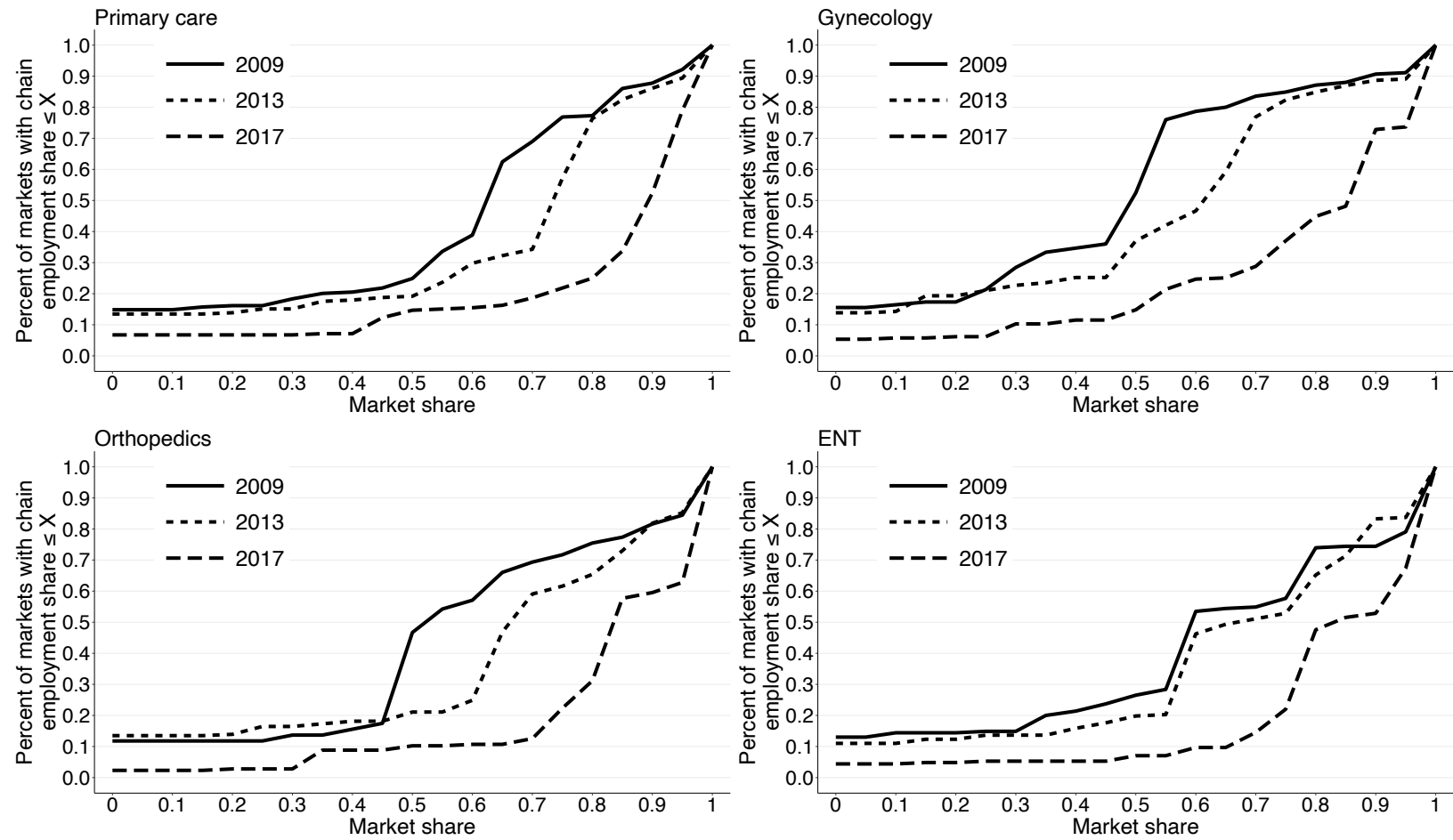

Figure A3: CDF of large firms' (chains') employment shares, by specialty and year

Notes: Each zip code has its own market area of a 30 kilometer radius. Y-axis is the cumulative fraction of markets that have a market share under or equal to the number depicted on the x-axis. Large firms' employment share is the number of physicians working in units that belong to these firms divided by the overall number of working physicians in the market. 


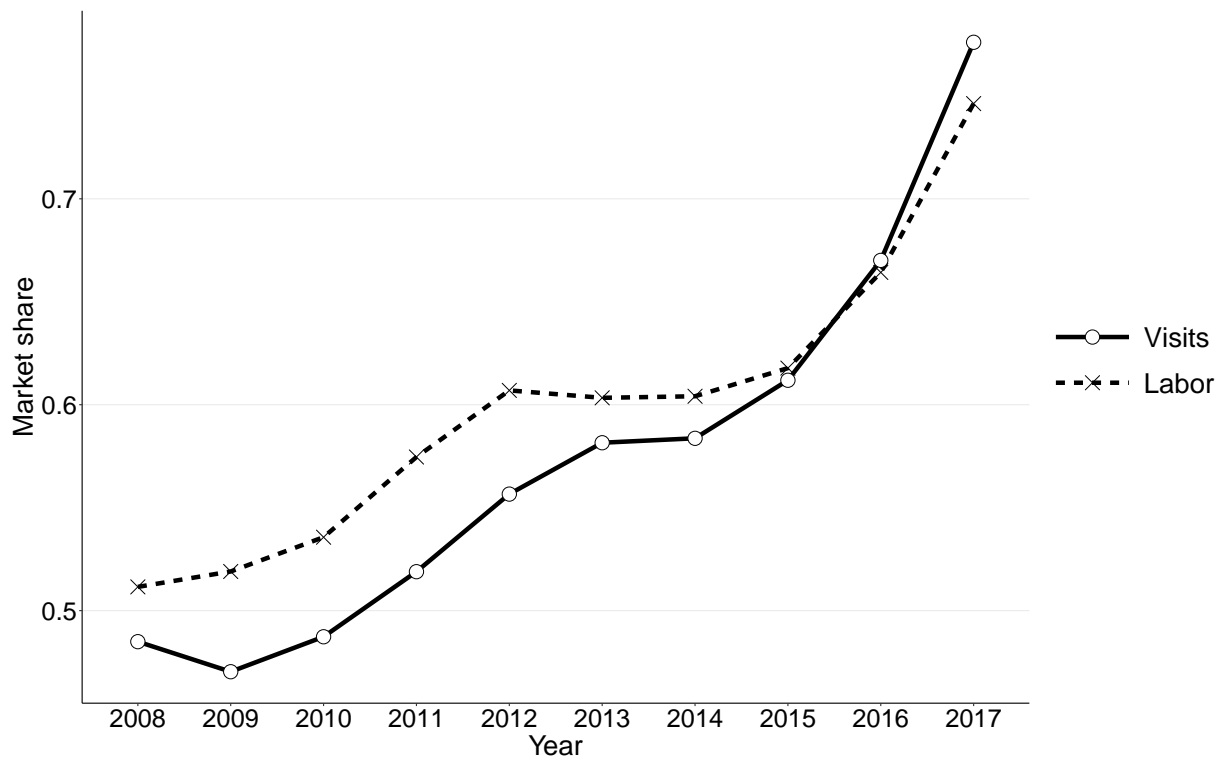

Figure A4: Market share of large firms (chains) in Finland, by year

Notes: The sample includes physicians from four specialties: primary care (unspecialized and general medicine), gynecology, orthopedics, and ENT. 


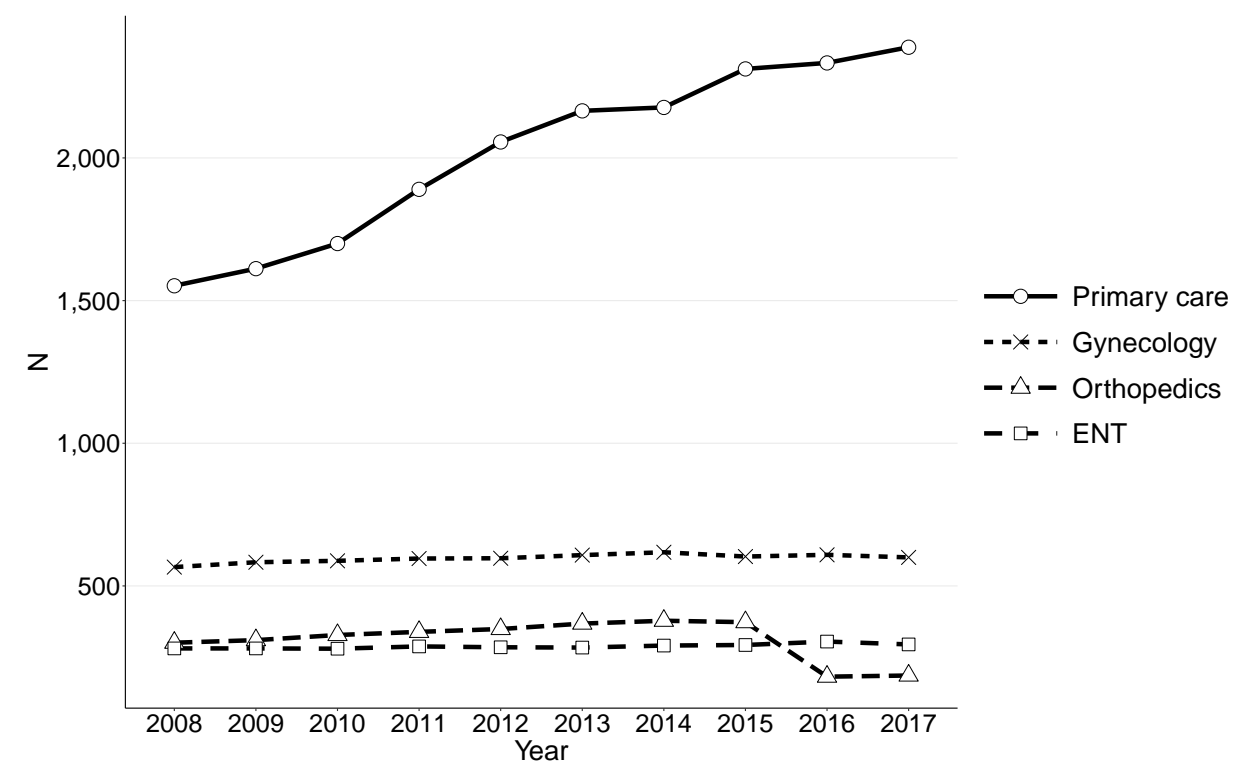

Figure A5: Number of physicians, by specialty and year

Notes: Primary care physicians include both general medicine and unspecialized physicians.

TABLE A2: Price per visit for incumbent physicians

\begin{tabular}{lcccc}
\hline & $(1)$ & $(2)$ & $(3)$ & $(4)$ \\
\hline Short-run & $0.011^{* *}$ & $0.011^{* *}$ & 0.007 & 0.005 \\
& $(0.005)$ & $(0.005)$ & $(0.005)$ & $(0.005)$ \\
Long-run & 0.008 & 0.008 & 0.001 & 0.000 \\
& $(0.010)$ & $(0.010)$ & $(0.011)$ & $(0.011)$ \\
Mean outcome & 68.276 & 68.276 & 68.276 & 68.276 \\
Observations & $5,753,640$ & $5,753,640$ & $5,753,640$ & $5,753,640$ \\
Adjusted $R^{2}$ & 0.776 & 0.784 & 0.776 & 0.784 \\
Time FE & & & & \\
Physician FE & Yes & Yes & Yes & Yes \\
Physician $\times$ Unit FE & Yes & & Yes & Yes \\
Treatment unit $\times$ Time FE & & & Yes & Yes \\
\hline
\end{tabular}

Notes: Unit of observation is physician $\times$ unit $\times$ visit. Treated physicians are those that worked in the acquired unit in the pre-acquisition period. Data include primary care physicians (unspecialized and general medicine), gynecologists, orthopedists, and ENT physicians. Each specification additionally controls for length of the visit fixed effects, whether there is a specialization fee included in the visit, patient gender, patient income, as well as physician and patient age and square of age. The mean outcome is the value before performing the log transformation. 


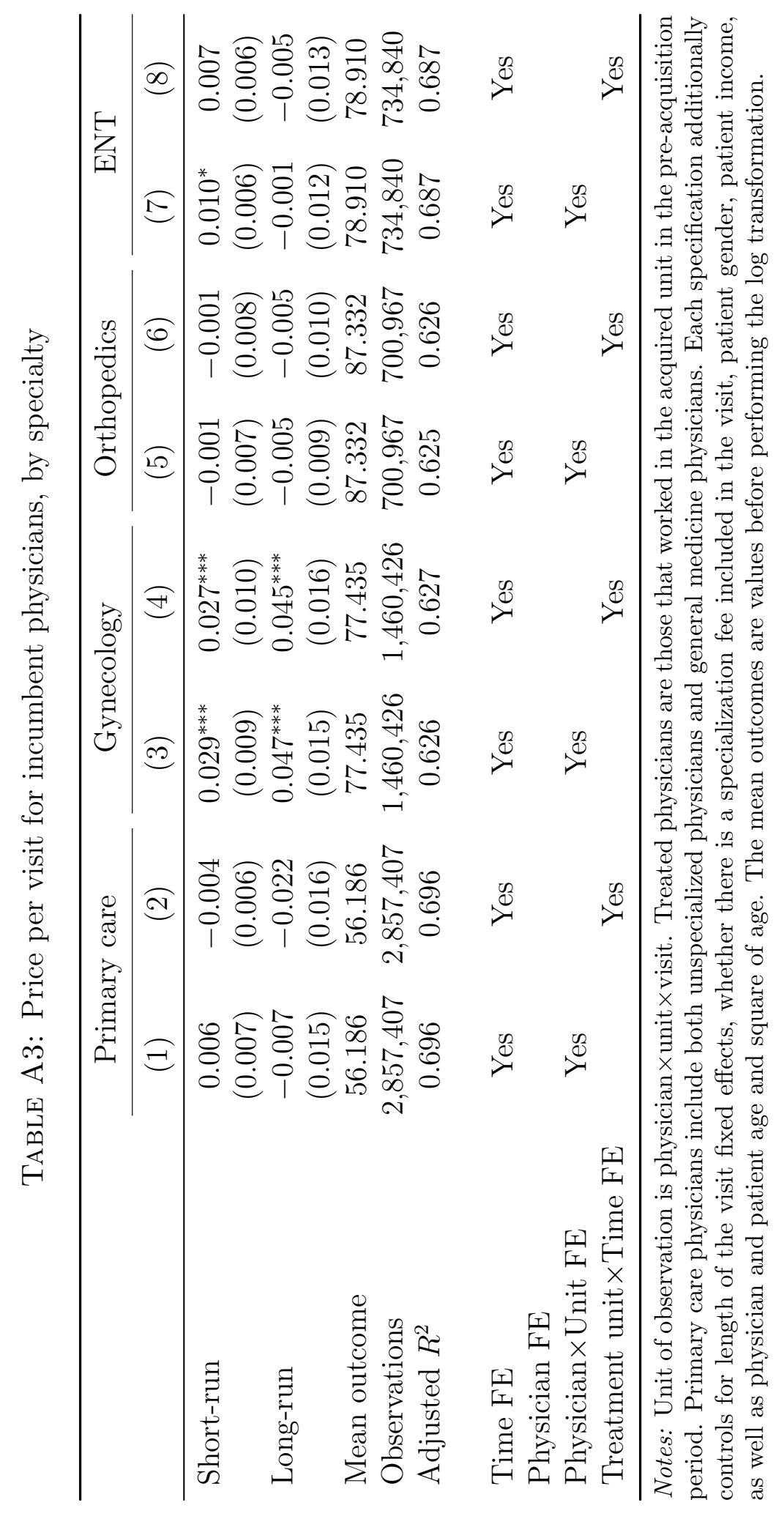



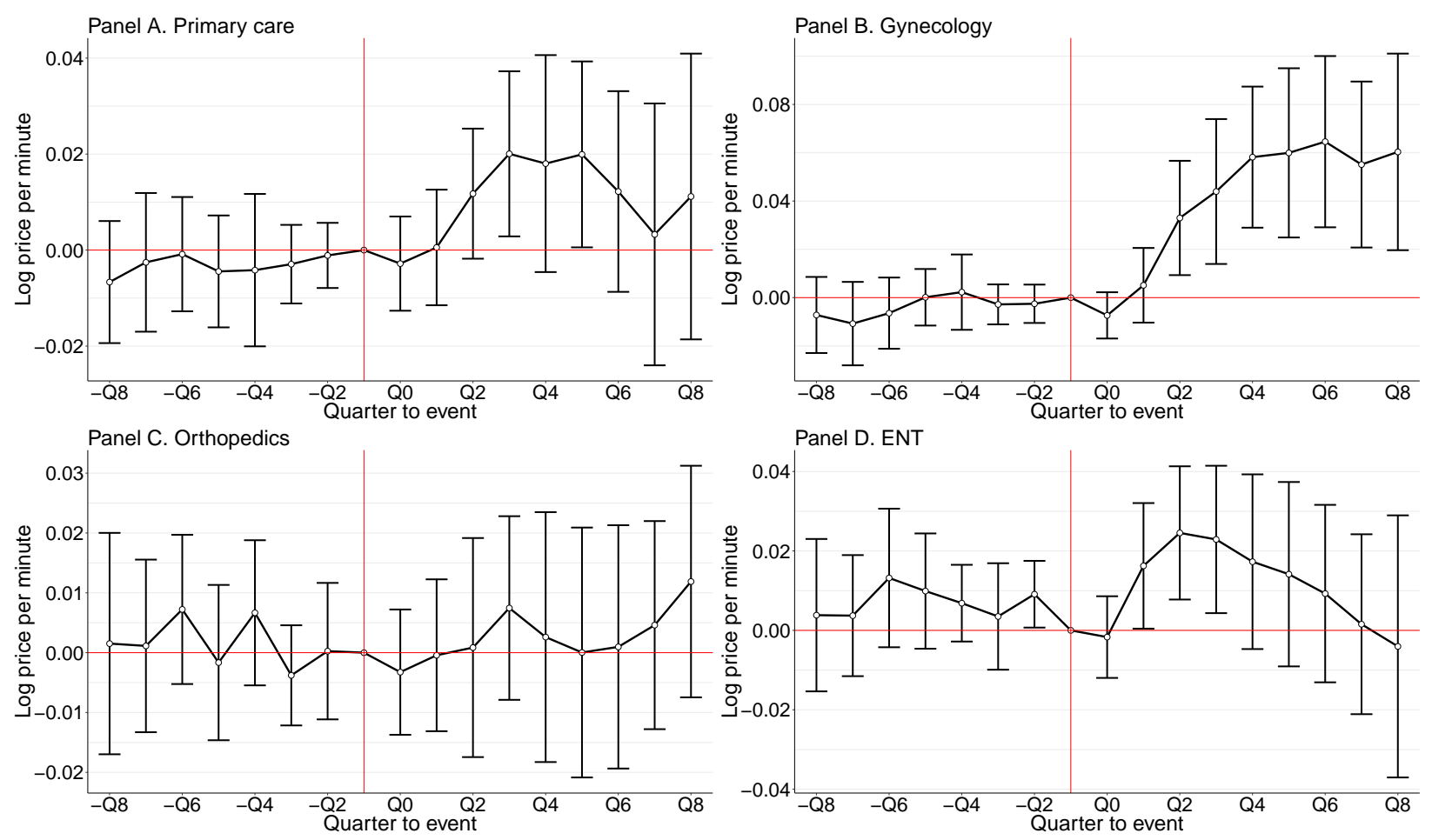

Figure A6: Price per minute, by specialty

Notes: Unit of observation is physician $\times$ unit $\times$ quarter. The outcome, price per minute, is the log of the physician's overall revenue divided by the total minutes of these visits (10, 20, 30, 45, 60 minute visits). Treated physicians are those that worked in the acquired unit in the pre-acquisition period. Primary care physicians include both unspecialized physicians and general medicine physicians. Controls include fixed effects for physician $\times$ unit, time period, physician age and square of age. 


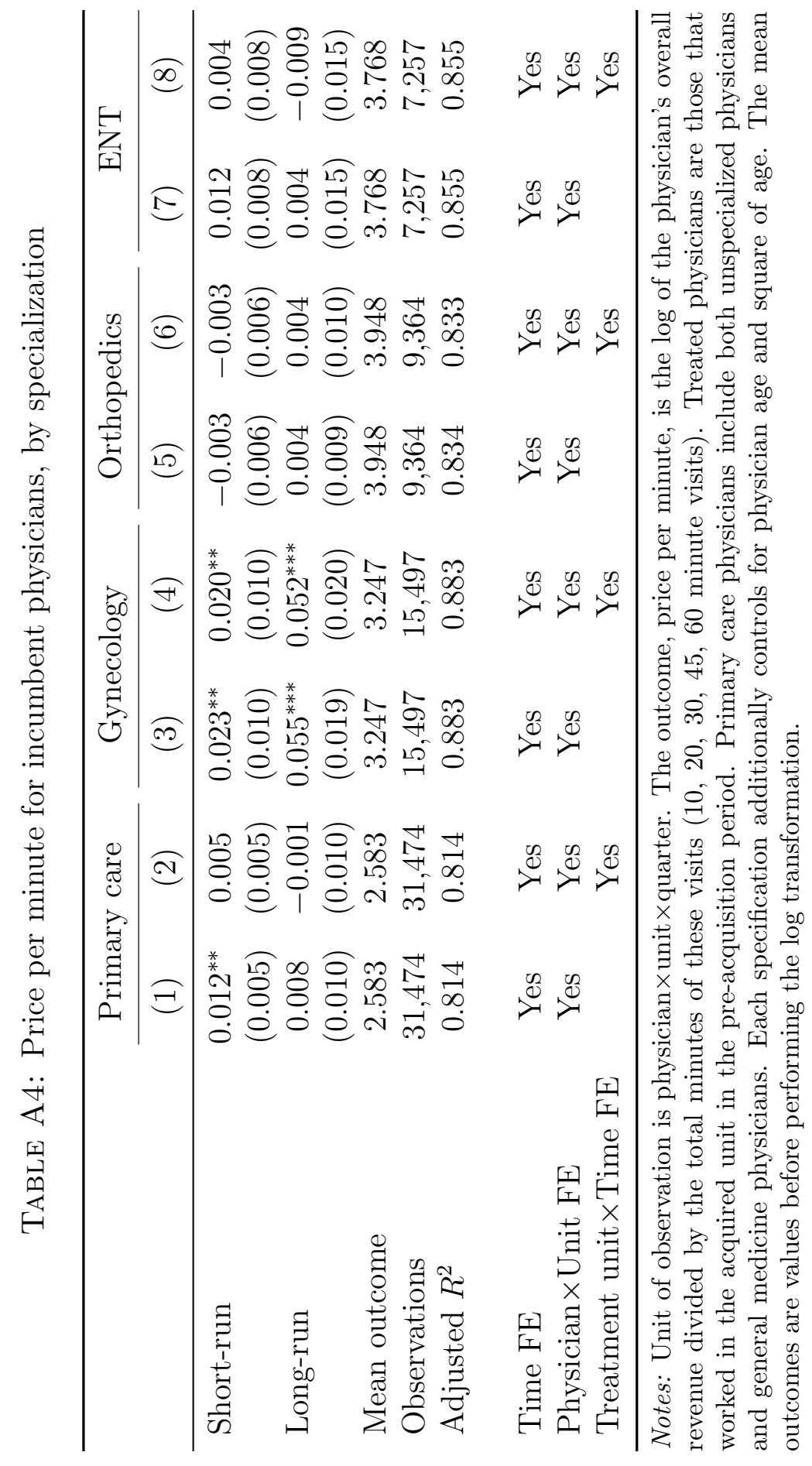


TABLE A5: Price per minute at the unit level

\begin{tabular}{|c|c|c|c|c|c|}
\hline & All physicians & Primary care & Gynecology & Orthopedics & ENT \\
\hline & (1) & $(2)$ & (3) & (4) & $(5)$ \\
\hline \multirow[t]{2}{*}{ Short-run } & $0.026^{* * *}$ & $0.019^{*}$ & $0.025^{* *}$ & -0.009 & 0.014 \\
\hline & $(0.010)$ & $(0.010)$ & $(0.013)$ & $(0.014)$ & $(0.016)$ \\
\hline \multirow[t]{2}{*}{ Long-run } & 0.028 & 0.017 & $0.051^{* *}$ & -0.010 & 0.008 \\
\hline & $(0.018)$ & $(0.020)$ & $(0.025)$ & $(0.020)$ & $(0.021)$ \\
\hline Mean outcome & 2.911 & 2.543 & 3.125 & 3.964 & 3.737 \\
\hline Observations & 3,886 & 3,554 & 3,298 & 2,670 & 2,586 \\
\hline Adjusted $R^{2}$ & 0.892 & 0.824 & 0.893 & 0.777 & 0.767 \\
\hline Time FE & Yes & Yes & Yes & Yes & Yes \\
\hline Unit FE & Yes & Yes & Yes & Yes & Yes \\
\hline
\end{tabular}

Notes: Unit of observation is unit $\times$ quarter. The outcome, price per minute, is the log of the unitquarter-level average of physicians' overall revenues divided by the total minutes of their visits $(10,20$, 30, 45, 60 minute visits). Primary care physicians include both unspecialized physicians and general medicine physicians. Solo practices are dropped from the data. The mean outcomes are values before performing the log transformation. 
TABLE A6: Unit market shares

\begin{tabular}{|c|c|c|c|c|c|}
\hline & All physicians & Primary care & Gynecology & Orthopedics & ENT \\
\hline & (1) & (2) & (3) & (4) & (5) \\
\hline \multirow[t]{2}{*}{ Short-run } & 0.000 & 0.003 & -0.008 & -0.015 & 0.000 \\
\hline & (0.016) & $(0.018)$ & $(0.012)$ & $(0.022)$ & $(0.011)$ \\
\hline \multirow[t]{2}{*}{ Long-run } & -0.001 & -0.027 & 0.007 & -0.010 & $\begin{array}{l}-0.026 \\
(0.029)\end{array}$ \\
\hline & $(0.025)$ & (0.031) & $(0.030)$ & $(0.029)$ & $\begin{array}{l}(0.022) \\
0.323\end{array}$ \\
\hline Mean outcome & 0.370 & 0.358 & 0.358 & 0.347 & $\begin{array}{l}0.333 \\
3.450\end{array}$ \\
\hline $\begin{array}{l}\text { Observations } \\
\text { Adjusted } R^{2}\end{array}$ & $\begin{array}{l}3,886 \\
0.895\end{array}$ & $\begin{array}{l}3,839 \\
0.882\end{array}$ & $\begin{array}{c}3,718 \\
0.93\end{array}$ & $\begin{array}{l}3,423 \\
0.907\end{array}$ & $\begin{array}{l}3,459 \\
0.958\end{array}$ \\
\hline Time FE & Yes & Yes & Yes & Yes & Yes \\
\hline Unit FE & Yes & Yes & Yes & Yes & Yes \\
\hline
\end{tabular}

Notes: Unit of observation is unit $\times$ quarter. The outcome is the number of physician visits to the unit divided by the overall number of visits in the market. Market areas are defined by radii of 30 kilometers, calculated from the centroid of the zip codes. Primary care physicians include both unspecialized physicians and general medicine physicians. Solo practices are dropped from the data. 


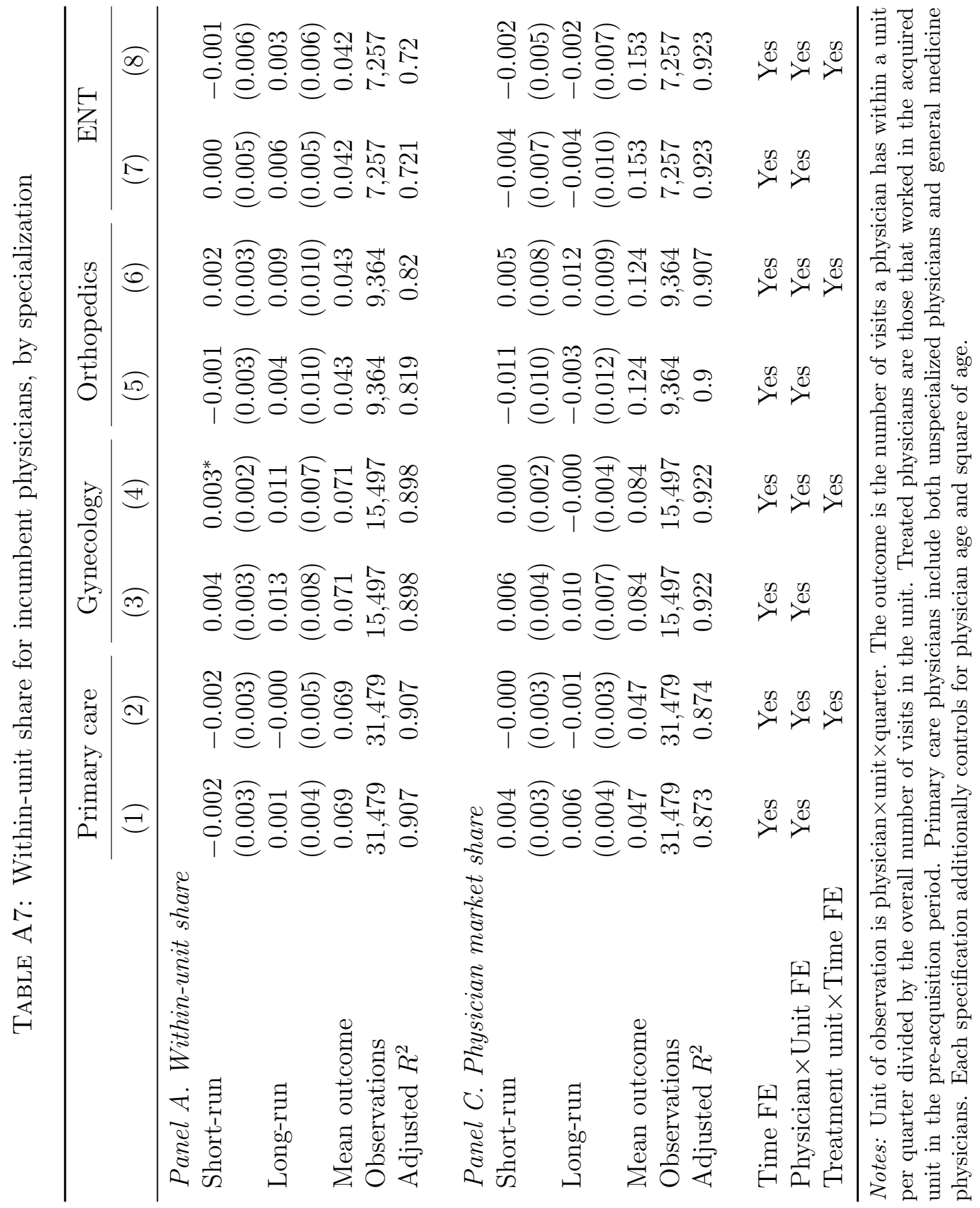



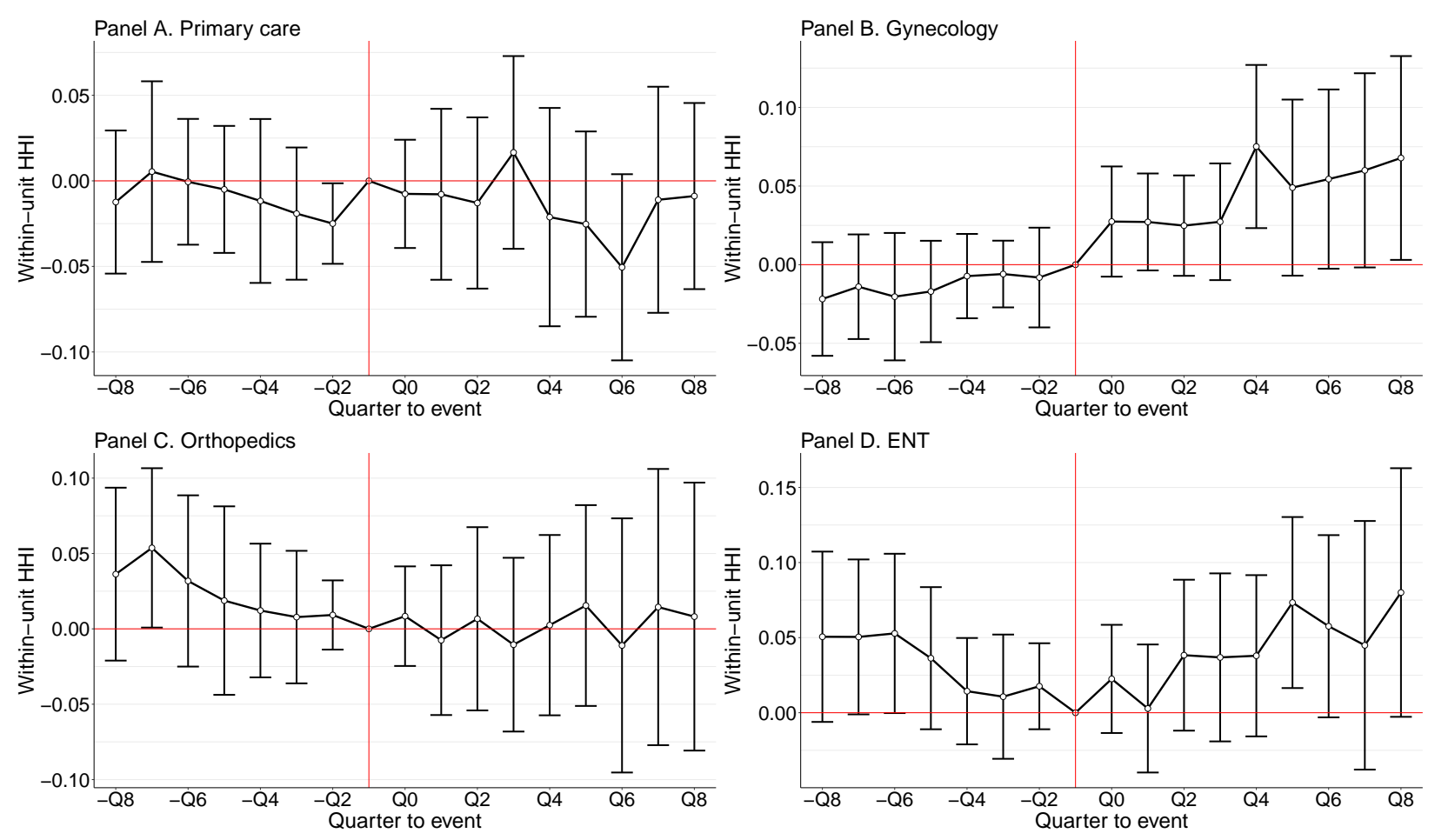

FIGURE A7: Within-unit HHI for different specialties

Notes: Unit of observation is unit $\times$ quarter. Each panel is plotted from a separate regression. The outcome is the within-unit Herfindahl-Hirschman Index (HHI), calculated by taking the sum of the squared market shares of each physician within a specialty and health care unit. Primary care physicians include both unspecialized physicians and general medicine physicians. Each regression controls for unit and time fixed effects. 
TABLE A8: Within-unit HHI

\begin{tabular}{|c|c|c|c|c|c|}
\hline & All physicians & Primary care & Gynecology & Orthopedics & ENT \\
\hline & (1) & (2) & (3) & (4) & (5) \\
\hline Short-run & $\begin{array}{c}-0.009 \\
(0.014)\end{array}$ & $\begin{array}{c}0.008 \\
(0.020)\end{array}$ & $\begin{array}{c}0.033^{*} \\
(0.018)\end{array}$ & $\begin{array}{l}-0.043 \\
(0.031)\end{array}$ & $\begin{array}{l}-0.017 \\
(0.025)\end{array}$ \\
\hline Long-run & $\begin{array}{c}0.031 \\
(0.029)\end{array}$ & $\begin{array}{c}0.010 \\
(0.024)\end{array}$ & $\begin{array}{c}0.077^{*} \\
(0.040)\end{array}$ & $\begin{array}{c}0.005 \\
(0.042)\end{array}$ & $\begin{array}{c}0.013 \\
(0.032)\end{array}$ \\
\hline Mean outcome & 0.304 & 0.396 & 0.496 & 0.612 & 0.636 \\
\hline Observations & 3,886 & 3,554 & 3,298 & 2,670 & 2,586 \\
\hline Adjusted $R^{2}$ & 0.872 & 0.843 & 0.855 & 0.787 & 0.821 \\
\hline Time FE & Yes & Yes & Yes & Yes & Yes \\
\hline Unit FE & Yes & Yes & Yes & Yes & Yes \\
\hline
\end{tabular}

Notes: Unit of observation is unit $\times$ quarter. The outcome is the within-unit Herfindahl-Hirschman Index (HHI), calculated by taking the sum of the squared market shares of each physician within a specialty and health care unit. Primary care physicians include both unspecialized physicians and general medicine physicians. Solo practices are dropped from the data. 


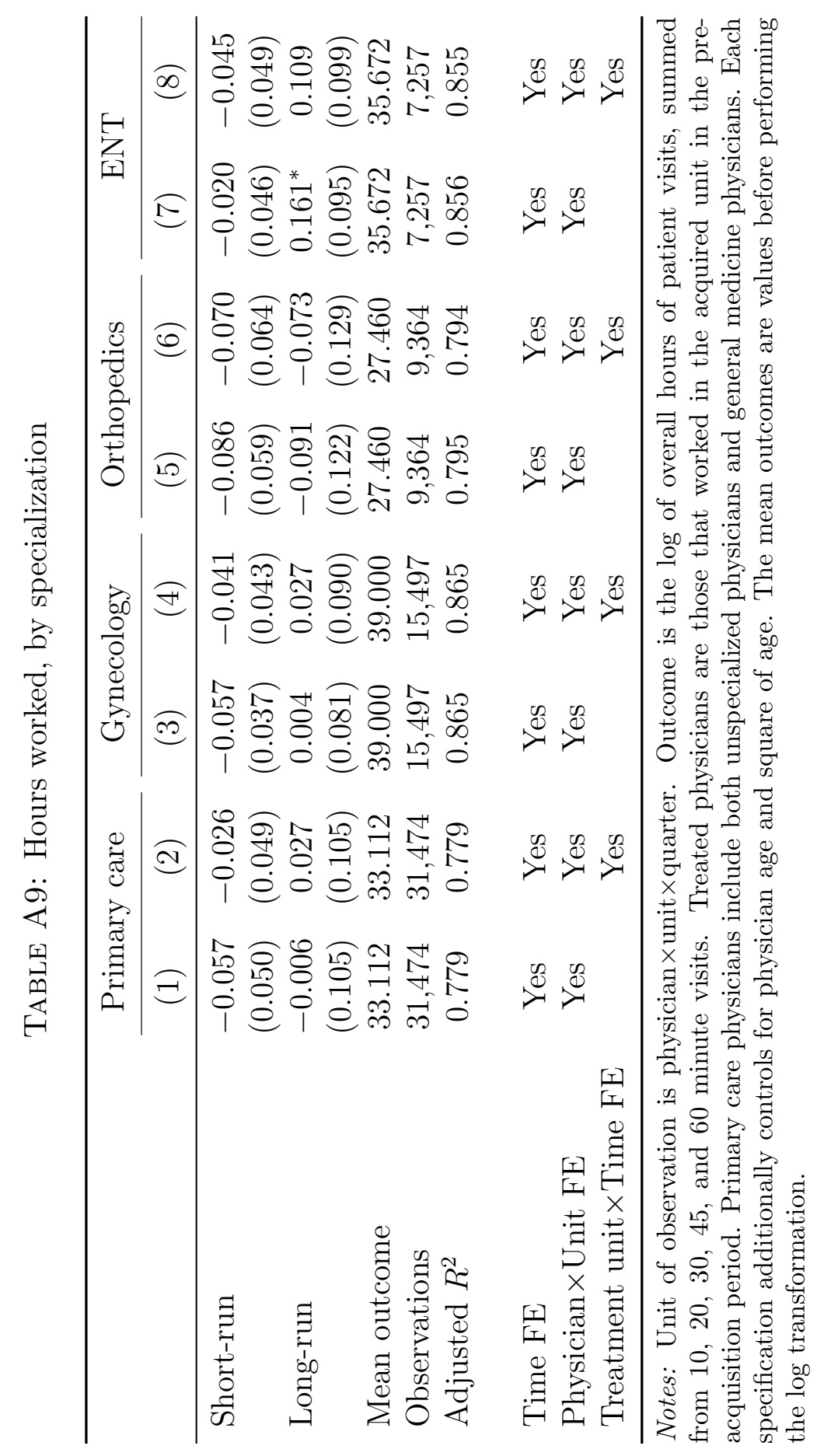


TABLE A10: Decomposition of new physicians

\begin{tabular}{|c|c|c|c|c|c|}
\hline & All physicians & Primary care & Gynecology & Orthopedics & ENT \\
\hline & $(1)$ & $(2)$ & $(3)$ & $(4)$ & $(5)$ \\
\hline \multicolumn{6}{|c|}{ Panel A. Log number of new physicians from units within the market } \\
\hline \multirow[t]{2}{*}{ Short-run } & $0.164^{* * *}$ & $0.136^{* *}$ & $0.078^{*}$ & 0.026 & 0.040 \\
\hline & $(0.059)$ & $(0.052)$ & $(0.039)$ & $(0.024)$ & $(0.027)$ \\
\hline \multirow[t]{2}{*}{ Long-run } & 0.105 & 0.068 & 0.013 & 0.032 & -0.007 \\
\hline & $(0.069)$ & $(0.065)$ & $(0.028)$ & $(0.027)$ & $(0.023)$ \\
\hline Mean outcome & 0.990 & 0.658 & 0.152 & 0.102 & 0.078 \\
\hline Observations & 3,758 & 3,758 & 3,758 & 3,758 & 3,758 \\
\hline Adjusted $R^{2}$ & 0.579 & 0.557 & 0.197 & 0.183 & 0.14 \\
\hline \multicolumn{6}{|c|}{ Panel B. Log number new physicians from units outside the market } \\
\hline \multirow[t]{2}{*}{ Short-run } & 0.104 & 0.093 & 0.025 & $0.055^{*}$ & 0.033 \\
\hline & $(0.067)$ & $(0.064)$ & $(0.038)$ & $(0.030)$ & $(0.031)$ \\
\hline \multirow[t]{2}{*}{ Long-run } & $0.185^{* *}$ & $0.204^{* * *}$ & -0.006 & $0.048^{*}$ & 0.006 \\
\hline & $(0.076)$ & $(0.063)$ & $(0.039)$ & $(0.028)$ & $(0.026)$ \\
\hline Mean outcome & 1.224 & 0.774 & 0.208 & 0.118 & 0.124 \\
\hline Observations & 3,758 & 3,758 & 3,758 & 3,758 & 3,758 \\
\hline Adjusted $R^{2}$ & 0.46 & 0.432 & 0.271 & 0.205 & 0.226 \\
\hline \multicolumn{6}{|c|}{ Panel C. Log number of new physicians not from private sector } \\
\hline \multirow[t]{2}{*}{ Short-run } & 0.026 & 0.034 & $-0.010^{*}$ & -0.002 & 0.003 \\
\hline & $(0.039)$ & $(0.039)$ & $(0.006)$ & $(0.005)$ & $(0.006)$ \\
\hline \multirow[t]{2}{*}{ Long-run } & $0.076^{*}$ & $0.083^{* *}$ & -0.005 & -0.000 & -0.005 \\
\hline & $(0.041)$ & $(0.039)$ & $(0.005)$ & $(0.005)$ & $(0.006)$ \\
\hline Mean outcome & 0.462 & 0.424 & 0.016 & 0.013 & 0.009 \\
\hline Observations & 3,758 & 3,758 & 3,758 & 3,758 & 3,758 \\
\hline Adjusted $R^{2}$ & 0.333 & 0.327 & 0.0154 & 0.0135 & 0.00922 \\
\hline Time FE & Yes & Yes & Yes & Yes & Yes \\
\hline Unit FE & Yes & Yes & Yes & Yes & Yes \\
\hline
\end{tabular}

Notes: Unit of observation is unit $\times$ quarter. To account for zeros in the data, a value of one is added to each observation before log-transformation of the outcome. New physicians are defined as those physicians that had no observations in the unit in the previous quarter. Physicians in Panel A are those that worked in the quarter prior to being flagged as a new physician in a unit that belonged to the same market. Physicians in Panel B are those that worked outside the market area prior to being flagged as a new physician. Physicians in Panel $\mathrm{C}$ are those that did not have observations in the data prior to the quarter they were flagged as a new physician. Primary care physicians include both unspecialized physicians and general medicine physicians. Each unit's first period and solo practices are dropped from the data. The mean outcomes are values before performing the log transformation. 
TABLE A11: Price per visit for incumbent competing physicians within 10 kilometers

\begin{tabular}{|c|c|c|c|c|}
\hline & Primary care & Gynecology & Orthopedics & ENT \\
\hline & (1) & $(2)$ & (3) & $(4)$ \\
\hline \multirow[t]{2}{*}{ Short-run } & -0.001 & -0.001 & $-0.010^{*}$ & 0.002 \\
\hline & $(0.006)$ & $(0.007)$ & $(0.006)$ & $(0.007)$ \\
\hline \multirow[t]{2}{*}{ Long-run } & 0.003 & -0.008 & -0.005 & 0.008 \\
\hline & $(0.010)$ & $(0.011)$ & $(0.010)$ & $(0.014)$ \\
\hline Mean outcome & 56.518 & 78.631 & 89.801 & 79.138 \\
\hline Observations & $1,808,326$ & $1,373,190$ & 427,656 & 702,294 \\
\hline Adjusted $R^{2}$ & 0.815 & 0.647 & 0.667 & 0.631 \\
\hline Time FE & Yes & Yes & Yes & Yes \\
\hline Physician $\times$ Unit FE & Yes & Yes & Yes & Yes \\
\hline
\end{tabular}

Notes: Unit of observation is physician $\times$ unit $\times$ visit. Treated physicians are those that work in units within a 10 kilometer radius of an acquired unit before the acquisition. The event time is relative to the acquisition in a neighboring unit. Primary care physicians include both unspecialized physicians and general medicine physicians. Each specification additionally controls for length of the visit fixed effects, whether there is a specialization fee included in the visit, patient gender, patient income, as well as physician and patient age and square of age. The mean outcomes are values before performing the log transformation. 


\section{B Online Appendix: Robustness Checks for Nearby Competitors}
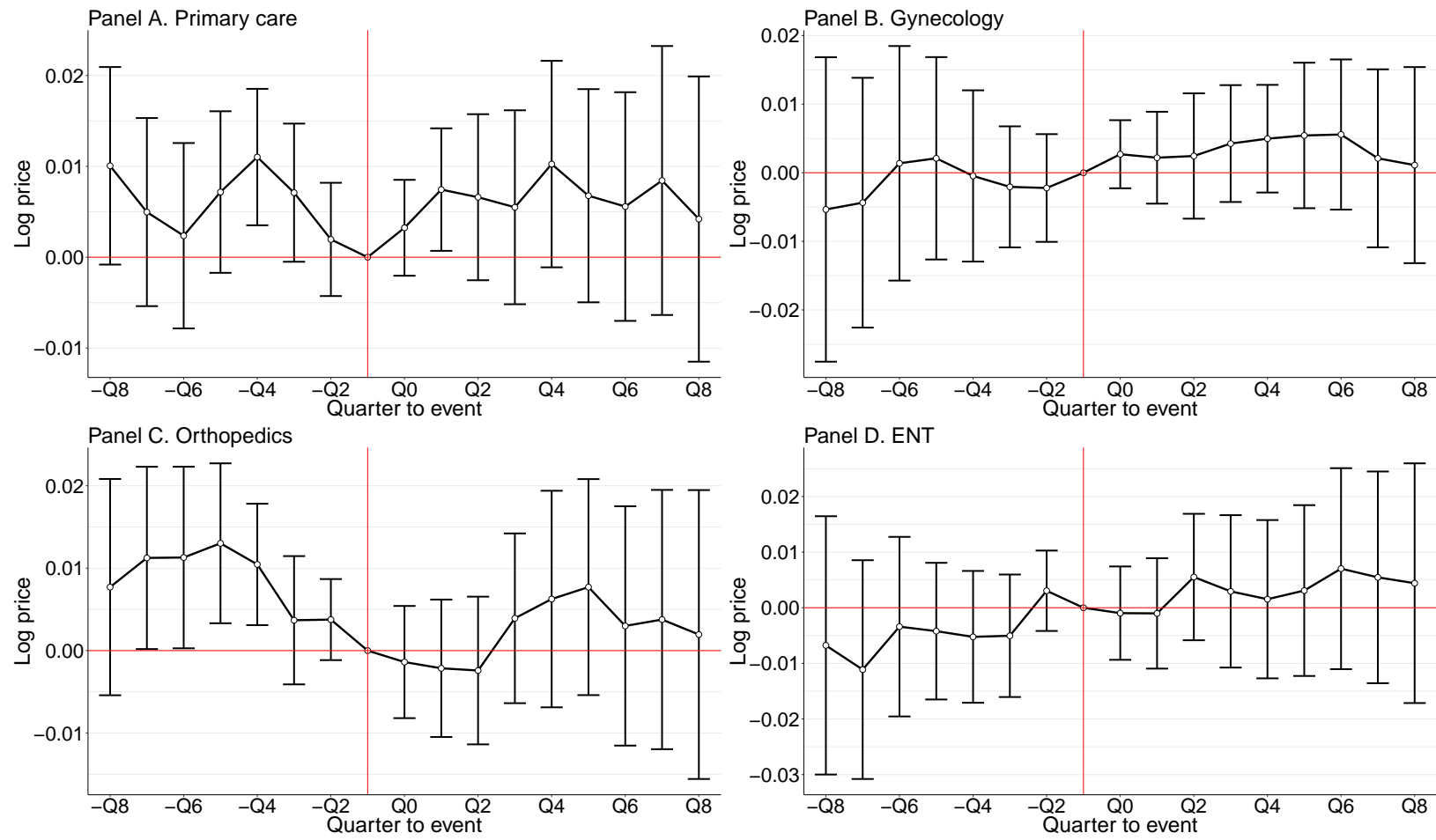

Figure A8: Price per visit for incumbent competing physicians in the market area

Notes: Unit of observation is physician $\times$ unit $\times$ visit. Treated physicians are those that work in units within a 30 kilometer radius of a target unit before the acquisition. The event time is relative to the acquisition in a neighboring unit. Primary care physicians include both unspecialized physicians and general medicine physicians. Controls include fixed effects for physician $\times$ unit, time period, length of the visit, whether there was a specialization fee included in the visit, patient gender, patient income, as well as controls for physician and patient age and square of age. 

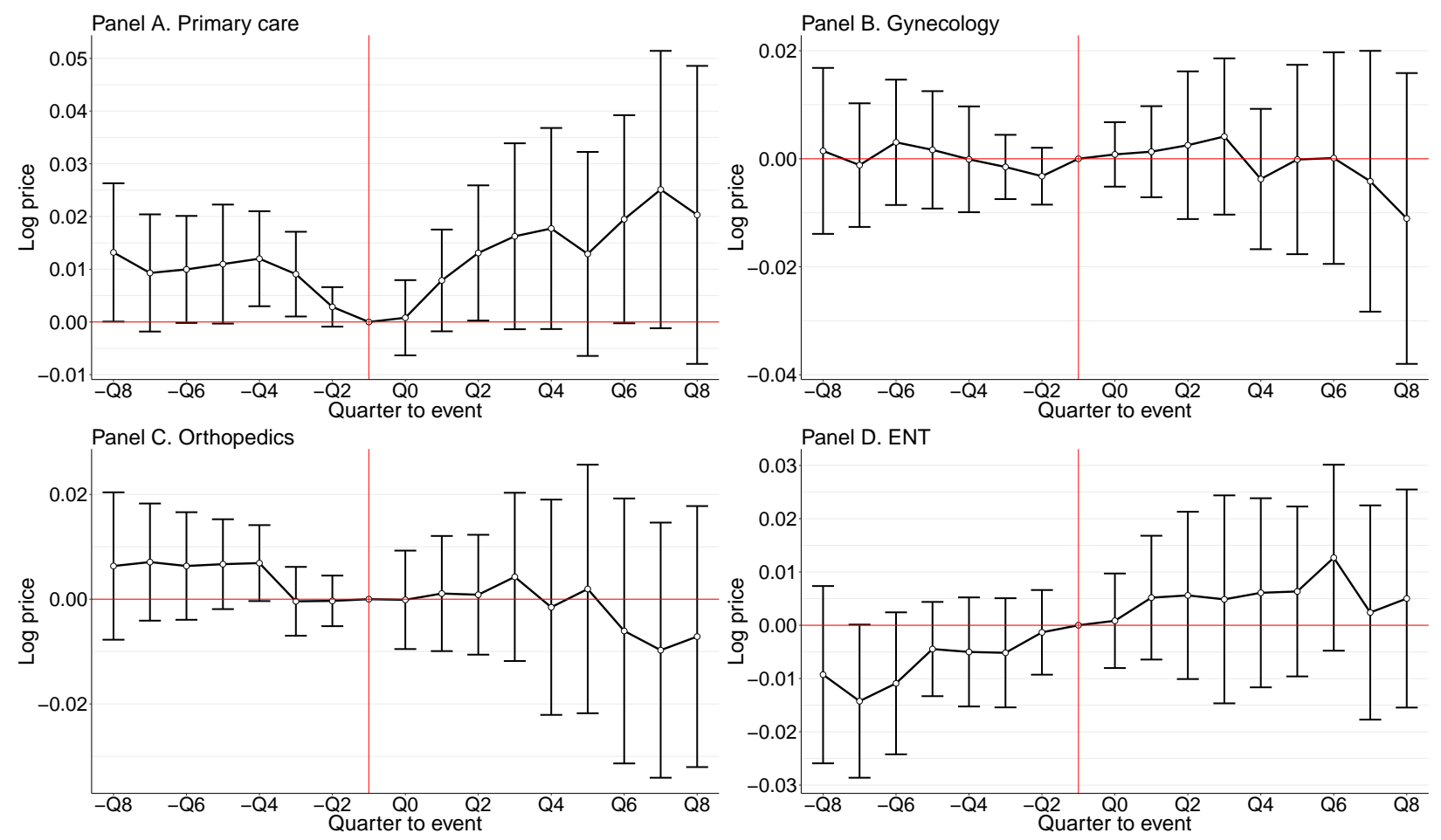

Figure A9: Price per visit for incumbent competing physicians within 10 kilometers, first acquisition in the market

Notes: Unit of observation is physician $\times$ unit $\times$ visit. Treated physicians are those that work in units within a 10 kilometer radius of a target unit before the acquisition. The event time is relative to the acquisition in a neighboring unit. Only the first acquisition in the market gets the treatment status and all rows after the second acquisition in the market are dropped. Primary care physicians include both unspecialized physicians and general medicine physicians. Controls include fixed effects for physician $\times$ unit, time period, length of the visit, whether there was a specialization fee included in the visit, patient gender, patient income, as well as controls for physician and patient age and square of age. 
TABLE A12: Unit market shares for rival units in the market area

\begin{tabular}{|c|c|c|c|c|c|}
\hline & All physicians & Primary care & Gynecology & Orthopedics & ENT \\
\hline & (1) & $(2)$ & $(3)$ & (4) & $(5)$ \\
\hline \multirow[t]{2}{*}{ Short-run } & $0.018^{*}$ & 0.011 & 0.005 & -0.005 & 0.001 \\
\hline & $(0.009)$ & $(0.011)$ & $(0.008)$ & $(0.012)$ & $(0.007)$ \\
\hline \multirow[t]{2}{*}{ Long-run } & 0.032 & 0.032 & 0.010 & -0.000 & 0.004 \\
\hline & $(0.019)$ & $(0.020)$ & $(0.018)$ & $(0.018)$ & $(0.017)$ \\
\hline Mean outcome & 0.178 & 0.174 & 0.154 & 0.125 & 0.136 \\
\hline Observations & 8,536 & 8,494 & 8,272 & 7,829 & 7,962 \\
\hline Adjusted $R^{2}$ & 0.93 & 0.918 & 0.948 & 0.903 & 0.955 \\
\hline Time FE & Yes & Yes & Yes & Yes & Yes \\
\hline Unit FE & Yes & Yes & Yes & Yes & Yes \\
\hline
\end{tabular}

Notes: Unit of observation is unit $\times$ quarter. The outcome is the number of physician visits to the unit divided by the overall number of visits in the market. Treated units are those that are located in the same market area as the acquired unit. Radius of the market area is 30 kilometers. The time of the treatment is generated from the acquisition in the neighboring unit. Primary care physicians include both unspecialized physicians and general medicine physicians. Solo practices are dropped from the data. 
TABLE A13: Unit market shares for rival units within 10 kilometers, first acquisition in the market

\begin{tabular}{|c|c|c|c|c|c|}
\hline & All physicians & Primary care & Gynecology & Orthopedics & ENT \\
\hline & (1) & $(2)$ & $(3)$ & (4) & $(5)$ \\
\hline \multirow[t]{2}{*}{ Short-run } & $0.022^{*}$ & 0.011 & 0.003 & 0.003 & 0.001 \\
\hline & $(0.012)$ & $(0.016)$ & $(0.010)$ & $(0.018)$ & $(0.009)$ \\
\hline \multirow[t]{2}{*}{ Long-run } & 0.035 & 0.025 & 0.011 & 0.005 & -0.004 \\
\hline & $(0.029)$ & $(0.030)$ & $(0.031)$ & $(0.029)$ & $(0.029)$ \\
\hline Mean outcome & 0.283 & 0.274 & 0.241 & 0.209 & 0.229 \\
\hline Observations & 4,772 & 4,730 & 4,508 & 4,123 & 4,219 \\
\hline Adjusted $R^{2}$ & 0.917 & 0.905 & 0.944 & 0.902 & 0.955 \\
\hline Time FE & Yes & Yes & Yes & Yes & Yes \\
\hline Unit FE & Yes & Yes & Yes & Yes & Yes \\
\hline
\end{tabular}

Notes: Unit of observation is unit $\times$ quarter. The outcome is the number of physician visits to the unit divided by the overall number of visits in the market. Treated units are those that are located within a 10 kilometer radius of an acquired unit. Only the first acquisition in the market gets the treatment status and all rows after the second acquisition in the market are dropped. The time of the treatment is generated from the acquisition in the neighboring unit. Primary care physicians include both unspecialized physicians and general medicine physicians. Solo practices are dropped from the data. 
C Online Appendix: In-Market and Out-of-Market Acquisitions 


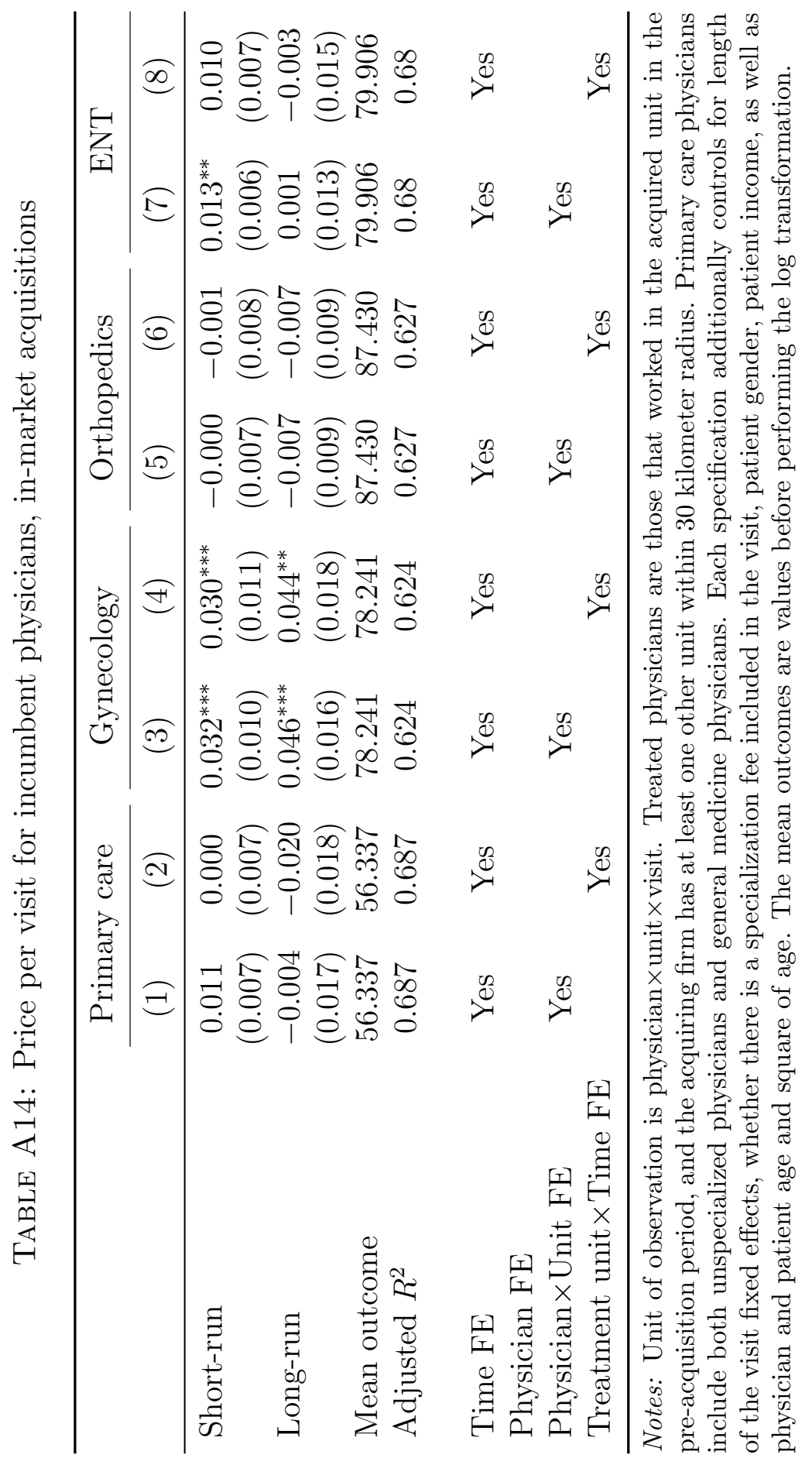




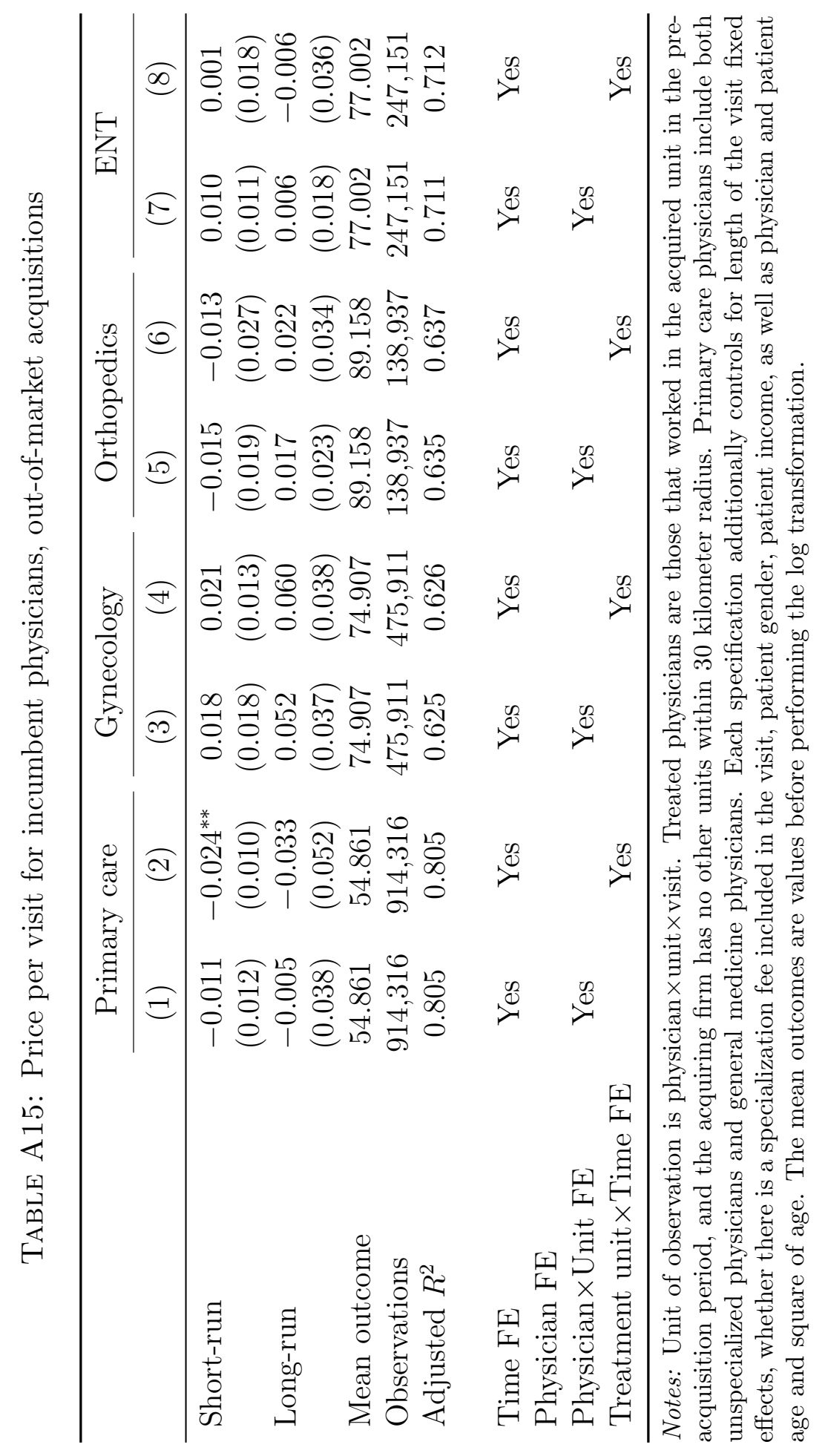


TABLE A16: Number of physicians in the unit, in-market acquisitions

\begin{tabular}{|c|c|c|c|c|c|}
\hline & All physicians & Primary care & Gynecology & Orthopedics & ENT \\
\hline & (1) & $(2)$ & $(3)$ & (4) & $(5)$ \\
\hline \multicolumn{6}{|c|}{ Panel A. Log number of physicians } \\
\hline \multirow[t]{2}{*}{ Short-run } & 0.101 & 0.076 & 0.077 & 0.114 & $0.142^{* *}$ \\
\hline & $(0.065)$ & $(0.072)$ & $(0.068)$ & $(0.073)$ & $(0.063)$ \\
\hline \multirow[t]{2}{*}{ Long-run } & -0.073 & 0.021 & -0.141 & -0.066 & 0.033 \\
\hline & $(0.088)$ & $(0.087)$ & $(0.092)$ & $(0.086)$ & $(0.067)$ \\
\hline Mean outcome & 20.820 & 11.188 & 4.546 & 2.883 & 2.203 \\
\hline Observations & 3,109 & 3,109 & 3,109 & 3,109 & 3,109 \\
\hline Adjusted $R^{2}$ & 0.935 & 0.924 & 0.885 & 0.87 & 0.886 \\
\hline \multicolumn{6}{|c|}{ Panel B. Log number of continuing physicians } \\
\hline \multirow[t]{2}{*}{ Short-run } & 0.056 & 0.012 & 0.052 & 0.092 & $0.099^{* *}$ \\
\hline & $(0.061)$ & $(0.064)$ & $(0.065)$ & $(0.064)$ & $(0.049)$ \\
\hline \multirow[t]{2}{*}{ Long-run } & -0.105 & -0.027 & -0.132 & -0.100 & 0.064 \\
\hline & $(0.092)$ & $(0.088)$ & $(0.099)$ & $(0.083)$ & $(0.070)$ \\
\hline Mean outcome & 17.847 & 9.096 & 4.137 & 2.640 & 1.973 \\
\hline Observations & 3,109 & 3,109 & 3,109 & 3,109 & 3,109 \\
\hline Adjusted $R^{2}$ & 0.929 & 0.918 & 0.894 & 0.883 & 0.908 \\
\hline \multicolumn{6}{|c|}{ Panel C. Log number of new physicians } \\
\hline \multirow[t]{2}{*}{ Short-run } & $0.253^{* *}$ & $0.216^{* *}$ & $0.154^{* *}$ & $0.095^{*}$ & $0.130^{* *}$ \\
\hline & $(0.097)$ & $(0.097)$ & $(0.073)$ & $(0.054)$ & $(0.059)$ \\
\hline \multirow[t]{2}{*}{ Long-run } & $0.222^{* *}$ & $0.256^{* * *}$ & 0.033 & $0.093^{*}$ & -0.001 \\
\hline & $(0.102)$ & $(0.097)$ & $(0.056)$ & $(0.047)$ & $(0.044)$ \\
\hline Mean outcome & 2.973 & 2.092 & 0.408 & 0.243 & 0.230 \\
\hline Observations & 3,109 & 3,109 & 3,109 & 3,109 & 3,109 \\
\hline Adjusted $R^{2}$ & 0.611 & 0.594 & 0.282 & 0.224 & 0.239 \\
\hline Time FE & Yes & Yes & Yes & Yes & Yes \\
\hline Unit FE & Yes & Yes & Yes & Yes & Yes \\
\hline
\end{tabular}

Notes: Unit of observation is unit $\times$ quarter. To account for zeros in the data, a value of one is added to each observation before log-transformation. Target units are those units that were acquired and the acquiring firm has at least one other unit within 30 kilometer radius. Continuing physicians are those that had an observation in the unit in the previous quarter. New physicians are defined as those physicians that had no observations in the unit in the previous quarter. Each unit's first period and solo practices are dropped from the data. The mean outcomes are values before performing the log transformation. 
TABLE A17: Number of physicians in the unit, out-of-market acquisitions

\begin{tabular}{|c|c|c|c|c|c|}
\hline & All physicians & Primary care & Gynecology & Orthopedics & ENT \\
\hline & (1) & (2) & $(3)$ & $(4)$ & $(5)$ \\
\hline \multicolumn{6}{|c|}{ Panel A. Log number of physicians } \\
\hline \multirow[t]{2}{*}{ Short-run } & 0.075 & 0.045 & 0.006 & 0.143 & 0.019 \\
\hline & $(0.074)$ & $(0.093)$ & $(0.055)$ & $(0.093)$ & $(0.073)$ \\
\hline \multirow[t]{2}{*}{ Long-run } & 0.128 & 0.133 & 0.078 & 0.110 & 0.029 \\
\hline & $(0.080)$ & $(0.107)$ & $(0.073)$ & $(0.086)$ & $(0.093)$ \\
\hline Mean outcome & 9.681 & 4.672 & 2.547 & 1.245 & 1.216 \\
\hline Observations & 2,260 & 2,260 & 2,260 & 2,260 & 2,260 \\
\hline Adjusted $R^{2}$ & 0.934 & 0.884 & 0.904 & 0.824 & 0.878 \\
\hline \multicolumn{6}{|c|}{ Panel B. Log number of continuing physicians } \\
\hline \multirow[t]{2}{*}{ Short-run } & 0.038 & -0.048 & -0.001 & 0.140 & 0.026 \\
\hline & $(0.073)$ & $(0.078)$ & $(0.052)$ & $(0.100)$ & $(0.064)$ \\
\hline \multirow[t]{2}{*}{ Long-run } & 0.098 & 0.055 & 0.081 & 0.109 & 0.003 \\
\hline & $(0.090)$ & $(0.097)$ & $(0.077)$ & $(0.090)$ & $(0.088)$ \\
\hline Mean outcome & 8.654 & 3.990 & 2.405 & 1.135 & 1.123 \\
\hline Observations & 2,260 & 2,260 & 2,260 & 2,260 & 2,260 \\
\hline Adjusted $R^{2}$ & 0.921 & 0.881 & 0.904 & 0.824 & 0.891 \\
\hline \multicolumn{6}{|c|}{ Panel C. Log number of new physicians } \\
\hline \multirow[t]{2}{*}{ Short-run } & $0.166^{*}$ & $0.179^{* *}$ & -0.007 & 0.039 & -0.021 \\
\hline & $(0.097)$ & $(0.084)$ & $(0.045)$ & $(0.024)$ & $(0.023)$ \\
\hline \multirow[t]{2}{*}{ Long-run } & $0.251^{* * *}$ & $0.248^{* * *}$ & -0.001 & 0.010 & 0.045 \\
\hline & $(0.091)$ & $(0.085)$ & $(0.083)$ & $(0.028)$ & $(0.034)$ \\
\hline Mean outcome & 1.027 & 0.682 & 0.142 & 0.110 & 0.093 \\
\hline Observations & 2,260 & 2,260 & 2,260 & 2,260 & 2,260 \\
\hline Adjusted $R^{2}$ & 0.441 & 0.391 & 0.107 & 0.177 & 0.0994 \\
\hline Time FE & Yes & Yes & Yes & Yes & Yes \\
\hline Unit FE & Yes & Yes & Yes & Yes & Yes \\
\hline
\end{tabular}

Notes: Unit of observation is unit×quarter. To account for zeros in the data, a value of one is added to each observation before log-transformation. Target units are those units that were acquired and the acquiring firm has no other units within 30 kilometer radius. Continuing physicians are those that had an observation in the unit in the previous quarter. New physicians are defined as those physicians that had no observations in the unit in the previous quarter. Each unit's first period and solo practices are dropped from the data. The mean outcomes are values before performing the log transformation. 


\section{Online Appendix: Different Market Sizes}
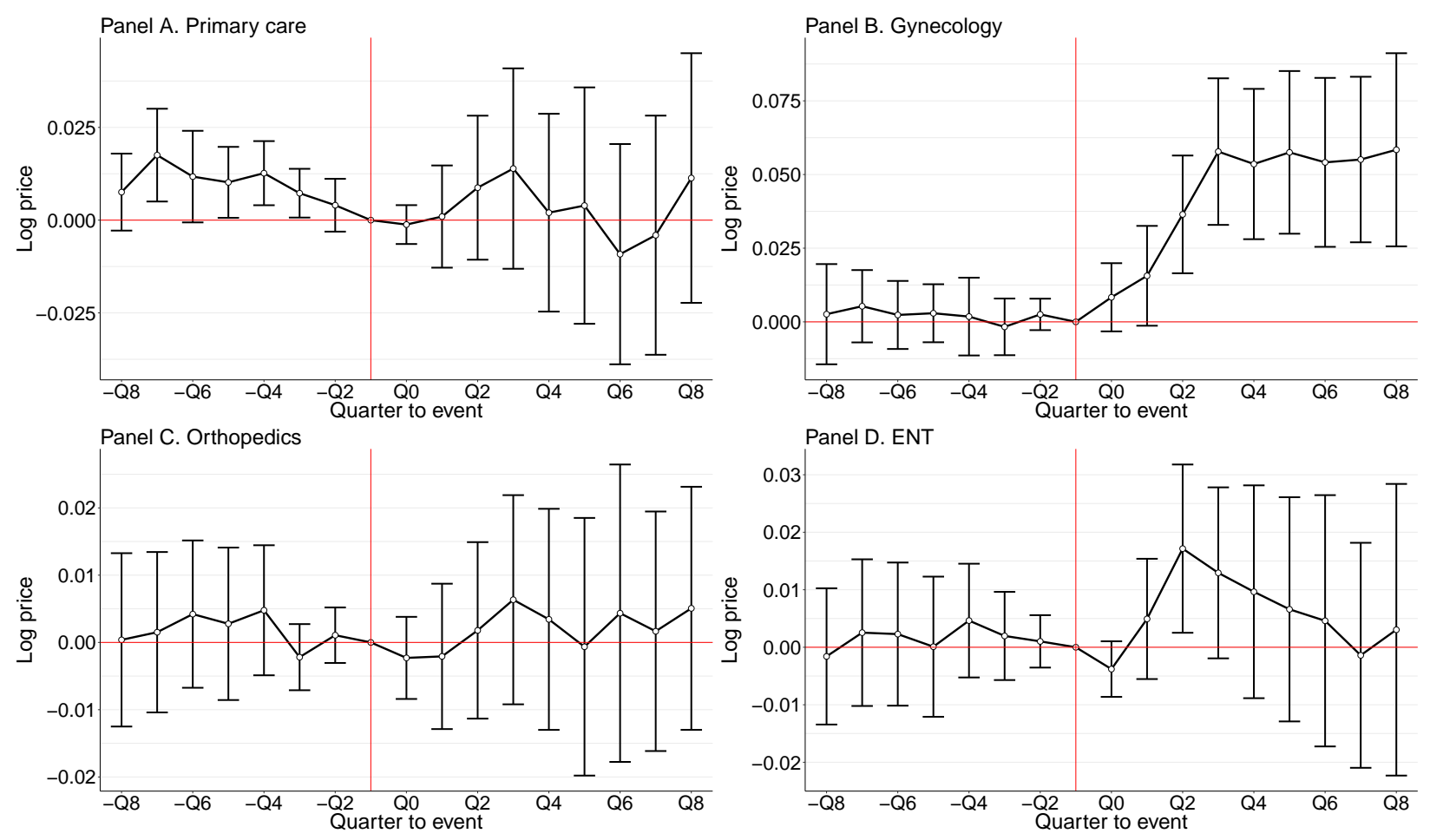

Figure A10: Price per visit for incumbent physicians with 50 kilometer market radius, by specialty

Notes: Unit of observation is physician $\times$ unit $\times$ visit. Treated physicians are those that worked in the acquired unit in the pre-acquisition period. Primary care physicians include both unspecialized physicians and general medicine physicians. Controls include fixed effects for physician $\times$ unit, time period, length of the visit, whether there was a specialization fee included in the visit, patient gender, patient income, as well as controls for physician and patient age and square of age. 

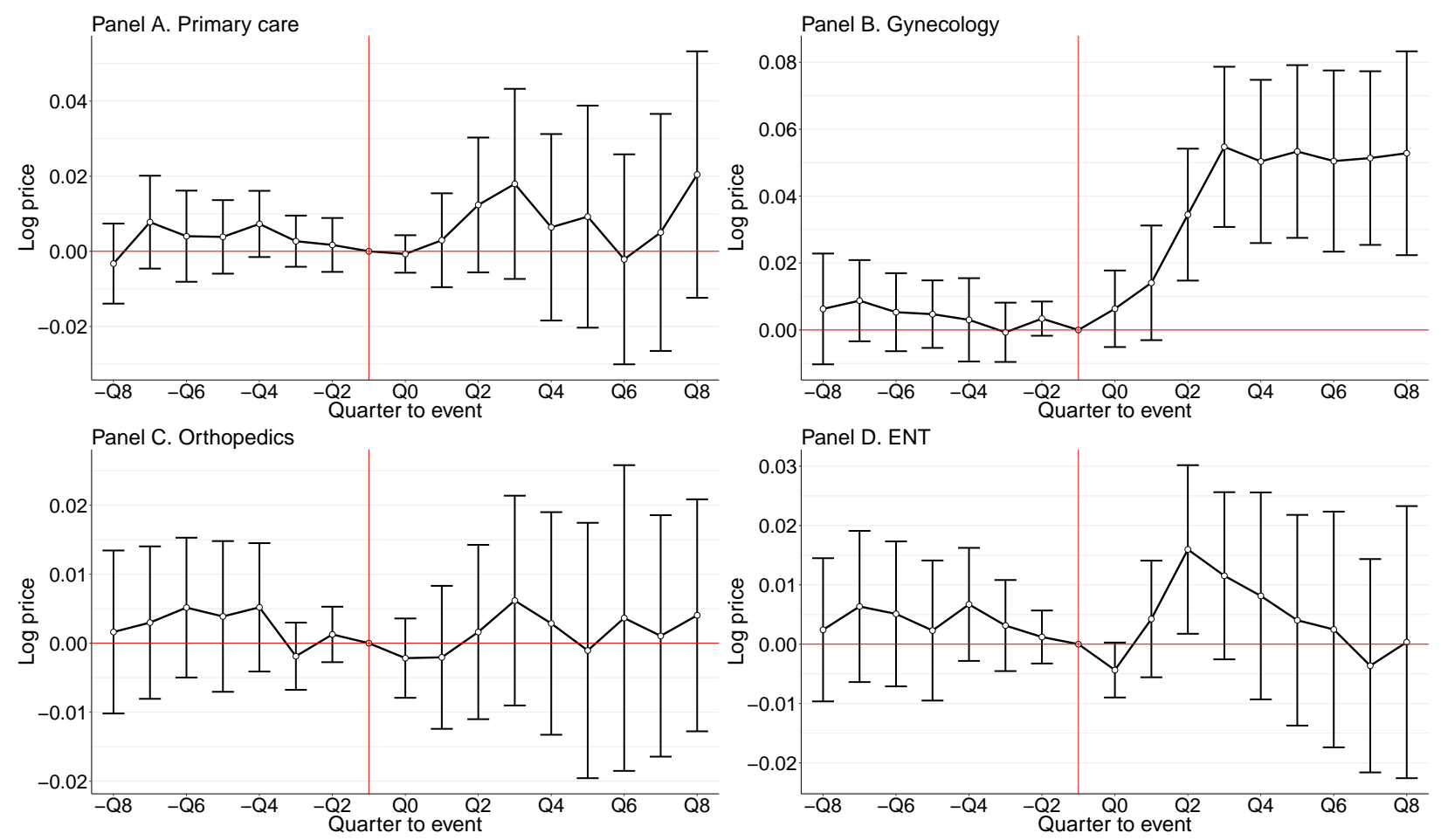

Figure A11: Price per visit for incumbent physicians with 20 kilometer market radius, by specialty

Notes: Unit of observation is physician $\times$ unit $\times$ visit. Treated physicians are those that worked in the acquired unit in the pre-acquisition period. Primary care physicians include both unspecialized physicians and general medicine physicians. Controls include fixed effects for physician $\times$ unit, time period, length of the visit, whether there was a specialization fee included in the visit, patient gender, patient income, as well as controls for physician and patient age and square of age. 

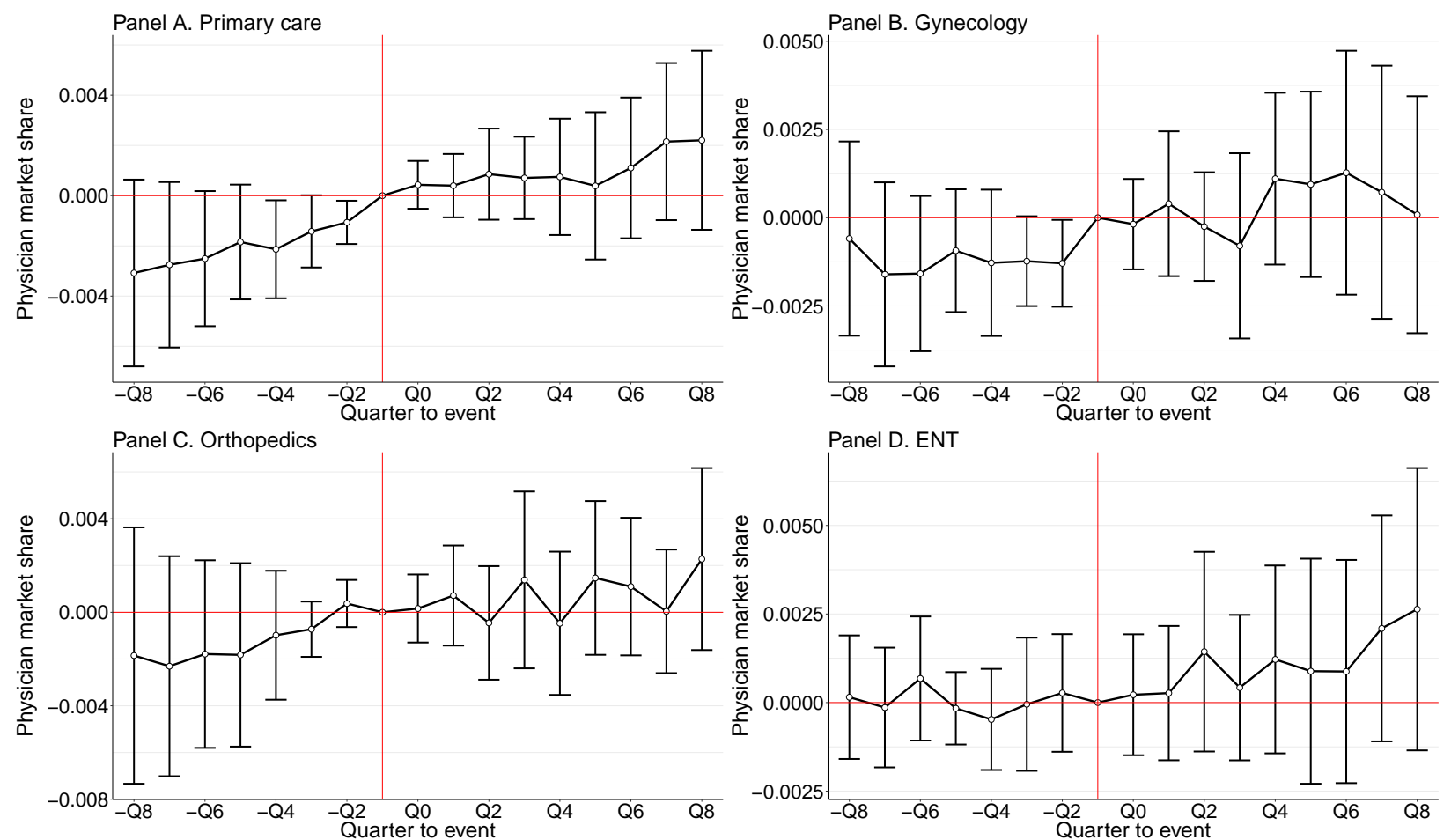

Figure A12: Physician overall market shares for incumbent physicians with 50 kilometer market radius, by specialty

Notes: Unit of observation is physician $\times$ unit $\times$ quarter. The outcome is the number of visits physician has within a unit per quarter divided by the overall number of visits in the market. Market areas are defined by radii of 50 kilometers, calculated from the centroid of the zip codes. Treated physicians are those that worked in the acquired unit in the pre-acquisition period. Primary care physicians include both unspecialized physicians and general medicine physicians. Controls include fixed effects for physician $\times$ unit, time period, as well as controls for physician age and square of age. 

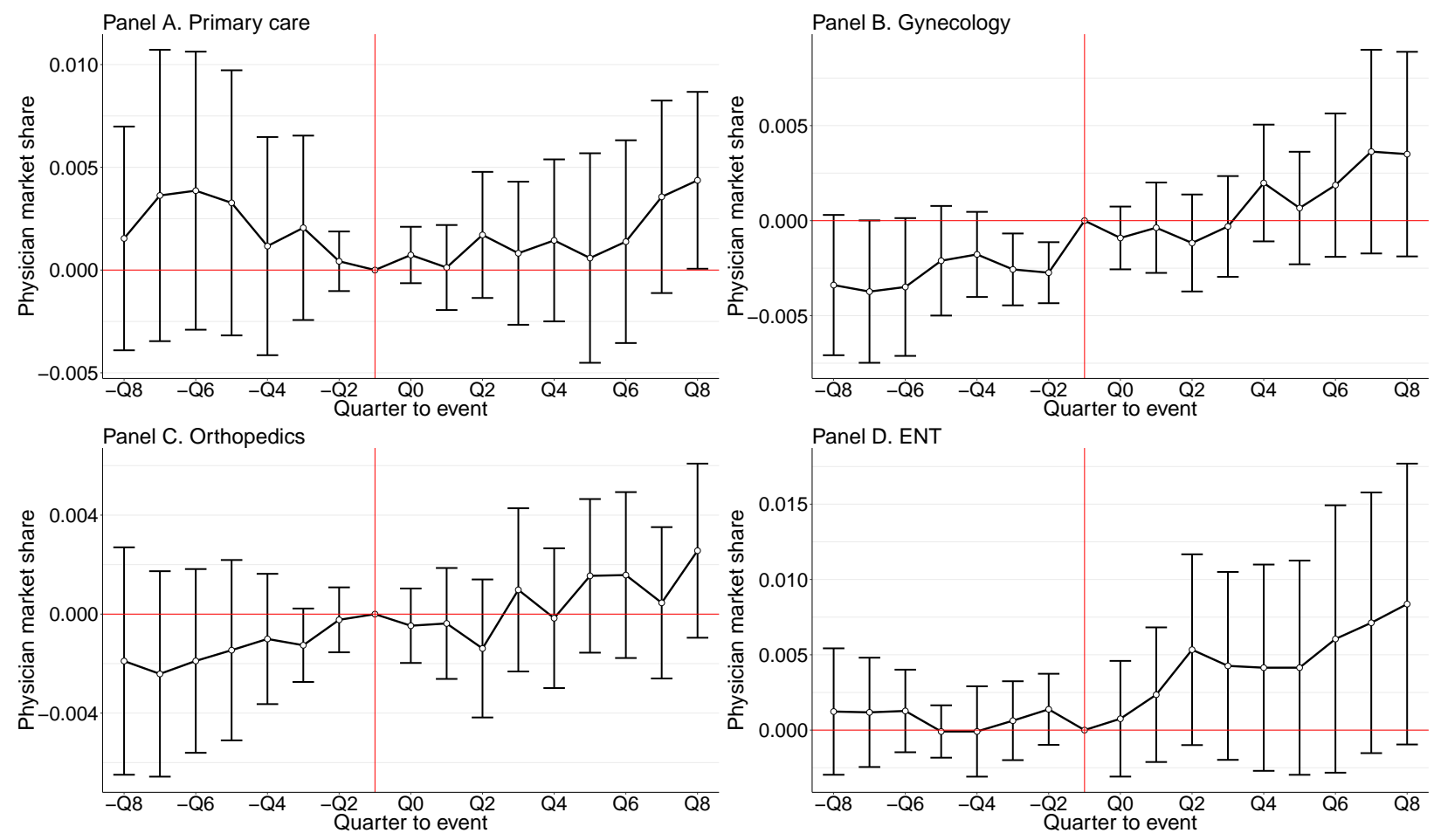

Figure A13: Physician overall market shares for incumbent physicians with 20 kilometer market radius, by specialty

Notes: Unit of observation is physician $\times$ unit $\times$ quarter. The outcome is the number of visits physician has within a unit per quarter divided by the overall number of visits in the market. Market areas are defined by radii of 20 kilometers, calculated from the centroid of the zip codes. Treated physicians are those that worked in the acquired unit in the pre-acquisition period. Primary care physicians include both unspecialized physicians and general medicine physicians. Controls include fixed effects for physician $\times$ unit, time period, as well as controls for physician age and square of age. 

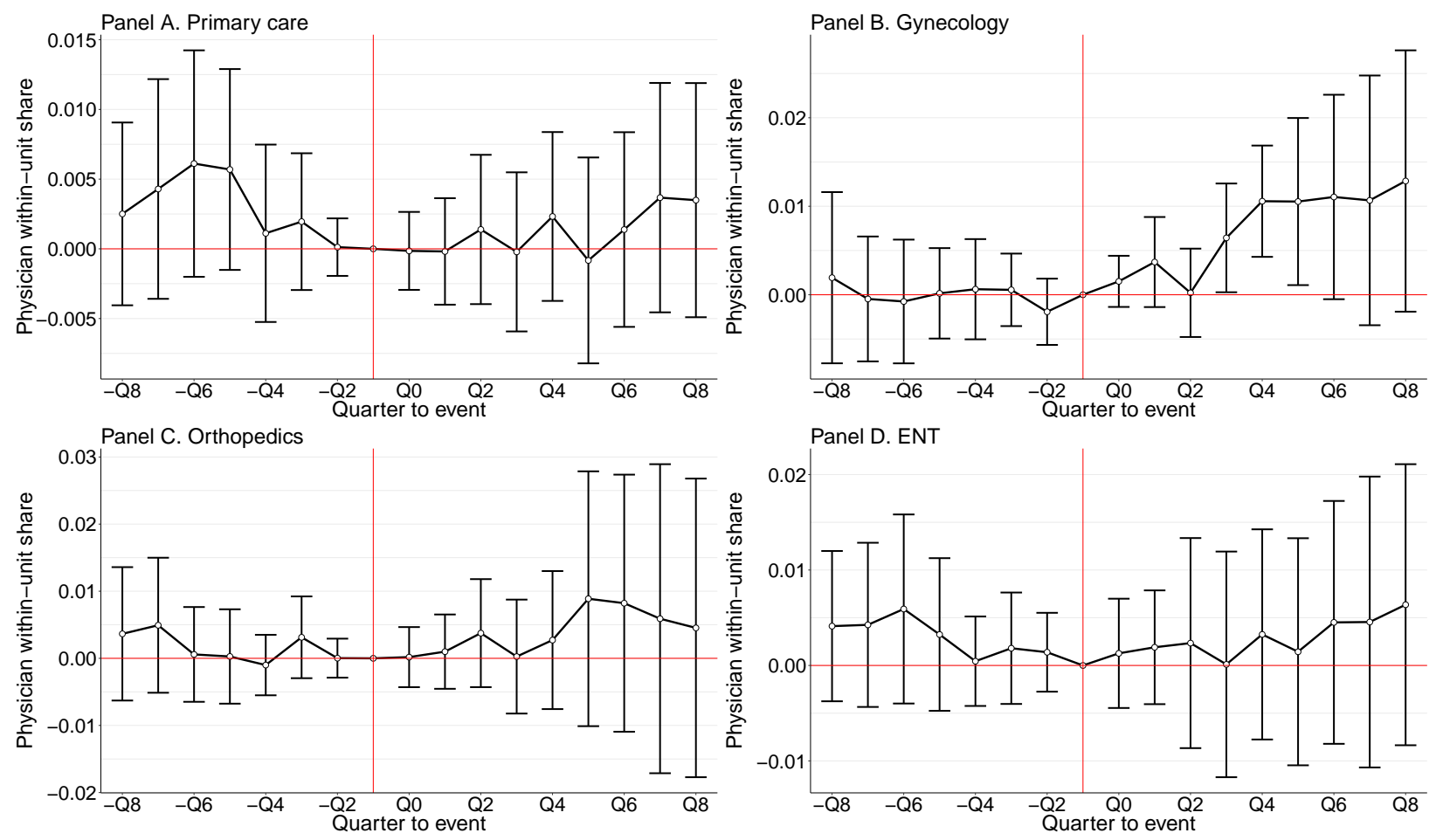

Figure A14: Physician within-unit share for incumbent physicians with 50 kilometer market radius, by specialty

Notes: Unit of observation is physician $\times$ unit $\times$ quarter. The outcome is the number of visits a physician has within a unit per quarter divided by the overall number of visits in the unit. Treated physicians are those that worked in the acquired unit in the pre-acquisition period. Primary care physicians include both unspecialized physicians and general medicine physicians. Controls include fixed effects for physician $\times$ unit, time period, as well as controls for physician age and square of age. 

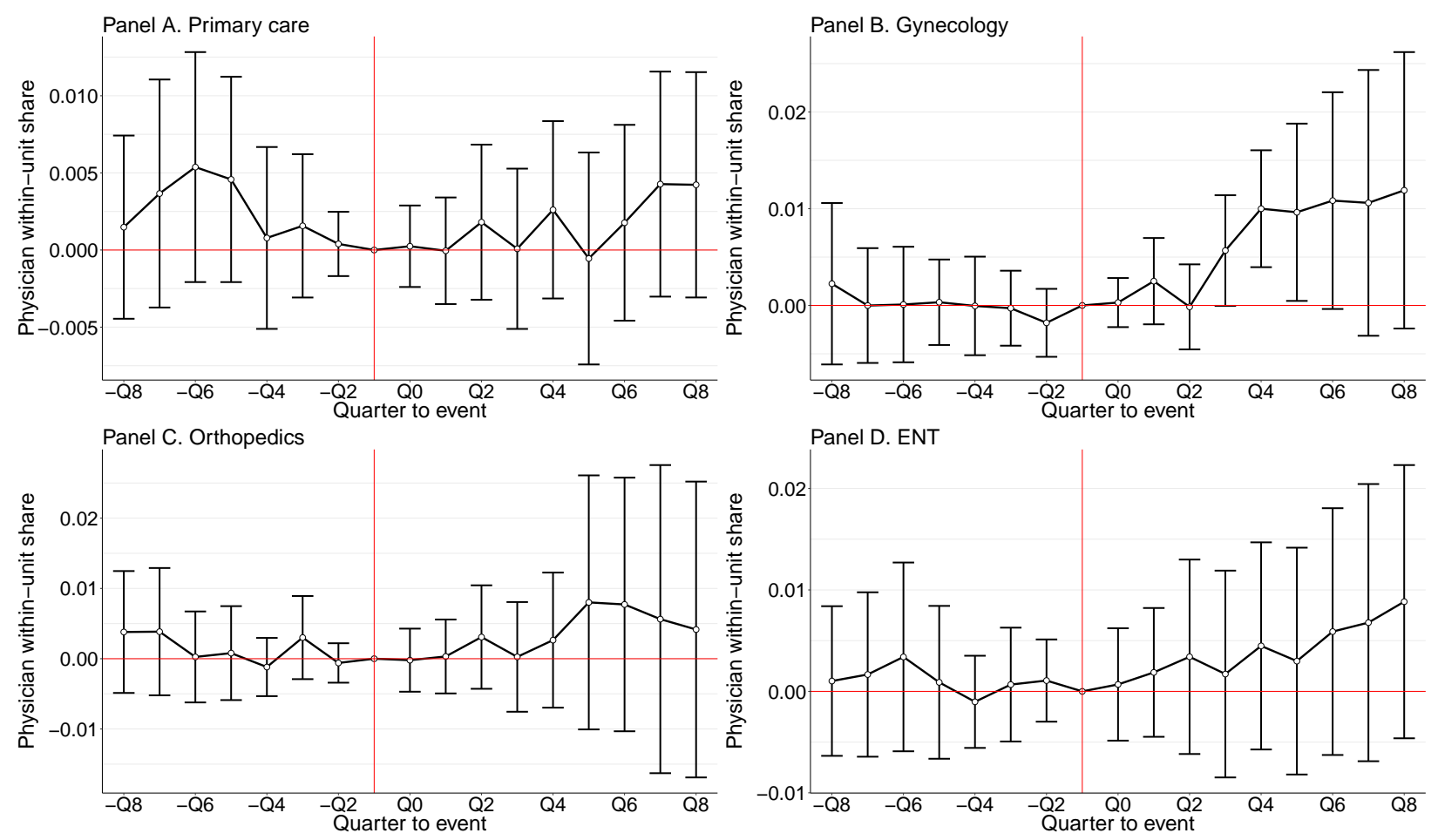

FIGURE A15: Physician within-unit share for incumbent physicians with 20 kilometer market radius, by specialty

Notes: Unit of observation is physician $\times$ unit $\times$ quarter. The outcome is the number of visits a physician has within a unit per quarter divided by the overall number of visits in the unit. Treated physicians are those that worked in the acquired unit in the pre-acquisition period. Primary care physicians include both unspecialized physicians and general medicine physicians. Controls include fixed effects for physician $\times$ unit, time period, as well as controls for physician age and square of age. 

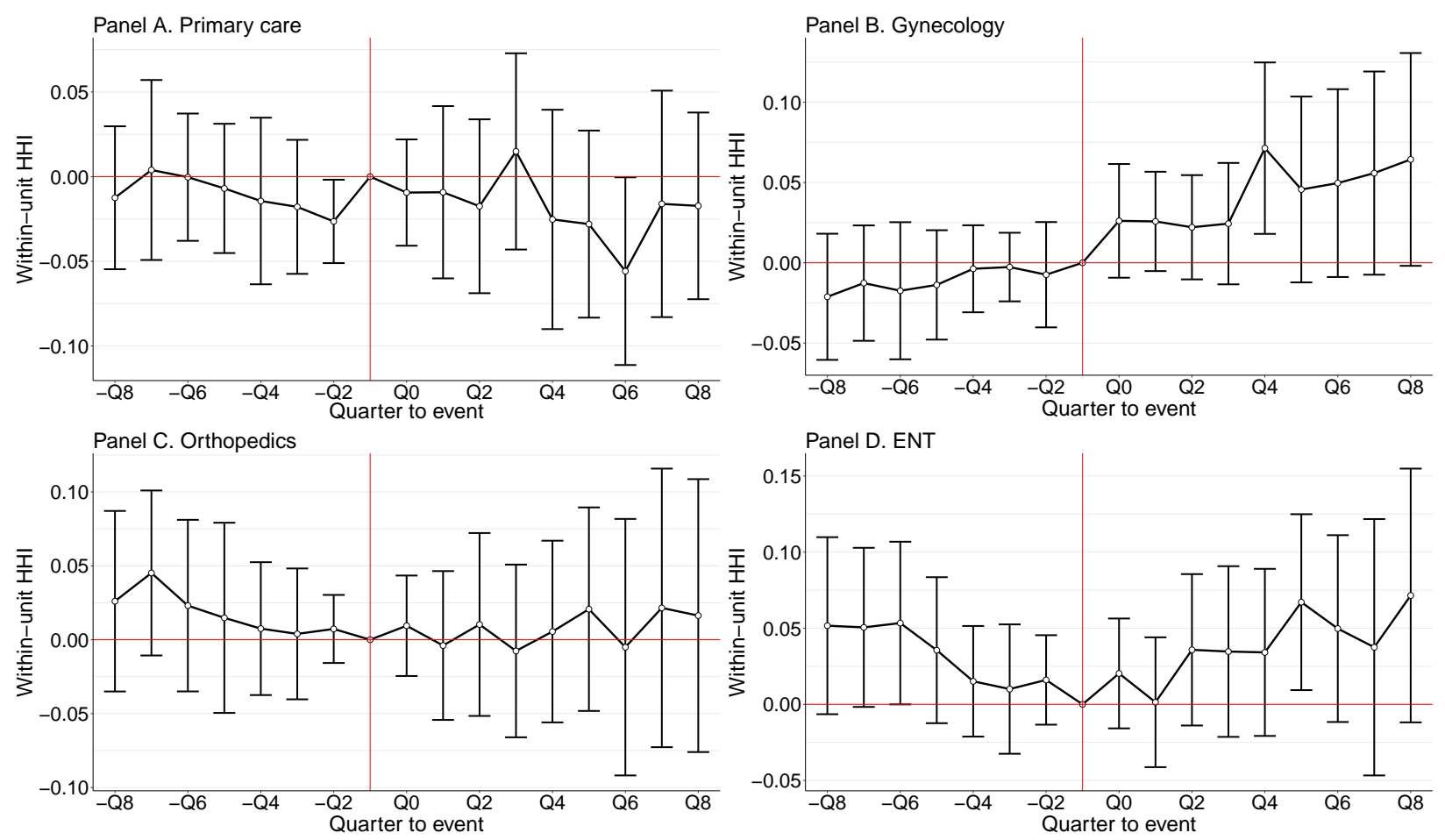

FiguRE A16: Within-unit HHI for different specialties with 50 kilometer market radius

Notes: Unit of observation is unit $\times$ quarter. Each panel is plotted from a separate regression. The outcome is the within-unit Herfindahl-Hirschman Index (HHI), calculated by taking the sum of the squared market shares of each physician within a specialty and health care unit. Primary care physicians include both unspecialized physicians and general medicine physicians. Each regression controls for unit and time fixed effects. 

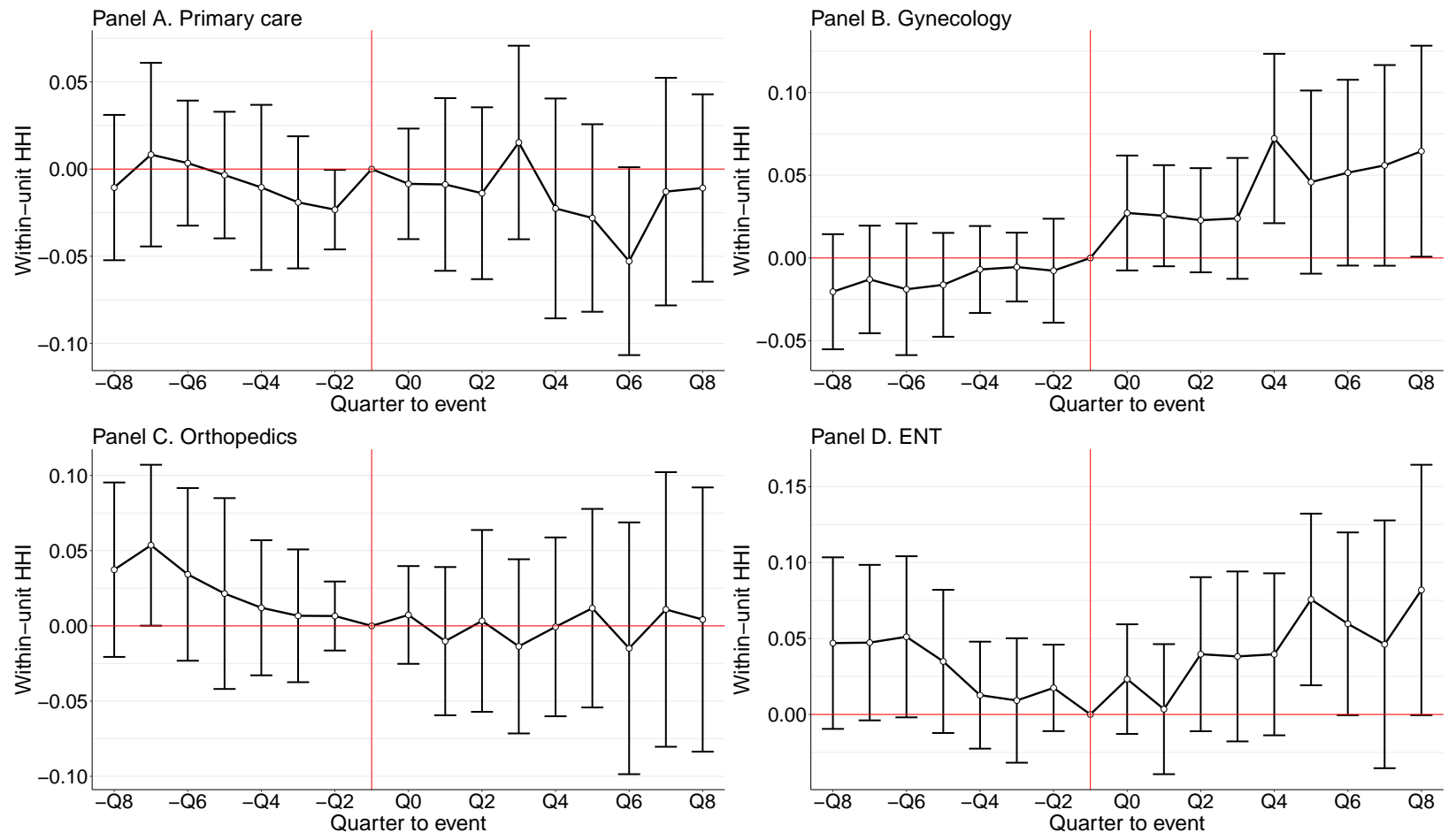

FIgURE A17: Within-unit HHI for different specialties with 20 kilometer market radius

Notes: Unit of observation is unit $\times$ quarter. Each panel is plotted from a separate regression. The outcome is the within-unit Herfindahl-Hirschman Index (HHI), calculated by taking the sum of the squared market shares of each physician within a specialty and health care unit. Primary care physicians include both unspecialized physicians and general medicine physicians. Each regression controls for unit and time fixed effects. 
TABLE A18: Number of physicians in the unit with 50 kilometer market radius

\begin{tabular}{|c|c|c|c|c|c|}
\hline & All physicians & Primary care & Gynecology & Orthopedics & ENT \\
\hline & (1) & (2) & (3) & (4) & (5) \\
\hline Panel A. Log $n$ & umber of physici & ans & & & \\
\hline Short-run & 0.054 & 0.033 & 0.017 & 0.088 & 0.066 \\
\hline & $(0.050)$ & $(0.060)$ & $(0.043)$ & $(0.058)$ & $(0.050)$ \\
\hline Long-run & -0.076 & 0.003 & $-0.132^{*}$ & -0.076 & -0.020 \\
\hline & $(0.079)$ & $(0.079)$ & $(0.080)$ & $(0.078)$ & $(0.066)$ \\
\hline Mean outcome & 22.023 & 11.481 & 4.949 & 3.191 & 2.402 \\
\hline Observations & 2,916 & 2,916 & 2,916 & 2,916 & 2,916 \\
\hline Adjusted $R^{2}$ & 0.915 & 0.906 & 0.854 & 0.846 & 0.863 \\
\hline Panel B. Log $n$ & mber of continu & ing physicians & & & \\
\hline Short-run & 0.020 & -0.031 & 0.008 & 0.072 & 0.047 \\
\hline & $(0.049)$ & $(0.054)$ & $(0.042)$ & $(0.056)$ & $(0.042)$ \\
\hline Long-run & -0.099 & -0.043 & -0.109 & -0.098 & 0.007 \\
\hline & $(0.081)$ & $(0.077)$ & $(0.083)$ & $(0.075)$ & $(0.064)$ \\
\hline Mean outcome & 18.849 & 9.300 & 4.497 & 2.908 & 2.144 \\
\hline Observations & 2,916 & 2,916 & 2,916 & 2,916 & 2,916 \\
\hline Adjusted $R^{2}$ & 0.908 & 0.901 & 0.869 & 0.86 & 0.891 \\
\hline Panel C. $\log n$ & mber of new ph & ysicians & & & \\
\hline Short-run & $0.168^{* *}$ & $0.150^{* *}$ & 0.053 & $0.076^{* *}$ & 0.056 \\
\hline & $(0.068)$ & $(0.068)$ & $(0.045)$ & $(0.036)$ & $(0.037)$ \\
\hline Long-run & $0.156^{*}$ & $0.184^{* *}$ & -0.043 & 0.063 & -0.027 \\
\hline & $(0.092)$ & $(0.085)$ & $(0.056)$ & $(0.045)$ & $(0.041)$ \\
\hline Mean outcome & 3.175 & 2.182 & 0.452 & 0.283 & 0.258 \\
\hline Observations & 2,916 & 2,916 & 2,916 & 2,916 & 2,916 \\
\hline Adjusted $R^{2}$ & 0.573 & 0.574 & 0.257 & 0.209 & 0.222 \\
\hline Time FE & Yes & Yes & Yes & Yes & Yes \\
\hline Unit FE & Yes & Yes & Yes & Yes & Yes \\
\hline
\end{tabular}

Notes: Unit of observation is health care unit $\times$ quarter. To account for zeros in the data, a value of one is added to each observation before log-transformation. Continuing physicians are those that had an observation in the unit in the previous quarter. New physicians are defined as those physicians that had no observations in the unit in the previous quarter. Each unit's first period and solo practices are dropped from the data. The mean outcomes are values before performing the log transformation. 
TABLE A19: Number of physicians in the unit with 20 kilometer market radius

\begin{tabular}{|c|c|c|c|c|c|}
\hline & All physicians & Primary care & Gynecology & Orthopedics & ENT \\
\hline & (1) & (2) & (3) & (4) & $(5)$ \\
\hline \multicolumn{6}{|c|}{ Panel A. Log number of physicians } \\
\hline Short-run & $\begin{array}{c}0.079 \\
(0.051)\end{array}$ & $\begin{array}{c}0.062 \\
(0.059)\end{array}$ & $\begin{array}{c}0.045 \\
(0.049)\end{array}$ & $\begin{array}{c}0.097 \\
(0.059)\end{array}$ & $\begin{array}{l}0.089^{*} \\
(0.051)\end{array}$ \\
\hline \multirow[t]{2}{*}{ Long-run } & -0.034 & 0.048 & -0.092 & -0.047 & 0.013 \\
\hline & $(0.071)$ & $(0.072)$ & $(0.073)$ & $(0.071)$ & $(0.058)$ \\
\hline Mean outcome & 18.073 & 9.412 & 4.225 & 2.448 & 1.988 \\
\hline Observations & 4,315 & 4,315 & 4,315 & 4,315 & 4,315 \\
\hline Adjusted $R^{2}$ & 0.934 & 0.916 & 0.888 & 0.859 & 0.886 \\
\hline \multicolumn{6}{|c|}{ Panel B. Log number of continuing physicians } \\
\hline \multirow[t]{2}{*}{ Short-run } & 0.036 & -0.009 & 0.026 & 0.084 & 0.062 \\
\hline & $(0.048)$ & $(0.051)$ & $(0.046)$ & $(0.056)$ & $(0.041)$ \\
\hline \multirow{2}{*}{ Long-run } & -0.067 & -0.005 & -0.085 & -0.069 & 0.029 \\
\hline & $(0.075)$ & $(0.071)$ & $(0.079)$ & $(0.070)$ & $(0.059)$ \\
\hline Mean outcome & 15.586 & 7.689 & 3.874 & 2.230 & 1.793 \\
\hline Observations & 4,315 & 4,315 & 4,315 & 4,315 & 4,315 \\
\hline Adjusted $R^{2}$ & 0.926 & 0.91 & 0.897 & 0.871 & 0.907 \\
\hline \multicolumn{6}{|c|}{ Panel C. Log number of new physicians } \\
\hline \multirow[t]{2}{*}{ Short-run } & $0.213^{* * *}$ & $0.188^{* * *}$ & $0.092^{*}$ & $0.075^{* *}$ & $0.078^{*}$ \\
\hline & $(0.073)$ & $(0.071)$ & $(0.052)$ & $(0.038)$ & $(0.041)$ \\
\hline \multirow[t]{2}{*}{ Long-run } & $0.227^{* * *}$ & $0.241^{* * *}$ & 0.016 & $0.073^{*}$ & 0.007 \\
\hline & $(0.080)$ & $(0.077)$ & $(0.047)$ & $(0.037)$ & $(0.033)$ \\
\hline Mean outcome & 2.487 & 1.723 & 0.351 & 0.218 & 0.195 \\
\hline Observations & 4,315 & 4,315 & 4,315 & 4,315 & 4,315 \\
\hline Adjusted $R^{2}$ & 0.582 & 0.572 & 0.245 & 0.212 & 0.22 \\
\hline Time FE & Yes & Yes & Yes & Yes & Yes \\
\hline Unit FE & Yes & Yes & Yes & Yes & Yes \\
\hline
\end{tabular}

Notes: Unit of observation is health care unit $\times$ quarter. To account for zeros in the data, a value of one is added to each observation before log-transformation. Continuing physicians are those that had an observation in the unit in the previous quarter. New physicians are defined as those physicians that had no observations in the unit in the previous quarter. Each unit's first period and solo practices are dropped from the data. The mean outcomes are values before performing the log transformation. 